\title{
WestVirginiaUniversity
}

THE RESEARCH REPOSITORY @ WVU

Graduate Theses, Dissertations, and Problem Reports

2006

\section{Aluminum resistance of mycorrhizal plants}

Katrina R. Klugh

West Virginia University

Follow this and additional works at: https://researchrepository.wvu.edu/etd

\section{Recommended Citation}

Klugh, Katrina R., "Aluminum resistance of mycorrhizal plants" (2006). Graduate Theses, Dissertations, and Problem Reports. 2412.

https://researchrepository.wvu.edu/etd/2412

This Dissertation is protected by copyright and/or related rights. It has been brought to you by the The Research Repository @ WVU with permission from the rights-holder(s). You are free to use this Dissertation in any way that is permitted by the copyright and related rights legislation that applies to your use. For other uses you must obtain permission from the rights-holder(s) directly, unless additional rights are indicated by a Creative Commons license in the record and/ or on the work itself. This Dissertation has been accepted for inclusion in WVU Graduate Theses, Dissertations, and Problem Reports collection by an authorized administrator of The Research Repository @ WVU.

For more information, please contact researchrepository@mail.wvu.edu. 


\title{
ALUMINUM RESISTANCE OF MYCORRHIZAL PLANTS
}

\author{
Katrina R. Klugh
}

\author{
Dissertation submitted to the \\ Eberly College of Arts and Sciences at \\ West Virginia University \\ in partial fulfillment of the requirements for the degree of \\ Doctor of Philosophy in Biology
}

\author{
Jonathan R. Cumming, Ph.D., Chair \\ Louis M. McDonald, Ph.D. \\ James B. McGraw, Ph.D. \\ Joseph B. Morton, Ph.D. \\ Richard B. Thomas, Ph.D. \\ Department of Biology \\ Eberly College of Arts and Sciences
}

\section{Morgantown, WV}

2006

Keywords: arbuscular mycorrhizal fungi, aluminum, Liriodendron tulipifera, Andropogon virginicus, acidic soils, organic acids

Copyright 2006 Katrina R. Klugh 


\section{ABSTRACT \\ Aluminum Resistance of Mycorrhizal Plants}

\section{Katrina R. Klugh}

Aluminum (Al) in acidic soils is toxic to plants, affecting growth, water uptake, and nutrient assimilation. Aluminum resistance of plants has been ascribed to organic acid exudation from roots and changes in plant physiology resulting from the arbuscular mycorrhizal (AM) fungal symbiosis. This dissertation describes four studies that address questions regarding Al resistance of mycorrhizal plants.

In chapter 2, Liriodendron tulipifera, a common tree species in northeastern U.S. forests, was inoculated with several species of AM fungi and exposed to Al. Biomass and plant nutritional data showed that the AM species Glomus clarum conferred the most benefit to plant hosts. Organic acids exuded from roots, which can chelate and detoxify Al in root zones, appeared to be related the observed benefit of plants colonized by this species. In chapters 3 and 5, when Andropogon virginicus, an early successional species that colonizes disturbed soils, was inoculated with several AM species and isolates, plants colonized by G. clarum were larger than plants colonized by other species. However, organic acid exudation was not clearly associated with the growth benefits observed in plants in these experiments. In chapter 5, trends in the data showed that, under Al exposure, plants were larger when colonized by AM inoculum cultivated under prior Al exposure. The combined results of these studies illustrate functional variation among AM fungi and the importance of AM diversity in ecosystems. Additionally, cultivation of AM fungi under stressful conditions could enhance the stress resistance of AM fungi through the selection of stress resistance genotypes.

A field study, described in chapter 4, explored the relationship between plant succession and $\mathrm{Al}$ availability on the extreme soils of an abandoned coal mine. Concentrations of phytotoxic Al were low in vegetated areas compared to non-vegetated ones. Soil solution $\mathrm{pH}$ and organic acid concentrations were higher in vegetated locations at the end of the growing season and may be related to increased exudation as plants reached maturity or increases in decomposing leaf litter from senescing plants. Initial colonization of extreme sites by $A$. virginicus may ameliorate the low $\mathrm{pH}$ and $\mathrm{Al}$ conditions, facilitating ecological succession with other plant species. 


\section{Acknowledgements}

As I type the final words of my dissertation and make the final edits, I have a few moments to reflect on this important milestone. Not just the defense and submission of my final draft, but of the journey that I've been taking. The road toward earning my doctorate degree has been long and littered with downed trees and potholes, and I owe thanks to so many people who have helped me map new routes and fix flat tires along the way. While writing these few words doesn't seem like enough to show my appreciation, it is a start.

To my wonderful advisor, Jonathan Cumming: Thank you for your patience, guidance, and support. But more importantly, thank you for always looking forward and teaching me to do the same. From you I've learned that life is short--dwell only on happy history and focus on good things to come. My committee members, Louis McDonald, Jim McGraw, Joe Morton, and Richard Thomas, have consistently been a source of encouragement. For sharing your knowledge, resources, and advice, thank you.

When in the throes of research, one can sometimes use a little help. The sets of hands, which helped with various experiment set-ups, harvests, and sample processing, belong to individuals who are most appreciated: Matt Duval, Kristen Hunter-Cevera, Joan Wright, Tom Milam, Chris Huffman, and Beth Taylor. Many fellow graduate students, colleagues, and mentors have shared knowledge, showed me some ropes, lent an ear, or cheered me on and I am grateful: Clint Springer, Suzy Sanders, Bill Wheeler, Dan Panaccione, Stefanie Whitmire, Heather Robertson, Zola Msiska, Ranamalie Amarasinghe, Martin Christ, Heather Frederick, John Hawse, Frank Secreto, and many others.

My dear friends, who know that this is not the easiest career path, I thank you for always pointing out the light at the end of the tunnel. Sandhya Mohan and Chintamani Manish, I couldn't have made it this far without you. Sarah Wennerberg, Nancy Sheets, and Charley Kelly, hugs and smiles are priceless. Susan Banaszak-Catena, Liza Hawley, and Becky McElheny, if ever I needed a boost, you were only a phone call away. My family, thanks for remembering it is taboo to ask a graduate student the question, "When will you be finished?" My sincere gratitude goes to my mom, Betty Klugh, my dad, Mike Klugh, my favorite sister, Lisette Cerra and family, and my grandparents, Charles and May Drexler.

And finally, I've written the last chapter of my dissertation and am ready to start the next chapter of my life with my husband, Jason Stewart. You have been there from Statistics 311 to my final presentation, and I can't thank you enough for your patience and encouragement through it all. 


\section{Table of Contents}

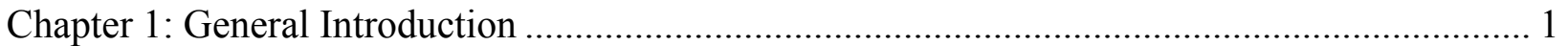

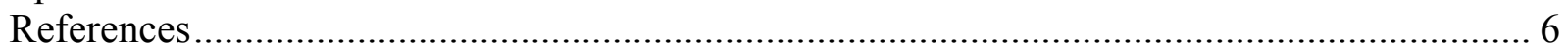

Chapter 2: Variation in organic acid exudation and aluminum resistance among arbuscular mycorrhizal species colonizing Liriodendron tulipifera (yellow-poplar) ............................... 10

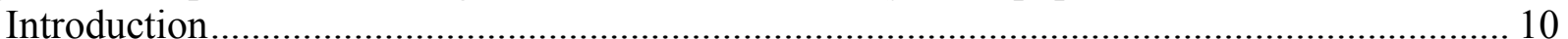

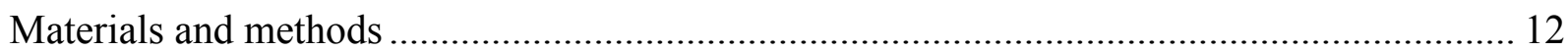

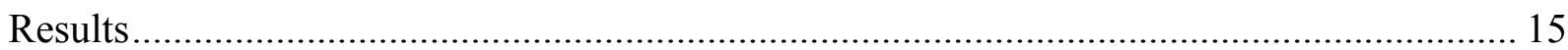

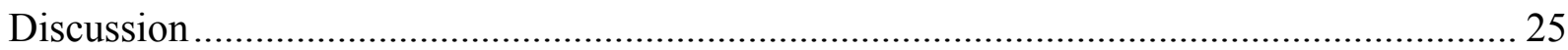

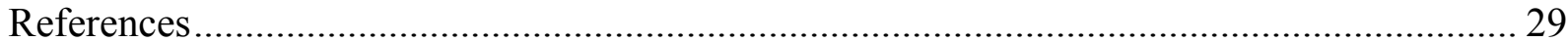

Chapter 3: Organic acid exudation by mycorrhizal Andropogon virginicus L. (broomsedge) roots

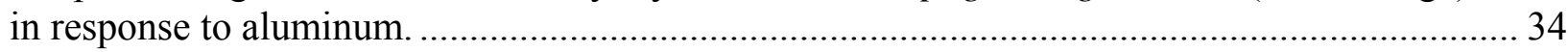

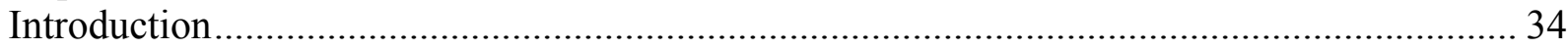

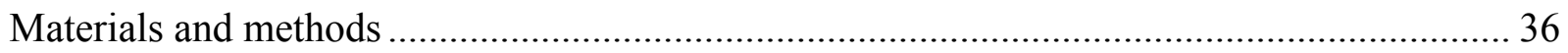

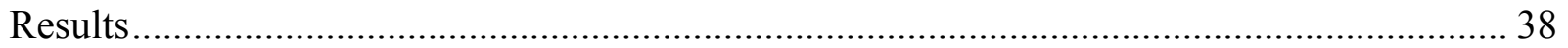

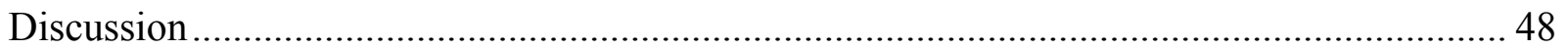

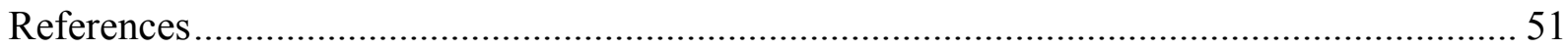

Chapter 4: Spatial vegetation patterns and soil solution aluminum of an abandoned coal mine.. 55

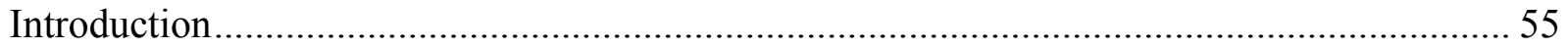

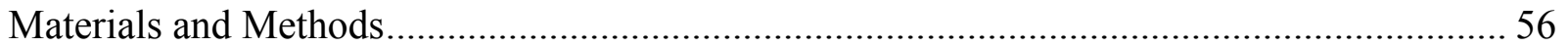

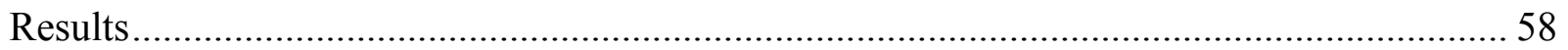

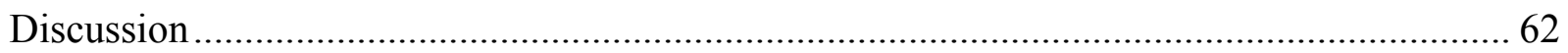

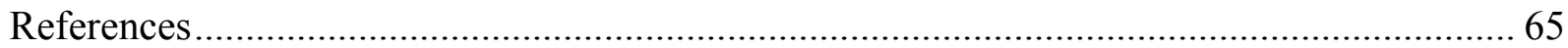

Chapter 5: Stability of aluminum stress resistance in arbuscular mycorrhizal fungi .................. 68

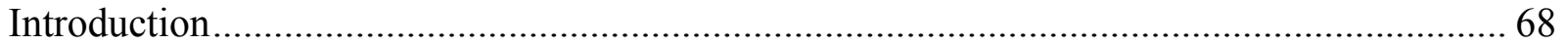

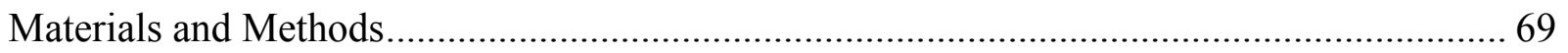

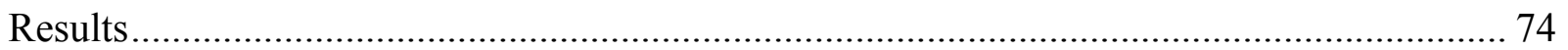

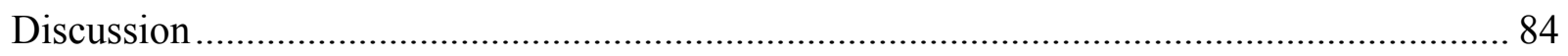

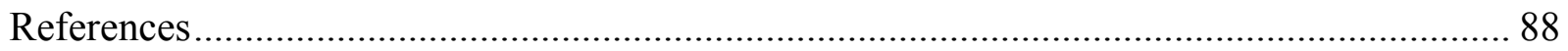

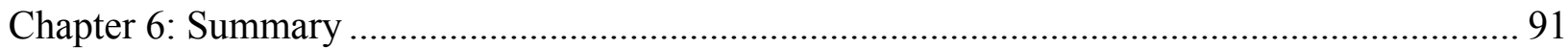




\section{List of Tables}

Chapter 2:

Table 1. Concentration profiles of organic acids measured in the root zones of mycorrhizal $L$. tulipifera exposed to $0 \mu \mathrm{M} \mathrm{Al}(\mu \mathrm{M})$. Values are mean organic acid concentrations $(\mathrm{n}=7)$. Abbreviations: $\mathrm{NM}=$ Non-mycorrhizal.

Table 2. Correlations between plant parameters and colonization for L. tulipifera under variable Al exposure. Correlations (Pearson's $r$ ) were calculated after arcsine square root transformations utilized to obtain normally distributed colonization data. Significance levels indicated by asterisks: $* * *=P<0.01 ; * *=P<0.05 ; *=P<0.10$; and $\mathrm{ns}=$ not significant. Organic acid (OA) production is calculated as the sum of citrate, malate, and oxalate per gram root mass.

Chapter 4:

Table 1. Mean organic acid concentrations $(\mu \mathrm{M})$ in soil solutions of vegetated and nonvegetated soils collected from Stewartstown Mine in the months of July, August, September, and October. Within a row, letters with the same letter do not differ significantly.....

Chapter 5:

Table 1. Concentrations of $\mathrm{Al}$ and $\mathrm{P}$ in shoot tissues of non-mycorrhizal (NM) and mycorrhizal

A. virginicus plants exposed to 0 and $200 \mu \mathrm{M}$ Al.

Table 2. Concentration of $\mathrm{Al}$ and $\mathrm{P}$ in shoot tissues of mycorrhizal $A$. virginicus plants inoculated with AM isolates of $A$. morrowiae, G. clarum and $S$. heterogama cultivated in the presence of $200 \mu \mathrm{M} \mathrm{Al}(+)$ or $0 \mu \mathrm{M} \mathrm{Al}(-)$ and exposed to 0 and $200 \mu \mathrm{M}$ Al.................................. 77 


\section{List of Figures}

Chapter 2:

Figure 1. Colonization of L. tulipifera seedlings by arbuscular mycorrhizal species at 0,50 , and

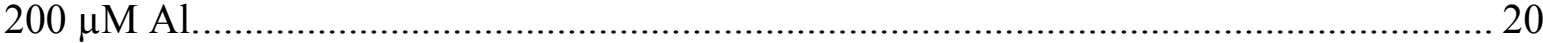

Figure 2. (a) Total biomass, (b) leaf Al, and (c) leaf P concentrations of non-mycorrhizal (NM)

L. tulipifera seedlings and seedlings colonized by arbuscular mycorrhizal fungi exposed to

0,50 , and $200 \mu \mathrm{M} \mathrm{Al}$.

Figure 3. (a) Citrate and (b) malate concentrations in root zones of non-mycorrhizal (NM) $L$. tulipifera seedlings and seedlings colonized by arbuscular mycorrhizal fungi exposed to 0 , 50 , and $200 \mu \mathrm{M} \mathrm{Al}$.

Figure 4. (a) Citrate and (b) malate production from roots ( $\mu \mathrm{mol} \mathrm{g}^{-1}$ root mass) of nonmycorrhizal (NM) L. tulipifera seedlings and seedlings colonized by arbuscular mycorrhizal fungi exposed to 0,50 , and $200 \mu \mathrm{M} \mathrm{Al}$.

Figure 5. Relationships between free $\mathrm{Al}\left(\mathrm{Al}^{3+}\right)$ concentrations estimated in root zones and biomass, leaf Al, and leaf $\mathrm{P}$ of non-mycorrhizal (NM) and mycorrhizal L. tulipifera. Symbols are as follows: $\diamond$ Non-mycorrhizal, $\bullet$ A. morrowiae, • G. claroideum, $\bullet G$. clarum, $\triangle P$. brasilianum.

Chapter 3:

Figure 1. Biomass of mycorrhizal plants inoculated with isolates collected from acidic soils and non-mycorrhizal (NM) exposed to 0 and $100 \mu \mathrm{M}$ Al............................................... 41

Figure 2. Colonization of $A$. virginicus plants inoculated with isolates collected from acidic soils and exposed to 0 and $100 \mu \mathrm{M} \mathrm{Al}$.

Figure 3. (a) Shoot phosphorous (P) concentrations and (b) shoot aluminum (Al) concentrations of mycorrhizal plants inoculated with isolates collected from acidic soils and nonmycorrhizal (NM) exposed to 0 and $100 \mu \mathrm{M}$ Al.

Figure 4. (a) Citrate and (b) malate concentrations in root zones of mycorrhizal plants inoculated with isolates collected from acidic soils and non-mycorrhizal (NM) exposed to 0 and 100 $\mu \mathrm{M}$ Al.

Figure 5. (a) Citrate and (b) malate production from root of mycorrhizal plants inoculated with isolates collected from acidic soils and non-mycorrhizal (NM) exposed to 0 and $100 \mu \mathrm{M} \mathrm{Al}$.

Figure 6. Biomass of plants inoculated with acidic and non-acidic isolates of G. clarum and $S$. heterogama and exposed to 0 and $100 \mu \mathrm{M} \mathrm{Al}$.

Figure 7. Colonization of $A$. virginicus plants inoculated with acidic and non-acidic isolates of $G$. clarum and $S$. heterogama and exposed to 0 and $100 \mu \mathrm{M} \mathrm{Al}$.

Figure 8. (a) Shoot phosphorous (P) concentrations and (b) shoot aluminum (Al) concentrations of plants inoculated with acidic and non-acidic isolates of G. clarum and S. heterogama and exposed to 0 and $100 \mu \mathrm{M}$ Al.

Figure 9. (a) Citrate and (b) malate concentrations in root zones of plants inoculated with acidic and non-acidic isolates of G. clarum and S. heterogama and exposed to 0 and $100 \mu \mathrm{M}$ Al.47 


\section{Chapter 4:}

Figure 1. Soil solution $\mathrm{pH}$ collected from non-vegetated and vegetated soils in July, August, September, and October.

Figure 2. Total Al in soil solutions collected from non-vegetated and vegetated soils in July,

August, September, and October.

Figure 3. 8-hydroxyquinoline extractable Al in soil solutions collected from non-vegetated and vegetated soils in July, August, September, and October.

\section{Chapter 5:}

Figure 1. Colonization of mycorrhizal plants inoculated with isolates of A. morrowiae, G. clarum and $S$. heterogama exposed to 0 and $200 \mu \mathrm{M} \mathrm{Al}$.

Figure 2. Biomass of non-mycorrhizal (NM) and mycorrhizal plants inoculated with isolates of A. morrowiae, G. clarum, and S. heterogama exposed to 0 and $200 \mu \mathrm{M} \mathrm{Al}$.

Figure 3. Relationship between \% colonization and total biomass of mycorrhizal plants inoculated with isolates of $A$. morrowiae, G. clarum and $S$. heterogama exposed to 0 and $200 \mu \mathrm{M} \mathrm{Al}$.

Figure 4. Colonization of mycorrhizal plants inoculated with isolates of A. morrowiae, G. clarum and $S$. heterogama cultivated in the presence of $200 \mu \mathrm{M} \mathrm{Al}(+)$ or $0 \mu \mathrm{M} \mathrm{Al}(-)$ and exposed to 0 ( $\square$ ) and $200 \mu \mathrm{M} \mathrm{Al}(\mathbf{\square})$

Figure 5. Biomass of non-mycorrhizal (NM) and mycorrhizal plants inoculated with isolates of A. morrowiae, G. clarum and S. heterogama cultivated in the presence of $200 \mu \mathrm{M} \mathrm{Al}(+)$ or $0 \mu \mathrm{M} \mathrm{Al}(-)$ and exposed to $0(\square)$ and $200 \mu \mathrm{M} \mathrm{Al} \mathrm{( \square ).}$ 80

Figure 6. Relationship between \% colonization and total biomass of mycorrhizal plants inoculated with isolates of $A$. morrowiae, $G$. clarum and $S$. heterogama cultivated in the presence of $200 \mu \mathrm{M} \mathrm{Al}(+)$ or $0 \mu \mathrm{M} \mathrm{Al}(-)$ and exposed to $0(\square)$ and $200 \mu \mathrm{M} \mathrm{Al}(\mathbf{\square}) \ldots . . . .80$

Figure 7. (a) Citrate and (b) malate concentrations $(\mu \mathrm{M})$ in root zones of non-mycorrhizal (NM) and mycorrhizal plants colonized by isolates cultivated in the presence of $200 \mu \mathrm{M} \mathrm{Al}(+)$ or $0 \mu \mathrm{M} \mathrm{Al}(-)$ and exposed to $0(\square)$ and $200 \mu \mathrm{M} \mathrm{Al}(\mathbf{\square})$.

Figure 8. (a) Citrate and (b) malate production ( $\mu \mathrm{mol} \mathrm{g}^{-1}$ root mass) in root zones of nonmycorrhizal (NM) and mycorrhizal plants colonized by isolates cultivated in the presence of $200 \mu \mathrm{M} \mathrm{Al}(+)$ or $0 \mu \mathrm{M} \mathrm{Al}(-)$ and exposed to $0(\square)$ and $200 \mu \mathrm{M} \mathrm{Al}(\mathbf{\square})$ 


\section{Chapter 1: General Introduction}

Approximately $80 \%$ of terrestrial plant species on Earth form associations with arbuscular mycorrhizal (AM) fungi (Smith \& Read; 1997). These fungi mediate plant-soil interactions, enhance nutrient uptake, and promote plant resistance to soil stresses (Marschner, 1991; Clark, 1997). Such interactions may have been instrumental in facilitating plant colonization of terrestrial habitats, as indicated by evidence of 400 million year old plant fossils and modern molecular techniques (Malloch et al., 1980; Remy et al., 1994; Brundrett, 2002). Arbuscular mycorrhizal fungi continue to have crucial roles in plant growth and survival, particularly in stressful environments.

Acid soils limit plant growth worldwide (Barinaga, 1997). Indeed, 30\% of the world's soils are classified as acidic and potentially limit plant productivity (von Uexküll \& Mutert, 1995). Plants colonizing these low $\mathrm{pH}$ soils are exposed to high aluminum (Al) concentrations, which can alter numerous physiological processes, including water and nutrient uptake, nutrient assimilation, and carbon allocation, ultimately impeding growth (Kochian, 1995)

Plants exhibit a range of sensitivity to $\mathrm{Al}$ and $\mathrm{Al}$ resistance in species and cultivars is often correlated with organic acid exudation by roots. Organic acids released by plant roots chelate Al in the rhizosphere and render it non-toxic (Hue et al., 1986; Miyasaka et al., 1991; Delhaize \& Ryan, 1995; Adams et al., 1999; Ma, 2000). A growing number of studies have illustrated the operation of this mechanism in a variety of species, including snapbean, wheat, corn, buckwheat, and soybean (Miyasaka et al., 1991; Pellet et al., 1995; Pellet et al., 1996; Zheng et al., 1998; Silva et al., 2001). Additionally, experiments with soybean and wheat showed that Al-resistant cultivars had lower Al accumulation than Al-sensitive cultivars in root tips, the site of Al-induced lesions (Delhaize et al., 1993a,b; Silva et al., 2001). This trend was positively correlated with organic acid exudation (Delhaize et al., 1993a; Samuels et al., 1997; Matsumoto, 2000; Silva et al., 2001), suggesting a link between organic acid exudation, Al exclusion from the sensitive root tip, and $\mathrm{Al}$ resistance.

The association of AM fungi with plant roots is an important factor in plant adaptation to acidic soils (Marschner, 1991; Clark, 1997). In acid soils where nutrient availability is typically low, fungal hyphae that extend and explore large volumes of soil can aid in the uptake of phosphorous $(\mathrm{P})$ and other diffusion-limited nutrients, including copper $(\mathrm{Cu})$ and zinc $(\mathrm{Zn})$ (Clarkson, 1985; Bolan, et al., 1991; Marschner, 1995). Additionally, AM fungi may play roles 
in conferring Al resistance to their plant hosts (Marschner, 1995). This has been demonstrated in Liriodendron tulipifera (yellow-poplar) (Lux \& Cumming, 2001), Andropogon virginicus (broomsedge) (Cumming \& Ning, 2003), Panicum virgatum (switchgrass) (Koslowsky \& Boerner, 1989), and Musa acuminata (banana) (Rufyikiri et al., 2000). All of these studies found that non-mycorrhizal plants were more sensitive to Al than mycorrhizal plants.

Until recently, AM fungi were assumed to be functionally redundant. However, the ability of AM fungi to promote plant growth varies among mycorrhizal species and environmental conditions (Clark et al., 1999; Bever et al., 2001; Helgason et al. 2002; Munkvold et al., 2004). In acidic soils and under Al exposure, AM species have exhibited varying resistances illustrated by differences in colonization of host plants, hyphal growth, spore germination, and host plant growth (Siqueira et al., 1984; Bartolome-Esteban \& Schenk, 1994; Vosatka et al., 1999; Kelly et al., 2005). Given the wide range of soil conditions throughout the world, it might be expected that such variation would be observed. Interestingly, geographicallyisolated fungal populations can exhibit similar ecotypic variation, suggesting that AM fungi can adapt to local environmental conditions (Bartolome-Esteban \& Schenk, 1994; Clark, 1997).

Despite their asexual reproduction, heritable phenotypic variation has been observed in AM fungi (Bentivenga et al., 1997; Bever \& Morton; 1999). Arbuscular mycorrhizal fungi are multinucleate and spores can contain hundreds to thousands of genetically distinct nuclei (Cooke et al., 1987; Bever \& Morton, 1999; Kuhn et al., 2001). Molecular techniques have detected high degrees of genetic variation within species, among spores of the same isolate, and even among nuclei of single spores (Sanders et al., 1996; Rosendahl \& Taylor, 1997; Kuhn et al., 2001; Sanders, 2004; Hijri \& Sanders, 2005). Several mechanisms may account for the maintenance of this genetic diversity, including exchange of nuclei between individuals after hyphal fusion, segregation of nuclei into spores, and potential recombination events (Sanders et al., 1996; Bever \& Morton, 1999; Kuhn et al., 2001; Vandenkoornhuyse et al., 2001).

Evidence for genetic variation and heritable phenotypes is important for understanding the potential adaptation and evolution of AM fungi under environmental stresses and could have implications for maintenance of AM fungal collections. Much of the source material for AM studies originates from collections where AM fungi are maintained in stress-free conditions, which may be very unlike the soil environments in their original collection site. Fungi maintained in culture may not be able to develop or maintain the ability to confer stress 
resistance to hosts without continued exposure to stress. In support of this, Malcová et al. (2003) presented evidence that an AM isolate maintained in metal-free cultivation was less tolerant of manganese $(\mathrm{Mn})$ than the same AM isolate maintained in the original metal contaminated soil. This phenomenon could potentially be observed with other stresses, such as acid soils and Al stress.

For my dissertation research, I was interested in the variation in conferred Al resistance among AM species and the physiological basis of Al stress resistance. I was also interested in exploring the ability of AM fungal species to maintain stress resistant phenotypes when cultured in stress-free conditions or, conversely, the ability of AM fungi to develop stress resistance when exposed to stress. The following chapters of this dissertation describe four studies that addressed a series of scientific questions.

In Chapter 2, I studied the capacity of four AM species to confer Al resistance to L. tulipifera and focused on AM mediated organic acid exudation as an Al resistance mechanism. Specifically, the following questions were addressed.

o Do AM fungal species differ in their capacity to confer Al resistance to L. tulipifera as measured by growth and nutrient acquisition?

o Does organic acid production facilitated by AM fungi vary among AM fungi in symbiosis with L. tulipifera plants and could this be a potential Al resistance mechanism?

Chapter 3, similarly, focused on the capacity of AM species to confer Al resistance to host plants. However, the plant species used was A. virginicus and eight AM isolates (an isolate is a single species collected from one location) were studied, including isolates from collection sites with dissimilar soil properties. Scientific questions addressed in Chapter 3 were:

0 Is there variation among AM species in conferred Al resistance (measured as plant biomass and tissue nutrient concentration) to A. virginicus?

o Does organic acid exudation vary among mycorrhizal roots of $A$. virginicus colonized by different AM species? 
o Do A. virginicus plants colonized by isolates collected from acidic and alkaline or neutral soils have similar growth, tissue nutrient concentrations, and organic acid exudation?

Chapter 4 describes a field study undertaken to examine the Al chemistry of an abandoned coal mine site and to discover whether spatial patterns in plant growth, notably A. virginicus, are correlated with patterns of available $\mathrm{Al}$ in the soils. The following questions were addressed in this chapter.

o Is the $\mathrm{Al}$ chemistry of soils with vegetation different from soils without vegetation at the Stewartstown Mine site?

o Are any spatial patterns in soil Al chemistry correlated with the presence of organic acids and vegetation?

Chapter 5 describes a study that was designed to examine the heritability of acid soil stress resistance of six AM isolates cultured in non-stressful conditions and under $\mathrm{Al}$ exposure using both whole plant and molecular techniques. The following questions were addressed:

o Is there variation in conferred $\mathrm{Al}$ resistance between $\mathrm{AM}$ fungi cultivated under $\mathrm{Al}$ exposure and non-stress conditions as measured by host plant growth and nutrition, colonization, and organic acid exudation?

o Are there differences in $\mathrm{Al}$ resistance between isolates collected from acidic and neutral or alkaline soils as measured by host plant growth and nutrition, colonization, and organic acid exudation?

o Do AM fungi collected from stressful environments retain resistance to stress after maintenance in stress-free cultivation and can AM fungi develop resistance to stress after exposure?

The results of these studies presented in the following chapters provide insight into the roles of AM fungi in conferring $\mathrm{Al}$ resistance to their host plants growing in acid soils. Variation in conferred $\mathrm{Al}$ resistance was observed among AM fungi and, in some cases, Al resistance 
appeared to be related to organic acid exudation, supporting current theories of $\mathrm{Al}$ resistance in non-mycorrhizal plants. 


\section{References}

Adams JF, Wood CW, Mitchell RI. 1999. Loblolly pine plant community structure and soil solution aluminum, organic acids, calcium, magnesium, and $\mathrm{pH}$. Communications in Soil Science and Plant Analysis 30: 1939-1950.

Barinaga M. 1997. Making plants aluminum tolerant. Science 276: 1497.

Bartolome-Esteban H, Schenck NC. 1994. Spore germination and hyphal growth of arbuscular mycorrhizal fungi in relation to soil aluminum saturation. Mycologia 86: 217-226.

Bentivenga SP, Bever JD, Morton JB. 1997. Genetic variation of morphological characters within a single isolate of the endomycorrhizal fungus Glomus clarum (Glomaceae). America Journal of Botany 84: 1211-1216.

Bever JD, Morton J. 1999. Heritable variation of mechanisms of inheritance of spore shape within a population of Scutelopspora pellucida, and Arbuscular mycorrhizal fungus. American Journal of Botany 86: 1209-1216.

Bever JD, Schultz PA, Pringle A, Morton JB. 2001. Arbuscular mycorrhizal fungi: more diverse than meets the eye, and the ecological tale of why. Bioscience 51: 923-931.

Bolan NS, White RE, Hedley MJ. 1991. Processes of soil acidification during nitrogen cycling with emphasis on legume based pastures. Developments in Plant and Soil Sciences 134: 55-63.

Brundrett MC. 2002. Coevolution of roots and mycorrhizas of land plants. New Phytologist 154: 275-304.

Clark RB. 1997. Arbuscular mycorrhizal adaptation, spore germination, root colonization, and host plant growth and mineral acquisition at low pH. Plant and Soil 192: 15-22.

Clark RB, Zobel RW, Zeto SK. 1999. Arbuscular mycorrhizal fungal isolate effectiveness on growth and root colonization of Panicum virgatum in acidic soil. Soil Biology and Biochemistry 31: 1757-173.

Clarkson DT. 1985. Factors affecting mineral nutrient acquisition by plants. Annual Review of Plant Physiology 36: 11-115.

Cooke JC, Gemma JN, Koske KE. 1987. Observations of nuclei in vesicular-arbuscular mycorrhizal fungi. Mycologia 79:331-333.

Cumming JR, Ning J. 2003. Arbuscular mycorrhizal fungi enhance aluminum resistance of broomsedge (Andropogon virginicus L.). Journal of Experimental Botany 54: 1447-1459.

Delhaize E, Craig S, Beaton CD, Bennet RJ, Jagadish VC, Randall PJ. 1993a. Aluminum tolerance in wheat (Triticum aestivum L.) I. Uptake and distribution of aluminum in root apices. Plant Physiology 103: 685-693. 
Delhaize E, Ryan PR. 1995. Aluminum toxicity and tolerance in plants. Plant Physiology 107: 315-321.

Delhaize E, Ryan PR, Randall PJ. 1993b. Aluminum tolerance in wheat (Triticum aestivum L.) II. Aluminum-stimulated excretion of malic acid from root apices. Plant Physiology 103: 695702.

Helgason T, Merryweather JW, Denison J, Wilson P, Young JPW, Fitter AH. 2002. Selectivity and functional diversity in arbuscular mycorrhizas of co-occurring fungi and plants from a temperate deciduous woodland. Journal of Ecology 90: 371-384.

Hijri M, Sanders IR. 2005. Low gene copy number shows that arbuscular mycorrhizal fungi inherit genetically different nuclei. Nature 433:160-163.

Hue NV, Craddock, GR, Adams F. 1986. Effect of organic acids on aluminum toxicity in subsoils. Soil Science Society of America Journal 50: 28-34.

Kelly CN, Morton JB, Cumming JR. 2005. Variation in aluminum resistance among arbuscular mycorrhizal fungi. Mycorrhiza 15: 193-201.

Kochian LV. 1995. Cellular mechanisms of aluminum toxicity and resistance in plants. Annual Review of Plant Physiology and Plant Molecular Biology 46: 237-260.

Koslowsky SD, Boerner RE. 1989. Interactive effects of aluminum, phosphorous and mycorrhizae on growth and nutrient uptake of Panicum virgatum L. (Poaceae). Environmental Pollution 61: 107-125.

Kuhn G, Hijri G, Sanders IR. 2001. Evidence for the evolution of multiple genomes in arbuscular mycorrhizal fungi. Nature 414: 745-748.

Lux HB, Cumming JR. 2001. Mycorrhizae confer aluminum resistance to tulip-poplar seedlings. Canadian Journal of Forest Research 31: 694-702.

Ma JF. 2000. Role of organic acids in detoxification of aluminum in higher plants. Plant and Cell Physiology 41: 383-390.

Malcová R, Rydlova J, Vosatka M. 2003. Metal-free cultivation of Glomus sp. BEG 140 isolated from Mn-contaminated soil reduces tolerance to Mn. Mycorrhiza 13: 151-157.

Malloch DW, Priozynski KA, Raven PH. 1980. Ecological and evolutionary significance of mycorrhizal symbioses in vascular plants (A review). Proceedings of the National Academy of Science 77: 2113-2118.

Marschner H. 1991. Mechanisms of adaptation of plants to acid soils. In: Wright RJ, Baligar VC, Murrman RP, eds. Plant-soil interactions at low $\mathrm{pH}$. Dordrecht, Netherlands: Kluwer Academic Publishers, 683-702.

Marschner H. 1995. Mineral nutrition of higher plants. San Diego, CA: Academic Press, Inc. 
Matsumoto H. 2000. Cell biology of aluminum toxicity and tolerance in higher plants. International Review of Cytology 200: 1-46.

Miyasaka SC, Buta GJ, Howell RK, Foy CD. 1991. Mechanism of aluminum tolerance in snapbeans. Plant Physiology 96: 737-743.

Munkvold L, Kjøller R, Vesberg M, Rosendahl S, Jakobsen, I. 2004. High functional diversity within species of arbuscular mycorrhizal fungi. New Phytologist 164: 357-364.

Pellet DM, Grunes DL, Kochian LV. 1995. Organic acid exudation as an aluminum-tolerance mechanism in maize (Zea mays L.). Planta 196: 788-795.

Pellet DM, Papernik LA, Kochian LV. 1996. Multiple aluminum-resistance mechanisms in wheat: Roles of root apical phosphate and malate exudation. Plant Physiology 112: 591-597.

Remy W, Taylor TN, Hass H, Kerp H. 1994. Four hundred-million-year-old vesicular arbuscular mycorrhizae. Proceedings of the National Academy of Science 91: 11841-11843.

Rosendahl S, Taylor JW. 1997. Development of multiple genetic markers for studies of genetic variation in arbuscular mycorrhizal fungi using ALFP'M . Molecular Ecology 6: 821-829.

Rufyikiri G, Declerck S, Dufey JE, Delvaux B. 2000. Arbuscular mycorrhizal fungi might alleviate aluminum toxicity in banana plants. New Phytologist 148: 343-352.

Samuels TD, Rincon-Zachary M, Kucukakyuz K. 1997. Al partitioning patterns and root growth as related to Al sensitivity and Al tolerance in wheat. Plant Physiology 113: 527-534.

Sanders IR. 2004. Intraspecific genetic variation in arbuscular mycorrhizal fungi and its consequences for molecular biology, ecology, and development of inoculum. Canadian Journal of Botany 82: 1057-1062.

Sanders IR, Clapp JP, Wiemken A. 1996. The genetic diversity of arbuscular mycorrhizal fungi in natural ecosystems - a key to understanding the ecology and functioning of the mycorrhizal symbiosis. New Phytologist 133: 123-134.

Silva IR, Smyth TJ, Raper CD, Carter TE, Rufty TW. 2001. Differential aluminum tolerance in soybean: An evaluation of the role of organic acids. Physiologia Plantarum 112: 200-210.

Siqueira JO, Hubbell DH, Mahmud AW. 1984. Effect of liming on spore germination, germ tube growth and root colonization by vesicular-arbuscular mycorrhizal fungi. Plant and Soil 76: 115-124.

Smith SE, Read DJ. 1997. Mycorrhizal symbiosis: $2^{\text {nd }}$ Edn. San Diego, USA: Academic Press.

Vandenkoornhuyse P, Leyval C, Bonnin I. 2001. High genetic diversity in arbuscular mycorrhizal fungi: evidence for recombination events. Heredity 87: 243-253. 
von Uexküll HR, Mutert E. 1995. Global extent, development and economic impact of acid soils. Plant and Soil 171: 1-15.

Vosatka M, Batkhuugyin E, Albrechtova J. 1999. Response of three arbuscular mycorrhizal fungi to simulated acid rain and aluminum stress. Biologia Plantarum 42: 289-296.

Zheng SJ, Ma JF, Matsumoto H. 1998. High aluminum resistance in Buckwheat I. Al-induced specific secretion of oxalic acid from root tips. Plant Physiology 117: 745-751. 


\section{Chapter 2: Variation in organic acid exudation and aluminum resistance among arbuscular mycorrhizal species colonizing Liriodendron tulipifera (yellow-poplar)}

\section{Introduction}

High aluminum (Al) concentrations are characteristic of acidic soils and Al toxicity is an impediment to crop production on 30 to $40 \%$ of arable soils worldwide (Von Uexküll \& Mutert, 1995). Plants exposed to Al are stunted due to inhibition of root cell division and elongation (Delhaize et al., 1993a; Le Van et al., 1994; Sivaguru \& Horst, 1998), reduced water uptake capacity (Rufyikiri et al., 2000; Purcell et al., 2002), and altered uptake and assimilation of numerous elements, including calcium $(\mathrm{Ca})$, phosphate $\left(\mathrm{P}_{\mathrm{i}}\right)$, and nitrate $\left(\mathrm{NO}_{3}{ }^{-}\right)$(Miranda \& Rowell, 1989; Huang et al., 1992; Rengel \& Elliot, 1992; Macklon et al., 1994; Antunes \& Nunes, 1997).

Plants exhibit a range of resistance to $\mathrm{Al}$ in the rhizosphere, which may result from the exudation of organic acids from roots (Hue et al., 1986; Miyasaka et al., 1991; Delhaize \& Ryan, 1995; Adams et al., 1999) or the accumulation of organic acids within root apoplasts (Kinraide et al., 2005). Organic acids exiting root cells via Al-activated anion channels chelate and render Al nontoxic to the plant (Ma, 2000; Piñeros et al., 2002; Kochian et al., 2004). Often, the release of organic acids is accompanied by reduced $\mathrm{Al}$ accumulation in root tips, the primary site of $\mathrm{Al}$ toxicity (Delhaize et al., 1993a; Samuels et al., 1997; Matsumoto, 2000; Silva et al., 2001). For example, Silva et al. (2001) and Delhaize et al. $(1993 a, b)$ found that high rates of organic acid exudation were correlated with exclusion of Al from root tips in Al-resistant cultivars of soybean and wheat. In both plant species, Al-sensitive cultivars accumulated more Al than Al-resistant lines. Experiments with woody species have yielded similar results. More Al was excluded from roots of Al-resistant slash and loblolly pine families than Al-sensitive families (Nowak \& Friend, 2005). In addition, Al-resistant eucalypt species exhibited increased concentrations of malate in root tips in response to Al treatments (Silva et al., 2004) and exudation of citrate at least partially accounted for differences in Al-resistance among tropical woody species (Nguyen et al., 2003).

The association of arbuscular mycorrhizal (AM) fungi with plant roots is an important factor in plant adaptation to acidic soils (Marschner, 1991; Clark, 1997). Mycorrhizal fungi are 
known for their ability to enhance plant nutrient uptake, particularly $\mathrm{P}_{\mathrm{i}}$, which may be important under Al exposure (Clarkson, 1985; Bolan, 1991). In Liriodendron tulipifera L., nonmycorrhizal plants exposed to $\mathrm{Al}$ had lower concentrations of $\mathrm{P}$ in the leaves and reduced biomass compared to plants colonized by AM fungi (Lux \& Cumming, 2001). Panicum virgatum L. plants colonized by AM fungi took up more Ca and were larger than nonmycorrhizal plants under Al exposure (Koslowsky \& Boerner, 1989), and mycorrhizal banana plants exhibited greater biomass, nutrient uptake, and water absorption compared with nonmycorrhizal banana plants exposed to Al (Rufyikiri et al., 2000). In spite of the common benefits observed in these studies, the mechanisms responsible for the amelioration of Al toxicity by AM fungi have not been elucidated.

Lux \& Cumming (2001) and Cumming \& Ning (2003) presented evidence that changes in rhizosphere Al speciation caused by AM fungi may have been responsible for observed mycorrhizal benefits. Root zone solutions from L. tulipifera seedlings and Andropogon virginicus L. plants colonized by mycorrhizal fungi contained significantly less reactive $\mathrm{Al}$ in comparison to solutions from non-mycorrhizal plants (Lux \& Cumming, 2001; Cumming \& Ning, 2003). These patterns may reflect enhanced organic acid production by mycorrhizal plants, the production of other fungal exudates that may have important roles in Al resistance, or Al binding or sequestration by fungal hyphae (Meharg \& Cairney, 2000).

Mycorrhizal fungal communities in ecosystems are very diverse. Until recently, various species of AM fungi were assumed to be functionally redundant. Current research, however, has shown that individual species of AM fungi differ in their effects on plant growth and nutrient acquisition (Clark et al., 1999; Bever et al., 2001; Helgason et al., 2002; Munkvold et al., 2004). Furthermore, fungal species change in distribution and abundance with changes in the edaphic environment of the soil (Bever et al., 2001). Vosatka et al. (1999) examined the response of several species of AM fungi to simulated acid rain and Al treatments added to soil. Spore germination, mycorrhizal colonization of host plants, and development of extraradical mycelium differed among fungal species in response to Al (Vosatka et al., 1999). Bartolome-Esteban \& Schenck (1994) and Siqueira et al. (1984) also noted that spore germination and hyphal growth of AM fungal species varied in response to acidic soil conditions and Al treatments. Variation in Al resistance among several AM fungal species and their capacity to confer Al resistance to 
plants was demonstrated by Kelly et al. (2005), using both AM colonization and growth of $A$. virginicus under exposure to $\mathrm{Al}$.

Liriodendron tulipifera L. (yellow-poplar) is a commercially and ecologically important tree species in the deciduous forests of the eastern United States (Fowells, 1965; Bonner \& Russel, 1974). These regions receive elevated levels of anthropogenic nitrogen deposition that can lead to soil acidification and subsequently elevated Al concentrations in soils (National Atmospheric Deposition Program, 1993; Driscoll et al., 2001). Tree species sensitive to Al, such as L. tulipifera, may experience declines in health (Aber et al., 1998), potentially leading to reductions in wood production and changes in community composition of deciduous forests. Arbuscular mycorrhizal associations that ameliorate Al toxicity in L. tulipifera (Lux \& Cumming, 2001) may be important in modulating forest community dynamics in systems receiving $\mathrm{N}$ deposition.

Given the variable effects of AM fungal species on plant growth and response to soil acidity and Al, we hypothesized that AM fungal species would differ in Al resistance as well as their capability to confer Al resistance to L. tulipifera and this variation would be related to organic acid production facilitated by AM fungi. In addition to assessment of growth and nutritional responses to $\mathrm{Al}$, we measured rhizosphere organic acid profiles as potential $\mathrm{Al}$ resistance mechanisms that may vary among AM fungi in symbiosis with L. tulipifera plants.

\section{Materials and methods}

Seeds of $L$. tulipifera were germinated in growth chambers after stratification in moist perlite at $4{ }^{\circ} \mathrm{C}$ for 90 days. One hundred and five seedlings were transplanted into $5 \mathrm{~cm}$ diameter $\times 18 \mathrm{~cm}$ deep pots (D-16 Deepots ${ }^{\circledR}$, Stuewe \& Sons, Corvallis, OR, USA) containing acid washed sand and fungal inoculum. Seedlings were inoculated with one of four AM fungal species from the International Culture Collection of Vesicular Arbuscular Mycorrhizae (INVAM, West Virginia University, Morgantown, WV, USA). Fungal inoculum, which was generated on roots of sudangrass, was wet-sieved (500 $\mu \mathrm{m}$ and $38 \mu \mathrm{m}$ mesh sizes) to remove most sudangrass roots, sand, and soil before adding the concentrated inoculum (collected on the $38 \mu \mathrm{m}$ sieve) containing mostly spores to acid-washed and autoclaved sand. Isolates of the fungal species Acaulospora morrowiae Spain \& Schenck (INVAM WV107-5), Glomus claroideum Schenck \& Smith (INVAM WV109E-3), G. clarum Nicol. \& Schenck (INVAM WV234-2), and Paraglomus brasilianum (Spain \& Miranda) Morton \& Redecker (INVAM 
BR105-6) collected from sites with acidic soils were used in the experiment. A mean infection percentage (MIP) assay (Moorman \& Reeves, 1979) was performed prior to the experiment to compare the level of colonization of the AM fungal isolates to be used and standardize volume of inoculum of each species for the experiment. In this assay, AM colonization (below) of corn, a highly mycotrophic species and common host plant for MIP assays, was assessed after 3 weeks of growth in a 1:10 inoculum:sterile soil/sand media mix. For the L. tulipifera experiment, inoculum was mixed with sand using a 1:12 dilution for G. clarum, 1:10 dilution for $A$. morrowiae and P. brasilianum, and a 1:5 dilution for G. claroideum based on MIP results. A control group of seedlings received sieved inoculum from roots of non-mycorrhizal sudangrass. Pots without plants were also included to assess organic acids produced by bacteria in the growing substrate.

Plants were watered three times daily to field capacity $(30 \mathrm{~mL}$ per pot) with nutrient solution containing $1.0 \mathrm{mM} \mathrm{NO}_{3}, 0.4 \mathrm{mM} \mathrm{NH}_{4}, 0.5 \mathrm{mM} \mathrm{K}, 0.2 \mathrm{mM} \mathrm{Ca}, 0.05 \mathrm{mM} \mathrm{H}_{2} \mathrm{PO}_{4}, 0.1$ $\mathrm{mM} \mathrm{Mg}$ and $\mathrm{SO}_{4}, 50.5 \mu \mathrm{M} \mathrm{Cl}, 20 \mu \mathrm{M} \mathrm{Fe}, 20 \mu \mathrm{M} \mathrm{B}, 2 \mu \mathrm{M} \mathrm{Mn}$ and $\mathrm{Zn}$, and $0.5 \mu \mathrm{M} \mathrm{Cu}, \mathrm{Na}, \mathrm{Co}$, and Mo. Nutrient solutions were modified with $\mathrm{Al}_{2}\left(\mathrm{SO}_{4}\right)_{3}$ to deliver $\mathrm{Al}$ concentrations of 0,50 , and $200 \mu \mathrm{M}$. All solutions were adjusted to $\mathrm{pH} 4.0$ with $\mathrm{HCl}$. Seedlings were maintained in growth chambers receiving light $\left(220 \mu \mathrm{mol} \mathrm{m}^{-2} \mathrm{~s}^{-1}\right.$ from mixed fluorescent and incandescent sources) for 14 hours each day and day/night temperatures of $24{ }^{\circ} \mathrm{C} / 19{ }^{\circ} \mathrm{C}$ and $60 \%$ relative humidity.

Plants were harvested after eight weeks of Al exposure. Plants did not receive solutions overnight during the 12 hours prior to harvest. Stems were clipped at the sand surface, and shoots were washed in a $0.1 \%$ Tween- 80 solution to remove surface contamination, rinsed with deionized water, dried at $60^{\circ} \mathrm{C}$, and weighed.

The contents of each pot (roots of one plant and sand) were placed in a beaker with 75 $\mathrm{mL}$ of water and allowed to stand for $5 \mathrm{~min}$. This water extract of the root zone was decanted and filtered $(0.45 \mu \mathrm{m})$ for analysis of root zone organic acid profiles (below). A root sample was removed from each plant, cleared in boiling $10 \% \mathrm{KOH}$ for 5 minutes, rinsed in water, acidified with $2 \% \mathrm{HCl}$ for 5 minutes, and stained with boiling $0.05 \%$ trypan blue in lactic acid and glycerol for 5 minutes. AM colonization was quantified using the gridline intersect method (Giovannetti \& Mosse, 1980) and was used as a measure of Al resistance of AM fungi. Remaining roots were dried at $60{ }^{\circ} \mathrm{C}$ and weighed. 
To prepare root zone extracts for organic acid analysis, $0.8 \mathrm{~mL}$ of $10 \mathrm{mM} \mathrm{Na}$-EDTA and 1 drop $1 \mathrm{~N} \mathrm{NaOH}$ were added to $5 \mathrm{~mL}$ of each extract. This procedure promoted the chelation of $\mathrm{Al}$ in the solution and prevented any suppression of organic acid detection by $\mathrm{Al}$ (Cumming et al., 2001). Samples were rotoevaporated and frozen for storage until analysis. Residual salts were dissolved in $1 \mathrm{~mL}$ deionized $\mathrm{H}_{2} \mathrm{O}$ and organic acids (acetate, citrate, formate, glycolate, lactate, malate, tartrate, succinate) were separated and quantified using ion chromatography using a Dionex ICE-AS6 column (Dionex Corp., Sunnydale, CA, USA) following the method of Cumming et al. (2001). Oxalate was also determined using ion chromatography, however using non-concentrated root zone extract samples and a Dionex AS4A anion separation column. This also allowed for the quantification of root zone chloride $(\mathrm{Cl})$ concentrations, which varied due to differential transpirational water loss from pots with plants with different sizes. The measured concentrations of $\mathrm{Cl}$ were used to normalize the concentrations of organic acids to prevent their overestimation due to differential transpiration. Measured $\mathrm{Cl}$ concentration in each sample was divided by nutrient solution $\mathrm{Cl}$ concentration, yielding a concentration factor reflecting transpirational water loss. Sample organic acid concentrations were divided by this factor to normalize them to values that would exist at field capacity. Concentrations of organic acids in pots without plants, which were low, were subtracted from values measured for each pot with a plant within the same Al treatment.

Dried leaves were ground to pass a 20 mesh screen and samples were digested in nitric acid and peroxide following procedures of Jones \& Case (1990). Digest solutions were analyzed for $\mathrm{Al}$ concentrations using a graphite furnace atomic absorption spectrometer (Varian, Inc., Mulgrave, Victoria, Australia). Inorganic phosphorous concentrations in digest solutions were quantified colorimetrically (Taussky \& Shorr, 1953). Concentrations of P in reference apple leaf tissue (National Institute of Standards and Technology Standard Reference Material 1515, Becker, 1990) indicated that the digestion method recovered approximately $80 \%$ of $\mathrm{P}$ in $L$. tulipifera leaf tissues.

The experiment was established as a blocked, two-way factorial design (6 blocks, $3 \mathrm{Al}$ concentrations $\times 5$ AM fungal treatments) with seven replicates $(n=7, N=105)$. Blocks accounted for potential environmental gradients within the growth chamber. Data were examined for normality using Shapiro-Wilk tests. Variance-stabilizing transformations were undertaken where necessary to conform to the assumptions of ANOVA. Subsequently, data 
were analyzed using a blocked, two-way ANOVA followed by Tukey-Kramer's HSD to identify significant differences among treatment groups. Correlation analyses were undertaken to assess relationships between measured variables. Data were analyzed using JMP 5.0.1 (SAS Institute Inc., Cary, $\mathrm{NC}$, USA). The concentration of free $\mathrm{Al}\left(\mathrm{Al}^{3+}\right)$ in the root zone was estimated with GEOCHEM-PC (Parker et al.,1995). The stability constant for the Al-malate complex was obtained from Hue et al. (1986) and added to the GEOCHEM-PC model.

\section{Results}

The effect of $\mathrm{Al}$ on AM colonization was dependent on fungal species and reflected Alresistant and $\mathrm{Al}$-sensitive species of $\mathrm{AM}$ fungi $(\mathrm{AM} \times \mathrm{Al}$ interaction $P<0.001)$ (Figure 1). Glomus clarum, G. claroideum, and P. brasilianum maintained levels of colonization under Al exposure that were similar to levels at $0 \mu \mathrm{M} \mathrm{Al}$, with mean colonization of $84 \%, 17 \%$, and $22 \%$, respectively. Acaulospora morrowiae was sensitive to Al, as colonization dropped from 48\% and $45 \%$ at 0 and $50 \mu \mathrm{M}$ Al to $17 \%$ at $200 \mu \mathrm{M} \mathrm{Al}$.

Plant biomass was dependent on $\mathrm{AM}$ species and solution $\mathrm{Al}(\mathrm{AM} \times \mathrm{Al}$ interaction $P=$ 0.033) (Figure 2a). Glomus clarum promoted resistance to $\mathrm{Al}$ at $50 \mu \mathrm{M}$ and protected plants to a substantial degree at $200 \mu \mathrm{M}$ Al. Plants colonized by other AM species did not exhibit this conferred Al resistance and growth responses did not differ significantly from the nonmycorrhizal plants within Al treatments.

Aluminum concentrations in leaf tissues increased with Al delivered to the root zone (Figure $2 \mathrm{~b})$. However, this pattern was not the same among $\mathrm{AM}$ fungi $(\mathrm{AM} \times \mathrm{Al}$ interaction $P=$ 0.001) and plants colonized by G. clarum accumulated the least leaf Al. Leaf P concentrations decreased with increasing Al treatments (Figure 2c), except in plants colonized by G. clarum $(\mathrm{AM} \times \mathrm{Al}$ interaction $P<0.001)$. At $200 \mu \mathrm{M} \mathrm{Al}$, plants colonized by $G$. clarum had 2- to 10fold higher leaf $\mathrm{P}$ concentrations than other mycorrhizal treatments. This pattern suggests that Al-P interactions may form the basis of Al toxicity in L. tulipifera and that the uncoupling of this interaction may represent a basis of $\mathrm{Al}$ resistance in plants colonized by G. clarum.

Organic acid concentration profiles measured in the root zones of L. tulipifera exposed to $0 \mu \mathrm{M}$ Al did not differ significantly among AM fungal treatments (Table 1). Malate, acetate, citrate, glycolate, and lactate were produced in the greatest amounts by L. tulipifera plants (Table 1). Of these, both citrate and malate are strong Al chelators. Under Al exposure, citrate concentrations in root zones of $L$. tulipifera colonized by G. clarum remained constant across all 
Al treatments (Figure 3a). In non-mycorrhizal plants and plants colonized by the other AM species, citrate concentrations remained constant or increased slightly at $50 \mu \mathrm{M} \mathrm{Al}$, but declined precipitously when plants were exposed to $200 \mu \mathrm{M} \mathrm{Al}(\mathrm{AM} \times \mathrm{Al}$ interaction $P=0.025$ ) (Figure 3a). Malate concentrations were highest in plants colonized by G. clarum (AM effect $P<0.001$ ) and were affected by $\mathrm{Al}$ treatment ( $\mathrm{Al}$ effect $P<0.001$ ). Across AM fungal treatments at $50 \mu \mathrm{M}$ $\mathrm{Al}$, malate concentrations were not different from $0 \mu \mathrm{M} \mathrm{Al}$ treatments. At $200 \mu \mathrm{M} \mathrm{Al}$, malate concentration was sustained in root zones of plants colonized by G. clarum relative to other mycorrhizal treatments (Figure 3b). Oxalate, another strong Al chelating organic acid, was detected at low concentrations (10 to $34 \mu \mathrm{M}$ ) relative to citrate and malate and did not vary among different AM fungi (AM effect $P=0.794$ ). Aluminum, however, impacted concentrations of oxalate across AM fungal treatments, with concentrations sustained at $50 \mu \mathrm{M}$ Al, but significantly reduced at $200 \mu \mathrm{M} \mathrm{Al}$ (Al effect $P<0.001$ ) (data not presented).

Production of organic acids ( $\mu \mathrm{mol} \mathrm{g}^{-1}$ root mass) was calculated to investigate potential changes in exudation induced by $\mathrm{Al}$ in root systems of $L$. tulipifera colonized by different AM fungi. All organic acids analyzed were constitutively present in the rhizosphere of L. tulipifera (Table 1). However, citrate production was stimulated at $50 \mu \mathrm{M} \mathrm{Al}$, although the extent of this stimulation varied with fungal species ( $\mathrm{AM} \times \mathrm{Al}$ interaction $P=0.012$ ) (Figure 4a). While production of citrate by plants colonized by G. clarum continued to increase with up to $200 \mu \mathrm{M}$ $\mathrm{Al}$, production declined at $200 \mu \mathrm{M} \mathrm{Al}$ in all other fungal treatments (Figure 4a). The effect of $\mathrm{Al}$ on malate production was similarly dependent on fungal species ( $\mathrm{AM} \times \mathrm{Al}$ interaction $P=0.054)$ (Figure 4b). Plants receiving $50 \mu \mathrm{M} \mathrm{Al}$ maintained or, in the case of P. brasilianum, increased malate production. However, at $200 \mu \mathrm{M} \mathrm{Al}$, only plants colonized by G. clarum continued to produce malate at similar levels to 0 and $50 \mu \mathrm{M} \mathrm{Al}$ treatments (Figure $4 \mathrm{~b}$ ).

Using measured concentrations of citrate and malate from root zone extracts, GEOCHEM-PC analysis was used to estimate the concentration of free $\mathrm{Al}$ in the rhizosphere. These values were used to investigate potential relationships between plant response and free $\mathrm{Al}$ across fungal treatments. Citrate was the primary organic acid responsible for the chelation of Al in the rhizosphere, with malate and oxalate playing substantially lesser roles. Although the production of organic acids by L. tulipifera roots was significant (Table 1, Figure 4), sufficient variation in free $\mathrm{Al}$ concentration among fungal treatments and across $\mathrm{Al}$ treatments provided insight into the factors driving plant response to $\mathrm{Al}$ in the rhizosphere. Plant growth (Figure 5a), 
leaf $\mathrm{Al}$ (Figure 5b), and leaf $\mathrm{P}$ (Figure 5c) each responded consistently to the concentration of free $\mathrm{Al}$ in the rhizosphere. Growth declined precipitously between 0 and $12 \mu \mathrm{M}$ free $\mathrm{Al}$, with no change in plant sensitivity above $20 \mu \mathrm{M}$ (Figure $5 \mathrm{a}$ ). The concentration of free $\mathrm{Al}$ in the rhizosphere leading to a $20 \%$ reduction in growth was estimated to be $5.3 \mu \mathrm{M}$ using the logarithmic fit highlighted in Figure 5a. The accumulation of $\mathrm{Al}$ in foliage was also related to free $\mathrm{Al}$ concentration, with significant accumulation occurring at free $\mathrm{Al}$ concentrations as low as $2.3 \mu \mathrm{M} \mathrm{Al}$ (Figure 5b). Leaf P concentrations also declined significantly with increasing rhizosphere $\mathrm{Al}$, with a $20 \%$ reduction in P occurring at $5.6 \mu \mathrm{M}$ free Al. Although L. tulipifera responded monotonally to free $\mathrm{Al}$ concentrations across the suite of $\mathrm{AM}$ fungi investigated, the benefit derived from G. clarum highlighted in Figures 2-4 resulted from this particular AM species' capacity to significantly reduce the free Al concentration in the rhizosphere, thereby reducing the impacts of total $\mathrm{Al}$ on growth (Figure 5a), $\mathrm{Al}$ accumulation (Figure 5b), and $\mathrm{P}$ acquisition (Figure 5c). Other AM fungi altered free $\mathrm{Al}$ concentrations to lesser extents (Figure $5 b)$.

Since large differences in colonization existed among fungal species, correlation analyses were used to investigate relationships between plant parameters and colonization within species to determine if colonization was a major factor determining plant response to Al. Relationships between colonization and biomass, leaf Al, leaf $\mathrm{P}$, or organic acid production varied among $\mathrm{AM}$ fungal species and, with the exception of A. morrowiae, colonization was not consistently related to plant performance under $\mathrm{Al}$ exposure (Table 2). For plants colonized by A. morrowiae, biomass, leaf $\mathrm{P}$, and organic acid production were positively correlated and leaf Al negatively correlated with colonization, reflecting concomitant reductions in colonization and fungal benefits under $\mathrm{Al}$ exposure in this species (Table 2). 
Table 1. Concentration profiles of organic acids measured in the root zones of mycorrhizal $L$. tulipifera exposed to $0 \mu \mathrm{M} \mathrm{Al}(\mu \mathrm{M})$. Values are mean organic acid concentrations $(\mathrm{n}=7)$. Abbreviations: $\mathrm{NM}=$ Non-mycorrhizal.

\begin{tabular}{llllll}
\hline Organic acid & NM & A. morrowiae & G. claroideum & G. clarum & P. brasilianum \\
\hline Acetate & 268.61 & 261.45 & 264.48 & 231.68 & 158.82 \\
Citrate & 194.38 & 202.40 & 244.17 & 279.36 & 217.17 \\
Formate & 45.99 & 58.85 & 83.50 & 110.53 & 7.91 \\
Glycolate & 105.04 & 159.94 & 173.14 & 156.29 & 82.61 \\
Lactate & 151.29 & 84.97 & 144.82 & 94.37 & 142.89 \\
Malate & 577.01 & 807.38 & 745.88 & 1136.34 & 749.01 \\
Oxalate & 31.21 & 26.17 & 28.65 & 32.00 & 30.92 \\
Succinate & 69.24 & 32.07 & 37.40 & 38.77 & 24.63 \\
Tartrate & 2.18 & 7.19 & 10.30 & 11.08 & 8.80 \\
\hline
\end{tabular}


Table 2. Correlations between plant parameters and colonization for L. tulipifera under variable Al exposure. Correlations (Pearson's $r$ ) were calculated after arcsine square root transformations utilized to obtain normally distributed colonization data. Significance levels indicated by asterisks: $* * *=P<0.01 ; * *=P<0.05 ; *=P<0.10$; and ns $=$ not significant. Organic acid $(\mathrm{OA})$ production is calculated as the sum of citrate, malate, and oxalate per gram root mass.

\begin{tabular}{lllll}
\hline Parameter & A. morrowiae & G. claroideum & G. clarum & P. brasilianum \\
\hline Plant biomass $(\mathrm{g})$ & $0.616^{* * *}$ & $-0.648^{* * *}$ & $\mathrm{~ns}$ & $\mathrm{~ns}$ \\
Leaf $\mathrm{Al}\left(\mu \mathrm{g} \mathrm{g}^{-1}\right)$ & $-0.551^{*}$ & $\mathrm{~ns}$ & $\mathrm{~ns}$ & $\mathrm{~ns}$ \\
Leaf P $\left(\mu \mathrm{g} \mathrm{g}^{-1}\right)$ & $0.759^{* * *}$ & $-0.728^{* *}$ & $-0.650^{* * *}$ & $-0.578^{* *}$ \\
$\begin{array}{l}\text { OA production } \\
\left.(\mu \mathrm{mol} \mathrm{g})^{-1}\right)\end{array}$ & $0.659^{* * *}$ & $\mathrm{~ns}$ & $\mathrm{~ns}$ & $\mathrm{~ns}$ \\
\end{tabular}




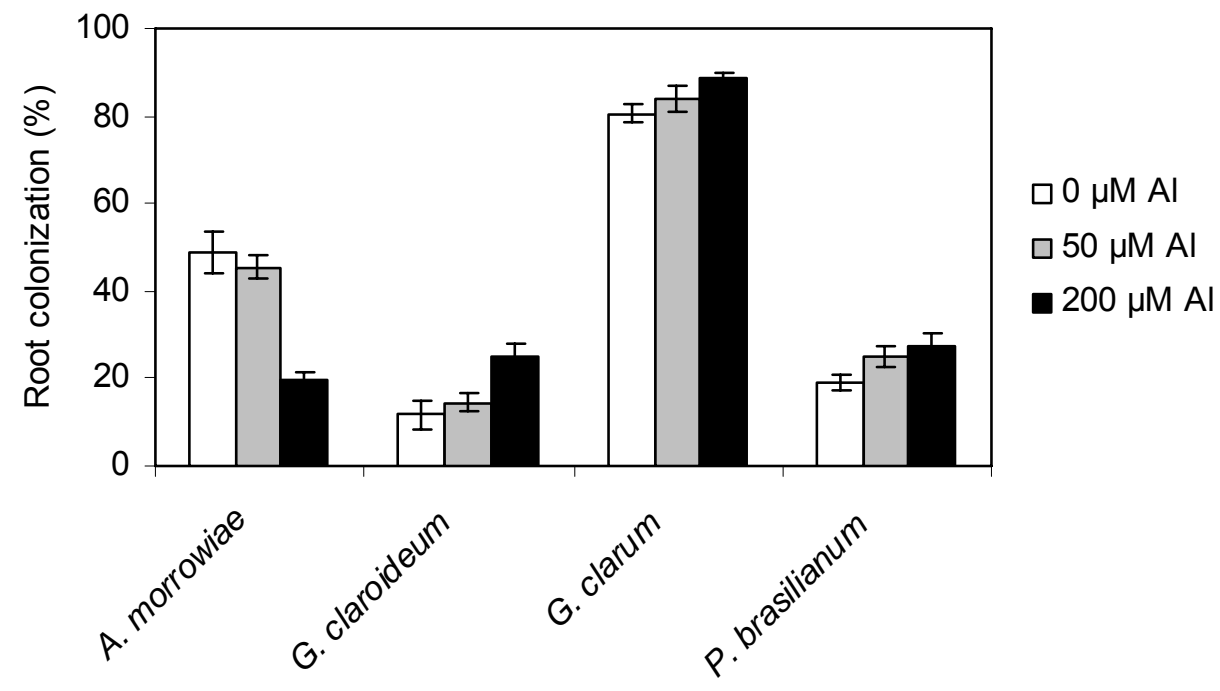

Figure 1. Colonization of $L$. tulipifera seedlings by arbuscular mycorrhizal species at 0,50 , and $200 \mu \mathrm{M} \mathrm{Al}$. 

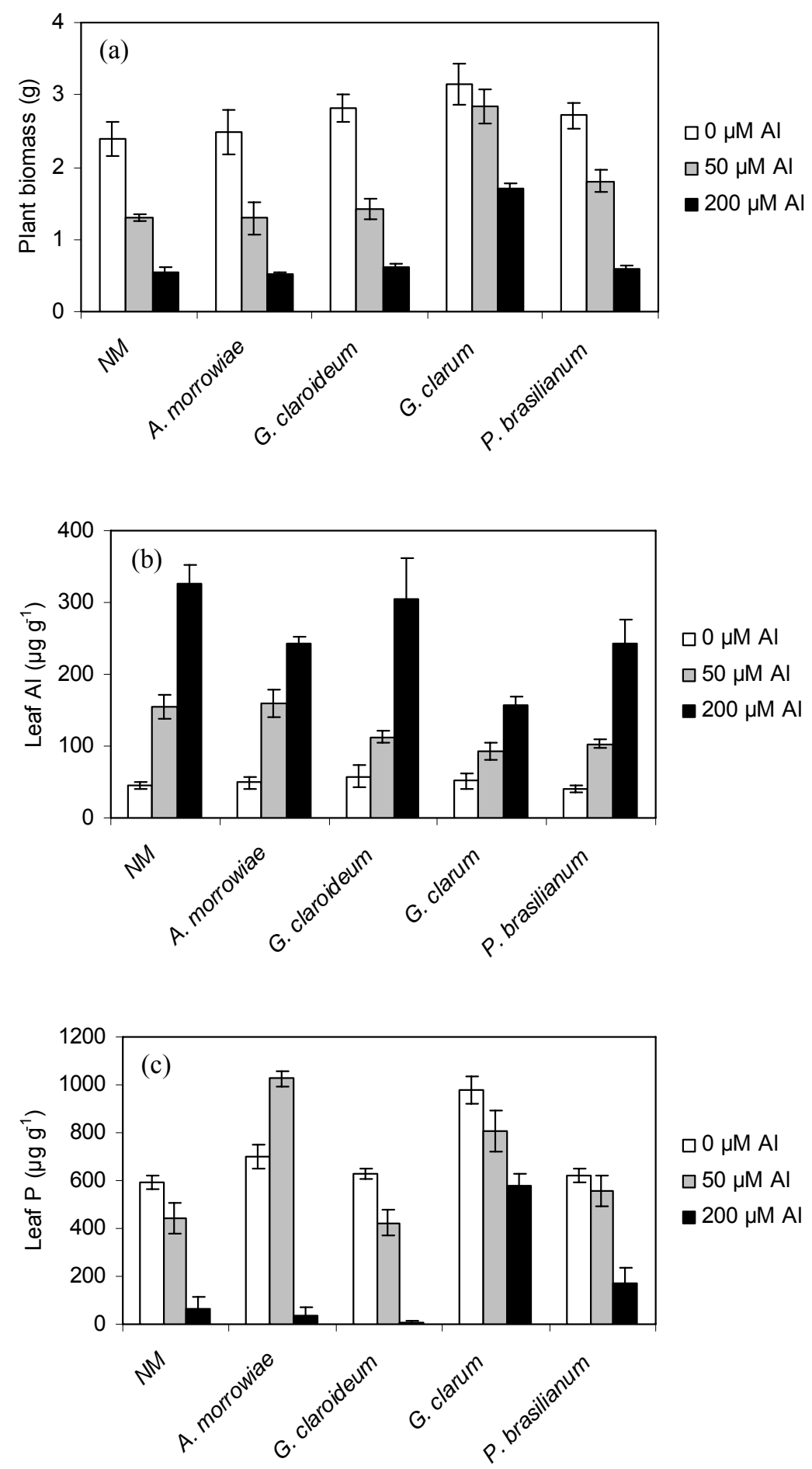

Figure 2. (a) Total biomass, (b) leaf Al, and (c) leaf P concentrations of non-mycorrhizal (NM) L. tulipifera seedlings and seedlings colonized by arbuscular mycorrhizal fungi exposed to 0,50 , and $200 \mu \mathrm{M} \mathrm{Al}$. 

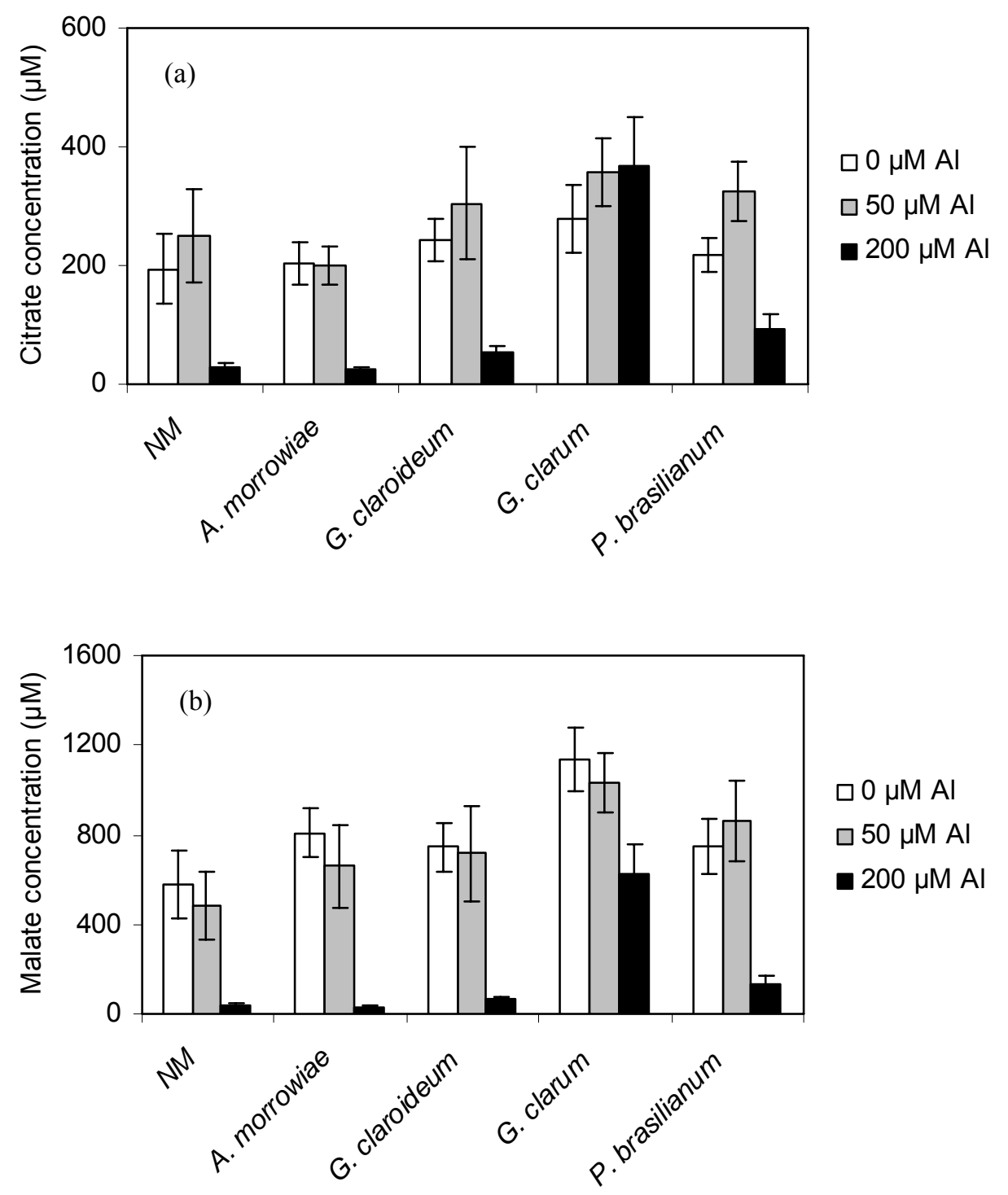

Figure 3. (a) Citrate and (b) malate concentrations in root zones of non-mycorrhizal (NM) $L$. tulipifera seedlings and seedlings colonized by arbuscular mycorrhizal fungi exposed to 0,50 , and $200 \mu \mathrm{M} \mathrm{Al}$. 

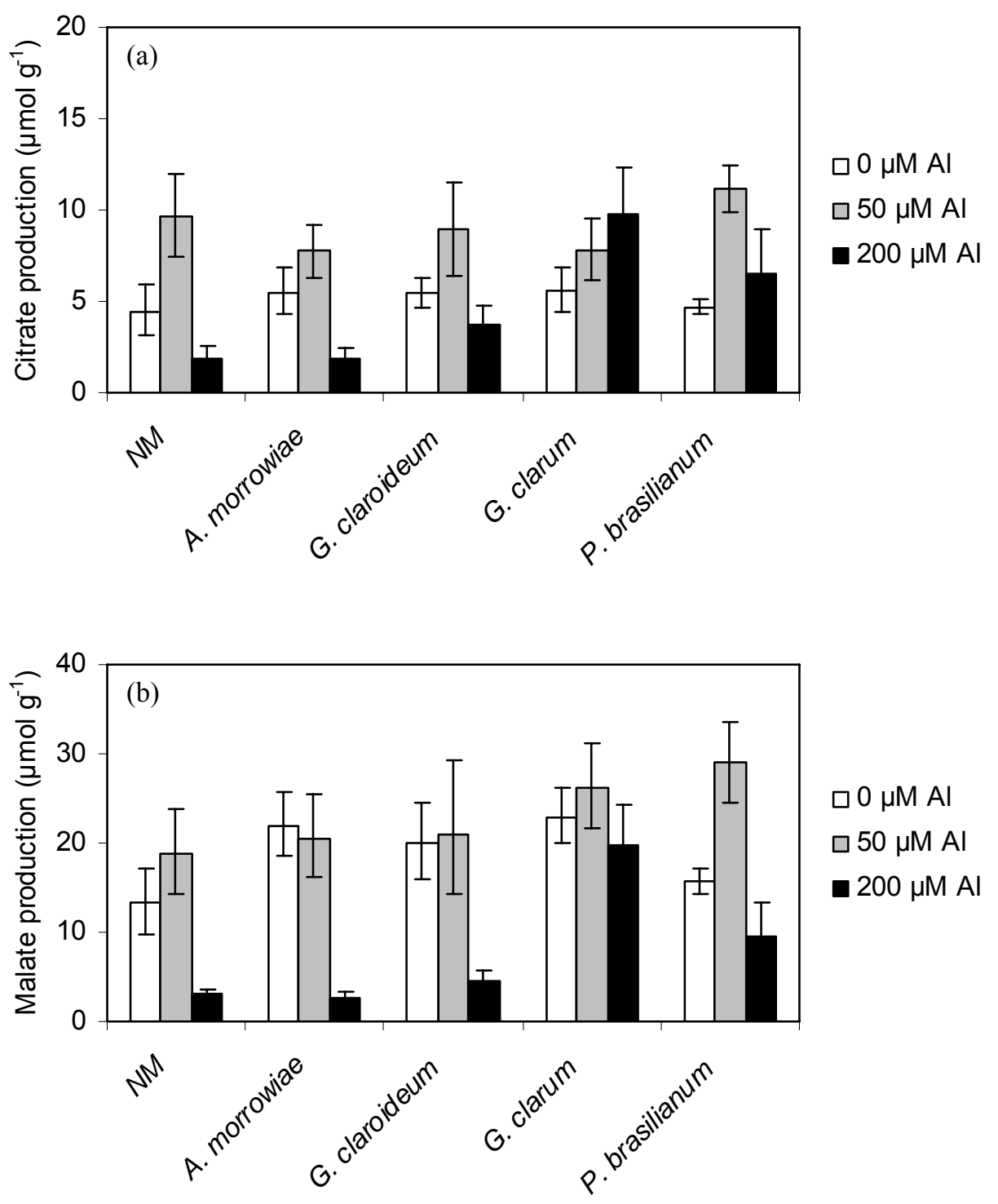

Figure 4. (a) Citrate and (b) malate production from roots ( $\mu \mathrm{mol} \mathrm{g}^{-1}$ root mass) of nonmycorrhizal (NM) L. tulipifera seedlings and seedlings colonized by arbuscular mycorrhizal fungi exposed to 0,50 , and $200 \mu \mathrm{M}$ Al. 

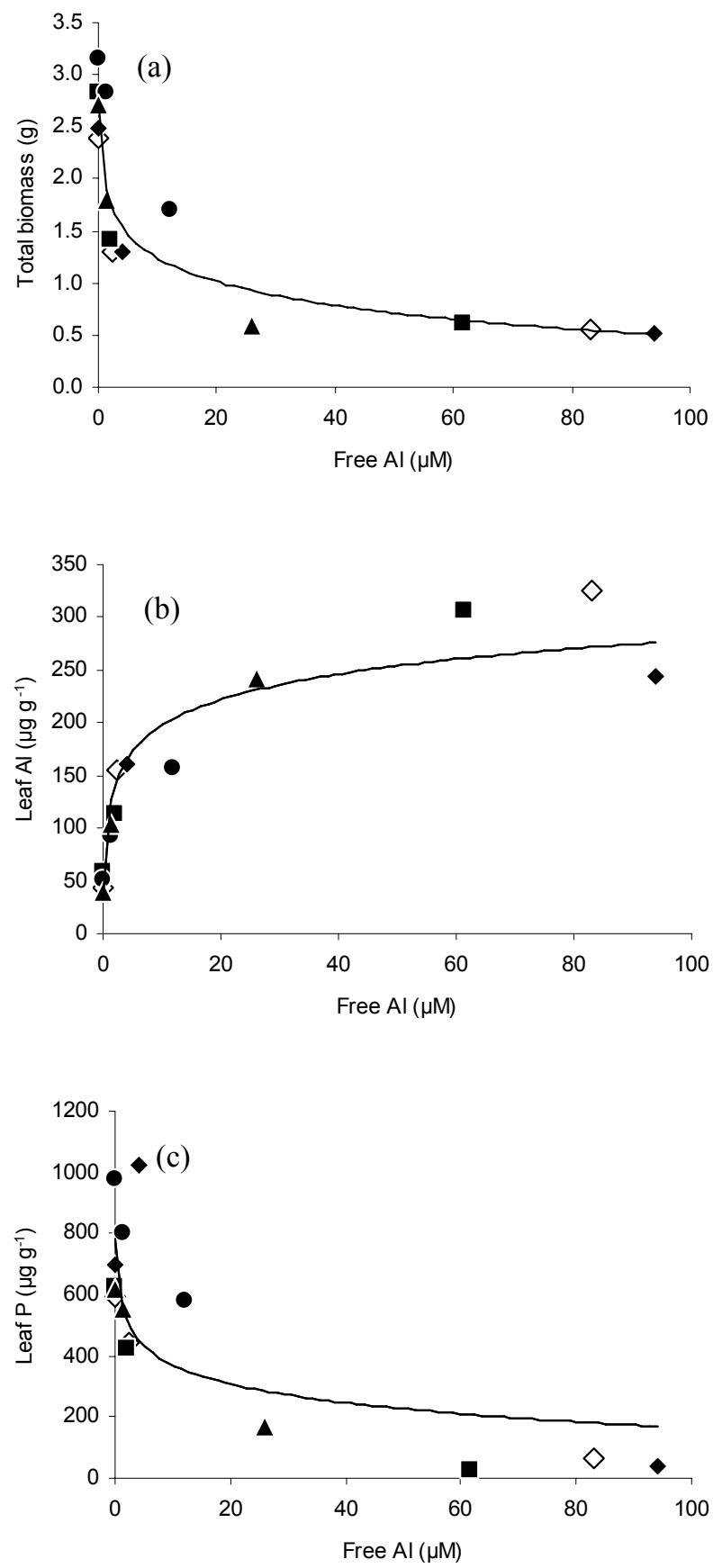

Figure 5. Relationships between free $\mathrm{Al}\left(\mathrm{Al}^{3+}\right)$ concentrations estimated in root zones and biomass, leaf Al, and leaf P of non-mycorrhizal (NM) and mycorrhizal L. tulipifera. Symbols are as follows: $\diamond$ Non-mycorrhizal, $\bullet$ A. morrowiae, $\bullet$ G. claroideum, $\bullet$ G. clarum, $\triangleleft P$. brasilianum. 


\section{Discussion}

Physiological responses of non-mycorrhizal plants to Al have been studied extensively and have been widely reviewed (Delhaize \& Ryan, 1995; Ma, 2000; Matsumoto, 2000; Kochian et al., 2004), but substantially less work has focused on plants colonized by mycorrhizal fungi. Resistance to $\mathrm{Al}$ in non-mycorrhizal plants appears to be associated with reduced $\mathrm{Al}$ accumulation in sensitive root tips (Matsumoto, 2000), which may be regulated by the exudation of organic acids by roots (Ma, 2000). The AM fungal symbiosis alters the responses of plants to acidic soils and Al (Koslowsky \& Boerner, 1989; Clark, 1997; Rufyikiri et al., 2000). Changes in Al speciation in the rhizosphere due to increased organic acid exudation by mycorrhizal plants is one potential Al detoxification mechanism (Lux \& Cumming, 2001), as would be the production of new $\mathrm{Al}$ chelating compounds by AM fungi or the binding and sequestration of $\mathrm{Al}$ on or in fungal hyphae (Gadd, 1993; Galli et al., 1994; Leyval et al., 1997; Kaldorf et al., 1999).

Variation in Al resistance of AM species noted by Kelly et al. (2005), Vosatka et al. (1999), Bartolome-Esteban \& Schenck (1994), and Siqueira et al. (1984) may result from differential carbon (C) allocation in plants colonized by these different fungi that leads to sustained exudation of Al-binding compounds into the rhizosphere. In the present study, organic acid profiles differed among fungal treatments under $\mathrm{Al}$ exposure, highlighting interspecific differences in $\mathrm{C}$ flux to the root zone in plants under stress. The sustained production of citrate and malate at high levels of Al may contribute to the Al resistance of L. tulipifera colonized by G. clarum or, conversely, may reflect the operation of other unknown Al resistance mechanisms unique to this host-symbiont combination, with sustained organic acid production simply the resulting response. The relatively high biomass, low leaf $\mathrm{Al}$, and high leaf $\mathrm{P}$ of plants colonized by G. clarum and exposed to $\mathrm{Al}$ were congruent with a reduction in free $\mathrm{Al}$ in the rhizosphere (Figure 5) and subsequent reductions in Al-P chemical interactions that may underlie $L$. tulipifera response to Al (Lux \& Cumming, 2001).

The chelation of Al by organic acids such as citrate and malate is an accepted Al resistance mechanism in higher plants (Hue et al., 1986; Miyasaka et al., 1991; Delhaize \& Ryan, 1995; Adams et al.,1999; Ma, 2000). In most cases, organic acid production is induced by exposure to $\mathrm{Al}$ in $\mathrm{Al}$-resistant genotypes. In the current study, relatively high levels of organic acids were noted in the root zones of L. tulipifera plants exposed to 0 and $50 \mu \mathrm{M}$ Al, although organic acid concentrations were maintained only in plants colonized by G. clarum when 
exposed to $200 \mu \mathrm{M} \mathrm{Al}$ (Table 1, Figure 3). Citrate production increased under exposure to 50 $\mu \mathrm{M}$ Al for all AM fungi, but this increase again was sustained at $200 \mu \mathrm{M}$ Al only in plants colonized by G. clarum (Figure 4). Estimates of Al speciation obtained from GEOCHEM-PC revealed that citrate was the primary organic acid that chelated $\mathrm{Al}$ and that fungi varied in their capacity to alter the concentration of free $\mathrm{Al}$ in the root zone. These shifts in free $\mathrm{Al}$ concentration reduced the accumulation of $\mathrm{Al}$, enhanced the availability of $\mathrm{P}$ for plants exposed to $\mathrm{Al}$, and subsequently reduced the toxic effects of $\mathrm{Al}$ on L. tulipifera seedlings (Figure 5).

Estimates of $\mathrm{C}$ transfer to the rhizosphere through exudation vary widely between 0.1 to $21 \%$ of photosynthesis, with this variation reflecting both methodological and interpretational components (Marschner, 1995; Grayston et al., 1996; Jones et al., 2004). Experimental estimates for root exudation by forest tree species are not numerous. However, their estimates are substantially lower that those reported for non-woody plants. For example, Uselman et al. (2000) reported that exudation by black locust accounted for $1.2 \%$ of net photosynthesis and exudation by Eucalyptus camaldulensis (Nguyen et al., 2003) was approximately half that reported by Uselman et al. (2000) for Robinia. This variation may result from differing approaches used that may significantly underestimate DOC in the root zone, and plant age and mycorrhizal status, which may affect the degree of root system development and the intensity of C flux into the rhizosphere (Marschner, 1995; Grayston et al., 1996; Jones et al., 2004). For the current study, calculated C flux rates into the rhizosphere of L. tulipifera plants (based on measured organic acid concentrations and watering flux through the root zone) are between 3.06 and $4.00 \mathrm{mg} \mathrm{C} \mathrm{g}^{-1} \mathrm{~d}^{-1}$, approximately 10-fold higher than rates reported by Uselman et al. (2000) and may be more in line with estimates of $\mathrm{C}$ flux in other species. Thus, the methods of organic acid measurement undertaken in the current study (root zone extraction from plants grown in intact soil systems with mycorrhizal fungi), may more effectively measure concentrations of dissolved organic compounds allocated to the rhizosphere of tree species (Jones et al., 2004). Even so, measured concentrations of organic acids in the current study may still represent underestimates of $\mathrm{C}$ flux to the rhizosphere because microbial activity may lead to the rapid sequestration and degradation of $\mathrm{C}$ exuded by roots (Jones et al., 2004). However, the balance between $\mathrm{C}$ release by roots and breakdown by soil microbes will represent the capacity of the root system to chelate metals in the environment, and our plant culture system may represent the 
best approach to assess the ecological importance of root exudates and AM fungi in conferring Al resistance to plants.

Glomus clarum was the most aggressive colonizer and provided the most benefits to $L$. tulipifera plants under $\mathrm{Al}$ exposure. Other species were not as aggressive and host plant responses did not differ significantly from non-mycorrhizal plants. An MIP assay performed prior to the experiment was undertaken to standardize AM inoculum dilutions. However, differences in colonization were still observed among AM fungi, which may reflect the use of different host species (corn) in the MIP and the experiment proper or fundamental functional differences in aggressiveness among AM species used. For example, given inoculum dilutions ranging between 1:12 for G. clarum and 1:5 for G. claroideum, the order of colonization among AM fungi remained G. clarum $>$ A. morrowiae $>$ P. brasilianum $>$ G. claroideum. This suggests that differences in aggressiveness or secondary colonization vary extensively among these AM fungal species. Such variation in colonization among AM species is common in experiments using multiple AM species (Clark et al., 1999; Vosatka et al., 1999) and exemplifies colonization level as a functional attribute that is not uniform among AM species.

In plants not exposed to $\mathrm{Al}$, organic acid production was independent of the degree of colonization across all AM species $(r=0.268, P=0.228)$ (data not presented). Likewise, organic acid production, plant biomass, and leaf $\mathrm{Al}$ accumulation were independent of colonization for P. brasilianum, G. clarum, and G. claroideum (Table 2), suggesting that colonization may not be controlling $\mathrm{Al}$ resistance in L. tulipifera, but rather variation in $\mathrm{Al}$ resistance is a functional trait that varies among AM species. Although colonization of $L$. tulipifera seedlings by P. brasilianum, G. clarum, and G. claroideum was unaffected by Al, only plants colonized by G. clarum exhibited Al resistance. Plants colonized by P. brasilianum and G. claroideum exhibited declines in organic acid production, elevated Al accumulation in leaves, and reductions in leaf $\mathrm{P}$ at high levels of $\mathrm{Al}$, suggesting that $\mathrm{AM}$ fungi confer varying levels of Al resistance even when colonization does not show Al sensitivity. In plants colonized by $A$. morrowiae, Al exposure reduced colonization and, additionally, A. morrowiae did not confer Al resistance to plant hosts. These conclusions are supported by Kelly et al. (2005), who found that A. morrowiae isolates were uniformly Al sensitive compared to isolates of other AM species, including G. clarum. 
The present study indicates that the level of conferred $\mathrm{Al}$ resistance is not uniform across AM fungal species associated with L. tulipifera and that G. clarum is more beneficial to its host than other species of AM fungi. All AM fungal isolates used in the current work were collected from acidic soils where $\mathrm{Al}$ would be expected to be a significant environmental factor. That there was variation among species may reflect innate differences in $\mathrm{Al}$ resistance or differences in the stability of Al resistance in culture (Malcová et al., 2003; Kelly et al., 2005). The G. clarum isolate used previously conferred near complete resistance to Al based on growth in $L$. tulipifera (Lux \& Cumming, 2001), whereas resistance to $200 \mu \mathrm{M} \mathrm{Al}$ was only $54 \%$ in the current study. Therefore, it seems that traits promoting Al resistance in AM fungi and/or conferring $\mathrm{Al}$ resistance to host plants may not be stable in pot culture and that isolates for environmental research should be maintained under edaphic conditions similar to those at the site of collection.

The data presented here are the first qualitative and quantitative data on organic acid exudation by mycorrhizal plants exposed to $\mathrm{Al}$ and the potential role of exudates in $\mathrm{Al}$ resistance of AM fungi and mycorrhizal plants. Under the complex propagation system used in this study, including long term growth in solid substrate with AM fungi, significant concentrations of a suite of organic acids were detected in the root zone. Citrate and malate were responsible for reducing free $\mathrm{Al}$ concentrations and, in the case of plants colonized by G. clarum, sustained production under $\mathrm{Al}$ exposure ameliorated $\mathrm{Al}$ phytotoxicity in L. tulipifera by reducing $\mathrm{Al}$ bioavailability and facilitating $\mathrm{P}$ acquisition. Other AM fungal species studied were not as successful as $G$. clarum in conferring $\mathrm{Al}$ resistance to L. tulipifera. Variation among AM fungal species in influencing $\mathrm{Al}$ resistance of L. tulipifera plants highlights the importance of accounting for AM fungal diversity in studies on plant and ecosystem responses to environmental stress. 


\section{References}

Aber J, McDowell W, Nadelhoffer K, Magill A, Berntson G, Kamakea M, McNulty S, Currie W, Rustad L, Fernandez I. 1998. Nitrogen saturation in temperate forest ecosystems. Bioscience 48: 921-934.

Adams JF, Wood CW, Mitchell RI. 1999. Loblolly pine plant community structure and soil solution aluminum, organic acids, calcium, magnesium, and $\mathrm{pH}$. Communications in Soil Science and Plant Analysis 30: 1939-1950.

Antunes AMG, Nunes MA. 1997. Effects of aluminum on nutrient solution $\mathrm{pH}$ and nitrate/ammonium uptake by triticale. Journal of Plant Nutrition 20: 1391-1401.

Bartolome-Esteban H, Schenck NC. 1994. Spore germination and hyphal growth of arbuscular mycorrhizal fungi in relation to soil aluminum saturation. Mycologia 86: 217-226.

Becker DA. 1990. Homogeneity and evaluation of the new NIST certified reference materials. In: Zeisler R, Guinn VP, eds. Nuclear Analytical Methods in the Life Sciences. Clifton, USA: Humana Press, 571-577.

Bever JD, Schultz PA, Pringle A, Morton JB. 2001. Arbuscular mycorrhizal fungi: more diverse than meets the eye, and the ecological tale of why. Bioscience 51: 923-931.

Bolan NS. 1991. A critical review on the role of mycorrhizal fungi in the uptake of phosphorous by plants. Plant and Soil 134: 189-207.

Bonner FT, Russell TE. 1974. Liriodendron tulipifera L. Yellow-poplar. In: Schopmeyer CS, ed. Seeds of Woody Plants in the Unites States. Washington, USA: US Department of Agriculture, 508-511.

Clark RB. 1997. Arbuscular mycorrhizal adaptation, spore germination, root colonization, and host plant growth and mineral acquisition at low pH. Plant and Soil 192: 15-22.

Clark RB, Zobel RW, Zeto SK. 1999. Arbuscular mycorrhizal fungal isolate effectiveness on growth and root colonization of Panicum virgatum in acidic soil. Soil Biology and Biochemistry 31: 1757-173.

Clarkson DT. 1985. Factors affecting mineral nutrient acquisition by plants. Annual Review of Plant Physiology 36: 11-115.

Cumming JR, Ning J. 2003. Arbuscular mycorrhizal fungi enhance aluminum resistance of broomsedge (Andropogon virginicus L.). Journal of Experimental Botany 54: 1447-1459.

Cumming JR, Swiger TD, Kurnik BS, Panaccione DG. 2001. Organic acid exudation by Laccaria bicolor and Pisolithus tinctorius exposed to aluminum in vitro. Canadian Journal of Forest Research 31: 703-710. 
Delhaize E, Craig S, Beaton CD, Bennet RJ, Jagadish VC, Randall PJ. 1993a. Aluminum tolerance in wheat (Triticum aestivum L.) I. Uptake and distribution of aluminum in root apices. Plant Physiology 103: 685-693.

Delhaize E, Ryan PR. 1995. Aluminum toxicity and tolerance in plants. Plant Physiology 107: 315-321.

Delhaize E, Ryan PR, Randall PJ. 1993b. Aluminum tolerance in wheat (Triticum aestivum L.) II. Aluminum-stimulated excretion of malic acid from root apices. Plant Physiology 103: 695702.

Driscoll CT, Lawrence GB, Bulger AJ, Butler TJ, Cronan CS, Eagar C, Lambert KF, Likens GE, Stoddard JL, Weathers KC. 2001. Acidic deposition in the northeastern United States: Sources and inputs, ecosystem effects, and management strategies. Bioscience 51: 180198.

Fowells HA. 1965. Silvics of Forest Trees of the United States. Washington, USA: US Government Printing Office.

Gadd GM. 1993. Interactions of fungi with toxic metals. New Phytologist 124: 25-60.

Galli U, Schüepp H, Brunold C. 1994. Heavy metal binding by mycorrhizal fungi. Physiologia Plantarum 92: 34-368.

Giovannetti M, Mosse B. 1980. An evaluation of techniques for measuring vesicular arbuscular mycorrhizal infection in roots. New Phytologist 84: 489-500.

Grayston SJ, Vaughan D, Jones D. 1996. Rhizosphere carbon flow in trees, in comparison with annual plants: the importance of root exudation and its impact on microbial activity and nutrient availability. Applied Soil Ecology 5: 29-56.

Helgason T, Merryweather JW, Denison J, Wilson P, Young JPW, Fitter AH. 2002. Selectivity and functional diversity in arbuscular mycorrhizas of co-occurring fungi and plants from a temperate deciduous woodland. Journal of Ecology 90: 371-384.

Huang JW, Shaff JE, Grunes DL, Kochian LV. 1992. Aluminum effects on calcium fluxes at the root apex of aluminum-tolerant and aluminum-sensitive wheat cultivars. Plant Physiology 98: $230-237$.

Hue NV, Craddock, GR, Adams F. 1986. Effect of organic acids on aluminum toxicity in subsoils. Soil Science Society of America Journal 50: 28-34.

Jones DL, Hodge A, Kuzyakov Y. 2004. Plant and mycorrhizal regulation of rhizodeposition. New Phytologist 163: 459-480.

Jones Jr. JB, Case VW. 1990. Sampling, handling, and analyzing plant tissue samples. In: Westerman RL, ed. Soil Testing and Plant Analysis, $3^{\text {rd }}$ edn. Madison, USA: Soil Science Society of America, 389-427. 
Kaldorf M, Kuhn AJ, Schröder WH, Hildebrandt U, Bothe H. 1999. Selective element deposits in maize colonized by a heavy metal tolerance conferring arbuscular mycorrhizal fungus. Journal of Plant Physiology 154: 718-728.

Kelly CN, Morton JB, Cumming JR. 2005. Variation in aluminum resistance among arbuscular mycorrhizal fungi. Mycorrhiza 15: 193-201.

Kinraide TB, Parker DR, Zobel RW. 2005. Organic acid secretion as a mechanism of aluminum resistance: a model incorporating the root cortex, epidermis, and the external unstirred layer. Journal of Experimental Botany 56: 1853-1865.

Kochian LV, Hoekenga OA, Piñeros MA. 2004. How do crop plants tolerate acid soils? Mechanisms of aluminum tolerance and phosphorous efficiency. Annual Review of Plant Biology 55: 459-493.

Koslowsky SD, Boerner RE. 1989. Interactive effects of aluminum, phosphorous and mycorrhizae on growth and nutrient uptake of Panicum virgatum L. (Poaceae). Environmental Pollution 61: 107-125.

Le Van H, Kuraishi S, Sakurai N. 1994. Aluminum-induced rapid root inhibition and changes in cell-wall components of squash seedlings. Plant Physiology 106: 971-976.

Leyval C, Turnau K, Haselwandter K. 1997. Effect of heavy metal pollution on mycorrhizal colonization and function: physiological, ecological and applied aspects. Mycorrhiza 7: 139153.

Lux HB, Cumming JR. 2001. Mycorrhizae confer aluminum resistance to tulip-poplar seedlings. Canadian Journal of Forest Research 31: 694-702.

Ma JF. 2000. Role of organic acids in detoxification of aluminum in higher plants. Plant and Cell Physiology 41: 383-390.

Macklon AES, Lumsdon DG, Sim A. 1994. Phosphate uptake and transport in Agrostis capillaris L.: Effects of non-toxic levels of aluminum and the significance of $\mathrm{P}$ and $\mathrm{Al}$ speciation. Journal of Experimental Botany 45: 887-894.

Malcová R, Rydlova J, Vosatka M. 2003. Metal-free cultivation of Glomus sp. BEG 140 isolated from Mn-contaminated soil reduces tolerance to Mn. Mycorrhiza 13: 151-157.

Marschner H. 1991. Mechanisms of adaptation of plants to acid soils. In: Wright RJ, Baligar VC, Murrman RP, eds. Plant-soil interactions at low pH. Dordrecht, Netherlands: Kluwer Academic Publishers, 683-702.

Matsumoto H. 2000. Cell biology of aluminum toxicity and tolerance in higher plants. International Review of Cytology 200: 1-46.

Meharg AA, Cairney JWG. 2000. Co-evolution of mycorrhizal symbionts and their hosts to metal-contaminated environments. Advances in Ecological Research 30: 69-112. 
Miranda LN DE, Rowell DL. 1989. Aluminum-phosphate interactions in wheat. New Phytologist 113: 7-12.

Miyasaka SC, Buta GJ, Howell RK, Foy CD. 1991. Mechanism of aluminum tolerance in snapbeans. Plant Physiology 96: 737-743.

Moorman T, Reeves FB. 1979. The role of endomycorrhizae in revegetation practices in the semi-arid West. II. A bioassay to determine the effect of land disturbance on endomycorrhizal populations. American Journal of Botany 66: 14-18.

Munkvold L, Kjøller R, Vesberg M, Rosendahl S, Jakobsen, I. 2004. High functional diversity within species of arbuscular mycorrhizal fungi. New Phytologist 164: 357-364.

Nguyen TN, Nakabayashi K, Thompson J, Fujita K. 2003. Role of exudation of organic adics and phosphate in aluminum tolerance of four tropical woody species. Tree Physiology 23: 10411050.

Nowak J, Friend AL. 2002. Aluminum fractions in root tips of slash pine and loblolly pine families differing in Al resistance. Tree Physiology 25: 245-250.

Parker DR, Norvell WA, Chaney RL. 1995. GEOCHEM-PC: A chemical speciation program for IBM and compatible personal computers. In: Loeppert RH, Schwab AP, Goldberg S, eds. Chemical Equilibrium and Reaction Models, SSSA Spec. Publ. No. 42. Madison, USA: ASA and SSSA, 253-269.

Purcell LC, Keisling TC, Sneller CH. 2002. Soybean yield and water extraction in response to deep tillage and high soil aluminum. Communications in Soil Science and Plant Analysis 33: 3723-3735.

Piñeros MA, Magalhaes JV, Carvalho Alves VM, Kochian LV. 2002. The physiology and biophysics of an aluminum tolerance mechanism based on root citrate exudation in maize. Plant Physiology 129: 1194-1206.

Rengel Z, Elliott DC. 1992. Mechanism of aluminum inhibition of net ${ }^{45} \mathrm{Ca}^{2+}$ uptake by Amaranthus protoplasts. Plant Physiology 98: 632-638.

Rufyikiri G, Declerck S, Dufey JE, Delvaux B. 2000. Arbuscular mycorrhizal fungi might alleviate aluminum toxicity in banana plants. New Phytologist 148: 343-352.

Samuels TD, Rincon-Zachary M, Kucukakyuz K. 1997. Al partitioning patterns and root growth as related to Al sensitivity and Al tolerance in wheat. Plant Physiology 113: 527-534.

Silva IR, Novias RF, Jham GN, Barros NF, Gebrim FO, Nunes FN, Neves JCL, Leite FP. 2004. Responses of eucalypt species to aluminum: the possible involvement of low molecular weight organic acids in the Al tolerance mechanism. Tree Physiology 24: 1267-1277.

Silva IR, Smyth TJ, Raper CD, Carter TE, Rufty TW. 2001. Differential aluminum tolerance in soybean: An evaluation of the role of organic acids. Physiologia Plantarum 112: 200-210. 
Siqueira JO, Hubbell DH, Mahmud AW. 1984. Effect of liming on spore germination, germ tube growth and root colonization by vesicular-arbuscular mycorrhizal fungi. Plant and Soil 76: 115-124.

Sivaguru M, Horst WJ. 1998. The distal part of the trasition zone is the most aluminumsensitive apical root zone of maize. Plant Physiology 116: 155-163.

Taussky HH, Shorr E. 1953. A microcolorimetric method for the determination of inorganic phosphorus. Journal of Biological Chemistry 202: 675-685.

Uselman SM, Qualls RG, Thomas RB. 2000. Effects of increased atmospheric $\mathrm{CO}_{2}$, temperature, and soil $\mathrm{N}$ availability on root exudation of dissolved organic carbon by a $\mathrm{N}$-fixing tree (Robinia pseudoacacia L.). Plant and Soil 222: 191-202.

von Uexküll HR, Mutert E. 1995. Global extent, development and economic impact of acid soils. Plant and Soil 171: 1-15.

Vosatka M, Batkhuugyin E, Albrechtova J. 1999. Response of three arbuscular mycorrhizal fungi to simulated acid rain and aluminum stress. Biologia Plantarum 42: 289-296. 


\section{Chapter 3: Organic acid exudation by mycorrhizal Andropogon virginicus L. (broomsedge) roots in response to aluminum.}

\section{Introduction}

Approximately $30 \%$ of the world's soils are classified as acidic and have $\mathrm{pH}<5.5$ (von Uexküll \& Mutert, 1995; Havlin et al., 1999). Sources of acidity vary from site to site and can be natural or anthropogenic (Havlin et al., 1999). Some natural sources of soil acidity include decomposition of organic matter, root respiration, and uptake of ammonium $\left(\mathrm{NH}_{4}\right)$, processes that can impact soil $\mathrm{pH}$ on local scales. On larger scales, weathering of parent materials and the subsequent leaching of basic cations, such as potassium $(\mathrm{K})$, calcium $(\mathrm{Ca})$, and magnesium $(\mathrm{Mg})$, lead to soil acidification (Bolan et al., 1991; Driscoll et al., 2001). Human activity also influences the $\mathrm{pH}$ of soils. The most common example is the acidification of soils through the industrial emissions of sulfur dioxide and nitrogen oxides that return to the earth as acid deposition (Driscoll et al., 2001). Additions of ammonia fertilizers in high-input farming practices also acidify agricultural soils (Kochian et al., 2004). In the eastern United States, coal mining can produce local acidic conditions, as acidic rock layers are disturbed and rapidly weathered.

The high aluminum (Al) concentrations that characterize acidic soils pose numerous challenges to plants (Kochian, 1995, 2002). Plant roots exposed to Al are stunted due to inhibition of cell division and elongation, and subsequently exhibit reduced water and nutrient uptake capacity (Kochian, 1995; Marschner, 1995). Aluminum also disrupts nutrient physiology by altering the acquisition and assimilation of numerous elements (Miranda \& Rowell, 1989; Huang et al., 1992; Rengel \& Elliot, 1992; Antunes \& Nunes, 1997). Indeed, soil acidity and Al toxicity significantly affect plant productivity worldwide, falling behind drought as impediments to plant growth (Barinaga, 1997).

Plants adapted to acid soils possess several mechanisms to resist Al toxicity. Resistance to $\mathrm{Al}$ is commonly attributed to organic acid exudation into the rhizosphere, where $\mathrm{Al}$ is chelated rendering it non-toxic to the plant (Hue et al., 1986; Miyasaka et al., 1991; Delhaize \& Ryan, 1995; Adams et al., 1999; Ma, 2000). Many Al-resistant plant species and/or genotypes exhibit an elevated release of organic acids into the rhizosphere when exposed to Al. For example, malate was released from roots of Al-resistant wheat cultivars when exposed to Al (Delhaize et 
al., 1993b; Pellet et al., 1996). Citrate was produced by snapbean (Miyasaka et al., 1991), soybean (Silva et al., 2001), and corn (Pellet et al., 1995), and the release of oxalate from buckwheat was also observed (Ma et al., 1998). Reduced Al accumulation in root tips is often correlated with organic acid exudation (Delhaize et al., 1993a; Samuels et al., 1997; Matsumoto, 2000; Silva et al., 2001). In both soybean and wheat, Al-resistant cultivars acumulated less Al than their Al-sensitive counterparts and had high rates of organic acid exudation (Silva et al., 2001; Delhaize et al., 1993a). Thus, the production of organic acids, and the subsequent chelation of $\mathrm{Al}$ in the rhizosphere, is apparently associated with reduced Al bioavailability and toxicity.

Associations with arbuscular mycorrhizal (AM) fungi are important for plant survival on acid soils (Clark, 1997). Mycorrhizal fungi are known for their ability to enhance nutrient uptake, particularly phosphorous (P) (Clarkson, 1985; Bolan, 1991; Marschner, 1995). Additionally, AM fungi may play roles in conferring Al resistance to their plant hosts (Marschner, 1991), a phenomenon that has been demonstrated in Liriodendron tulipifera (Lux \& Cumming, 1999), Andropogon virginicus (Cumming \& Ning, 2003), Panicum virgatum (Koslowsky \& Boerner, 1989), and Musa acuminata (Rufyikiri et al., 2000). In all of these species, non-mycorrhizal plants were more sensitive to Al than mycorrhizal plants, which were larger and absorbed more nutrients and water. In spite of the benefits observed in these examples, the mechanisms of amelioration of Al toxicity have not been elucidated. However, Lux \& Cumming (2001) and Cumming \& Ning (2003) noted that reactive Al concentrations in root zones differed between mycorrhizal and non-mycorrhizal plants in L. tulipifera and A. virginicus and suggested changes in Al bioavailability may be responsible for the observed mycorrhizal benefit.

Ecosystems contain diverse communities of mycorrhizal fungi and, until recently, researchers have assumed functional redundancy among species. Current research, however, has highlighted variation among species in their effects on host plant growth and nutrient acquisition (Clark et al., 1999; Bever et al., 2001; Helgason et al., 2002). For example, changes in edaphic environments have resulted in changes in species abundance and distribution (Bever et al., 2001). Several AM species had variable responses to acid soil conditions, simulated acid rain, and Al, exhibiting differences in spore germination, hyphal growth, and colonization and growth 
of host plants (Siqueira et al., 1984; Bartolome-Esteban and Schenck, 1994; Vosatka et al., 1999; Kelly et al., 2005).

Evidence of variation among AM isolates and species in responses to their environments led to the present investigation of the variation among AM species, collected from sites with similar soil properties, in conferred Al resistance to A. virginicus. I hypothesized that there would be differences in $\mathrm{Al}$ resistance conferred by AM fungi to A. virginicus as measured by plant growth and nutritional responses to Al. I also measured organic acid profiles as a potential Al resistance mechanism that may be influenced by AM fungi. Additionally, AM isolates collected from sites with dissimilar soil properties were compared to determine if they had different influences on growth, nutrient status of host plants, and Al resistance. Arbuscular mycorrhizal fungi collected from low $\mathrm{pH}$ soils have likely adapted to characteristic conditions, such as high Al concentrations, and I hypothesized that they could potentially confer a higher degree of $\mathrm{Al}$ resistance to host plants than those isolates collected from non-acidic soils.

\section{Materials and methods}

Two experiments were established to address the objectives. For both experiments, seeds of Andropogon virginicus were stratified in moist perlite at $4{ }^{\circ} \mathrm{C}$ for 90 days. The seeds were planted in $4 \mathrm{~cm}$ diameter $\times 21 \mathrm{~cm}$ deep pots ("Cone-tainers" "TM , Stuewe $\&$ Sons, Corvalis, OR, USA) containing acid washed sand and fungal inoculum from the International Culture Collection of Vesicular Arbuscular Mycorrhizae (INVAM, West Virginia University, Morgantown, WV, USA). In experiment 1, six fungal species were used: Acaulospora morrowiae (INVAM WV107-5), Glomus claroideum (INVAM WV 109E-3), G. clarum (INVAM WV234-2), G. etunicatum (INVAM VZ103A-3), Paraglomus brasilianum (INVAM BR105-6), and Scutellospora heterogama (INVAM WV108-6). A control group received inoculum from roots of non-mycorrhizal sudangrass. The isolates were originally collected from acidic soils. In experiment 2, isolates collected from acidic and non-acidic soils were compared. Two isolates each of two species, Glomus clarum (INVAM WV234-2, acidic and INVAM WV 219A-7, non-acidic) and S. heterogama (INVAM WV 108-6, acidic and INVAM NY 320-8, non-acidic), were used. All inoculum was wet-sieved to remove soil before mixing with sand. After allowing the seeds to germinate in the laboratory for one week, plants were thinned to leave one plant per pot and were moved to growth chambers where they received light (400 $\mu \mathrm{mol} \mathrm{m} \mathrm{m}^{-2}$ from fluorescent and incandescent sources) for 14 hours each day and day/night 
temperatures of $28{ }^{\circ} \mathrm{C} / 20{ }^{\circ} \mathrm{C}$ and $60 \%$ relative humidity. Nutrient solution containing $1.0 \mathrm{mM}$ $\mathrm{NO}_{3}, 0.4 \mathrm{mM} \mathrm{NH}_{4}, 0.5 \mathrm{mM} \mathrm{K}, 0.2 \mathrm{mM} \mathrm{Ca}, 0.05 \mathrm{mM} \mathrm{H}_{2} \mathrm{PO}_{4}, 0.1 \mathrm{mM} \mathrm{Mg}$ and $\mathrm{SO}_{4}, 50.5 \mu \mathrm{M} \mathrm{Cl}$, $20 \mu \mathrm{M} \mathrm{Fe}, 25 \mu \mathrm{M}$ B, $2 \mu \mathrm{M} \mathrm{Mn}$ and $\mathrm{Zn}$, and $0.5 \mu \mathrm{M} \mathrm{Cu}, \mathrm{Na}, \mathrm{Co}$, and Mo were supplied three times daily to field capacity. Nutrient solutions were modified to deliver $\mathrm{Al}\left(\mathrm{as}_{\mathrm{Al}}\left(\mathrm{SO}_{4}\right)_{3}\right)$ concentrations of 0 and $100 \mu \mathrm{M} \mathrm{Al}$ and were adjusted to $\mathrm{pH} 4.0$ with $\mathrm{HCl}$.

Plants were harvested after eight weeks of Al exposure. Stems were clipped at the sand surface and shoots were washed in $0.1 \%$ Tween- 80 solution to remove debris, rinsed, dried at 60 ${ }^{\circ} \mathrm{C}$, and weighed. Eight hours prior to harvest, solution delivery to plants was halted to prevent organic acids produced from being leached from cones. At harvest, the contents of each cone (plant roots and sand) were placed in a beaker and $40 \mathrm{ml}$ of water was added and allowed to stand for five minutes. This root zone (rhizosphere, rhizoplane, and bulk sand) extract was filtered through a $0.45 \mu \mathrm{m}$ pore size filter and used for organic acid analysis. To $8 \mathrm{ml}$ of root zone extract, 1 drop of $1 \mathrm{~N} \mathrm{NaOH}$ and $0.8 \mathrm{~mL}$ of $\mathrm{Na}_{2}$-EDTA were added to chelate $\mathrm{Al}$ which suppresses organic acid analysis (Cumming et al., 2001). Samples were rotoevaporated and frozen for storage. One $\mathrm{mL}$ of water was used to dissolve residual salts and concentrated solutions were passed through a reverse phase column and assessed for acetate, citrate, formate, glycolate, lactate, malate, tartrate, and succinate. The organic acids were separated and quantified using ion chromatography with an ICE-AS6 column (Dionex Corp., Sunnydale, CA, USA). Ion chromatography was also used to quantify oxalate using an AS4 anion separation column; however, no oxalate was detected in root zone samples.

A sample of root from each plant was used to determine AM colonization following boiling in $10 \% \mathrm{KOH}$ for five minutes, rinsing in water, acidifying with $2 \% \mathrm{HCl}$ for five minutes, staining with boiling $0.05 \%$ trypan blue in glycerol for five minutes, and destaining in water. The gridline intersect method was used to quantify colonization (Giovannetti \& Mosse, 1980). Prior to staining, fresh root samples were weighed. Remaining roots were rinsed free of sand, weighed fresh, dried at $60{ }^{\circ} \mathrm{C}$ and re-weighed. Fresh weight/dry weight ratios were used to determine total root biomass.

Dried shoots and roots were ground to pass through a 20 mesh screen and then digested in nitric acid and peroxide following procedures of Jones \& Case (1990). Tissue digests were analyzed for Al concentrations using a graphite furnace atomic absorption spectrophotometer 
(Varian, Inc., Mulgrave, Victoria, Australia) and inorganic phosphorous was quantified with the colorimetric method of Taussky \& Shorr (1953).

Experiment 1 was established as two-way factorial design $(2 \mathrm{Al}$ concentrations $\times 7 \mathrm{AM}$ fungal treatments), with three replicates $(\mathrm{n}=3, \mathrm{~N}=42)$. Experiment 2 was established as a nested analysis of variance ( $2 \mathrm{Al}$ concentrations, 2 AM Species, and 2 isolates within each species), with three replicates $(\mathrm{n}=3, \mathrm{~N}=24)$. Data were statistically analyzed using JMP 5.0.1 (SAS Institute Inc., Cary, NC, USA). Data were examined for normality using Shapiro-Wilk tests. Transformations were undertaken where necessary to improve normality of the data. Subsequently, data were analyzed using either two-way ANOVAs (experiment 1) or nested ANOVAs (experiment 2) followed by Tukey-Kramer's HSD to identify significant differences among treatment groups.

\section{Results}

In experiment 1 , biomass of plants colonized by acid isolates was dependent on AM fungal treatments and solution $\mathrm{Al}(\mathrm{AM} \times \mathrm{Al}$ interaction $P=0.003)$ (Figure 1). Plants exposed to $100 \mu \mathrm{M} \mathrm{Al}$ and colonized by G. clarum and S. heterogama were $29.5 \%$ and $27.3 \%$ smaller, respectively, than plants exposed to $0 \mu \mathrm{M}$ Al. However, under the same Al treatment, the growth of plants in other AM treatments ranged between $50.8 \%$ and $60.3 \%$ less than plants not exposed to Al (Figure 1). Non-mycorrhizal plants exposed to Al were $77.9 \%$ smaller than plants not receiving Al (Figure 1).

Mycorrhizal colonization percentages varied among fungi (AM effect $P<0.001$ ) with $G$. clarum having the highest colonization percentages (approximately 54\%). Plants colonized by G. clarum, S. heterogama, and A. morrowiae had significantly higher colonization than other AM treatments (Figure 2). Colonization did not differ between Al treatments, suggesting that these acidic isolates were all Al resistant.

The concentration of $\mathrm{P}$ in shoot tissues exhibited was not affected independently by AM fungal treatments or solution Al, although plants colonized by G. claroideum and nonmycorrhizal plants exhibited increases in shoot $\mathrm{P}$ concentrations upon $\mathrm{Al}$ exposure $(\mathrm{AM} \times \mathrm{Al}$ interaction $P<0.084$ ) (Figure 3a). However, plants colonized by other AM species did not exhibit altered shoot $\mathrm{P}$ with added $\mathrm{Al}$. Concentrations of $\mathrm{Al}$ in shoot tissues were only affected by $\mathrm{Al}$ (Al effect $P<0.001)$, but did not vary among AM fungal treatments; plants in all AM treatments had similar Al concentrations in shoot tissues (Figure 3b). 
Concentrations of citrate and malate, two organic acids commonly cited as Al chelators and associated with $\mathrm{Al}$ resistance, were measured in A. virginicus root zones and were affected by $\mathrm{AM}$ and $\mathrm{Al}$ treatments. Root zone citrate concentrations varied among AM fungal treatments (AM effect $P=0.003$ ), with plants colonized by $G$. clarum and $S$. heterogama and nonmycorrhizal plants having the highest concentrations in their root zones, ranging up to $350 \mu \mathrm{M}$ for G. clarum (Figure 4a). Citrate concentrations decreased with increasing Al concentrations in delivered solutions (Al effect $P<0.001$ ) for all AM treatments (Figure 4a). There was no significant $\mathrm{AM} \times \mathrm{Al}$ interaction. Similarly, malate concentrations depended on $\mathrm{Al}$ (Al effect $P<$ 0.001 ) and on AM treatments (AM effect $P=0.024$ ), and root zones of plants colonized by $G$. clarum and S. heterogama contained the highest malate concentrations, ranging up to $200 \mu \mathrm{M}$ for $S$. heterogama (Figure $4 \mathrm{~b}$ ). To further investigate potential changes in exudation by root systems colonized by different AM species, production of organic acids ( $\mu \mathrm{mol} \mathrm{g}^{-1}$ root mass) was calculated. Both citrate and malate production decreased with the addition of $100 \mu \mathrm{M} \mathrm{Al}$ ( $\mathrm{Al}$ effect $P<0.001$ for both citrate and malate production), but neither were affected by AM fungal species (Figures 5a,b).

In experiment 2, the objective was to determine if AM fungal isolates collected from acidic and non-acidic soils differed in their influence on A. virginicus growth, nutrition, and organic acid exudation responses to Al. Isolates of G. clarum and S. heterogama collected from acidic and non-acidic soils were studied. The interactive effect of $\mathrm{Al}$ and $\mathrm{pH}$ of collection site on biomass showed a trend toward significance for $G$. clarum and S. heterogama $(\mathrm{Al} \times \mathrm{pH}[\mathrm{AM}$ species] effect $P=0.084$ ) (Figure 6 ). The isolate of $G$. clarum collected from non-acidic soil did not exhibit a decrease in shoot biomass upon exposure to $100 \mu \mathrm{M}$ Al. However, other isolates had $27.3 \%$ to $53.3 \%$ reductions in biomass when exposed to $100 \mu \mathrm{M} \mathrm{Al}$ compared to the $0 \mu \mathrm{M}$ Al treatment. Mycorrhizal colonization by G. clarum was higher than that of S. heterogama (AM effect $P=0.016$ ), but neither $\mathrm{pH}$ of soil nor $\mathrm{Al}$ treatments influenced colonization (Figure 7).

Concentrations of $\mathrm{P}$ in shoot tissues were dependent on $\mathrm{AM}$ species (AM effect $P=$ 0.005), with S. heterogama having higher shoot $\mathrm{P}$ than G. clarum (Figure 8a). However, $\mathrm{P}$ concentrations in shoots were not influenced by $\mathrm{Al}$ treatments or the $\mathrm{pH}$ of soils at the collection site. Aluminum in solution was the only factor that affected the concentrations of $\mathrm{Al}$ in shoot tissues, with higher Al concentrations in plants supplied with $100 \mu \mathrm{M} \mathrm{Al}$ (Al effect $P=0.004$ ) 
(Figure $8 \mathrm{~b}$ ). Neither $\mathrm{AM}$ species nor $\mathrm{pH}$ of soils at site of isolation influenced $\mathrm{Al}$ in shoot tissues.

The measured concentrations of citrate and malate in root zones of plants exhibited similar responses to $\mathrm{Al}$ treatments. Both citrate and malate decreased with the addition of 100 $\mu \mathrm{M} \mathrm{Al}$ ( $\mathrm{Al}$ effect $P=0.009$ and $P=0.011$ respectively) and were not influenced by AM species or $\mathrm{pH}$ of soils at the collection site (Figures $9 \mathrm{a}, \mathrm{b})$. Production of organic acids ( $\mu \mathrm{mol} \mathrm{g} \mathrm{g}^{-1}$ root) was similar among Al treatments, soil $\mathrm{pH}$ levels, and AM species (data not presented). 


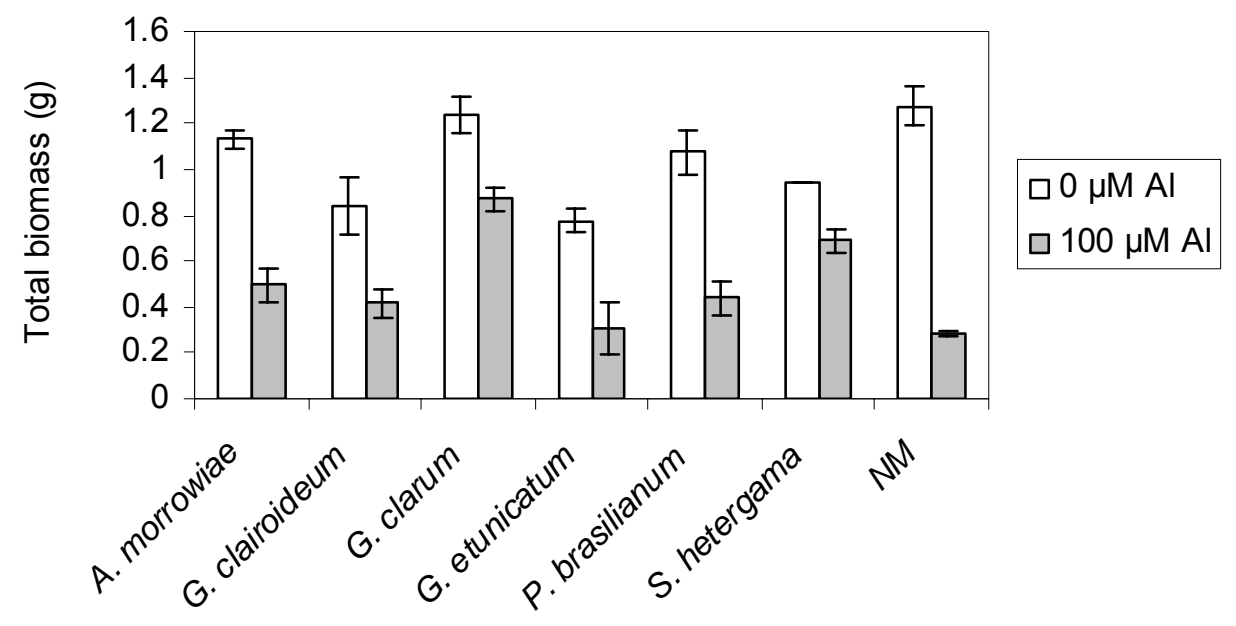

Figure 1. Biomass of mycorrhizal plants inoculated with isolates collected from acidic soils and non-mycorrhizal (NM) exposed to 0 and $100 \mu \mathrm{M}$ Al.

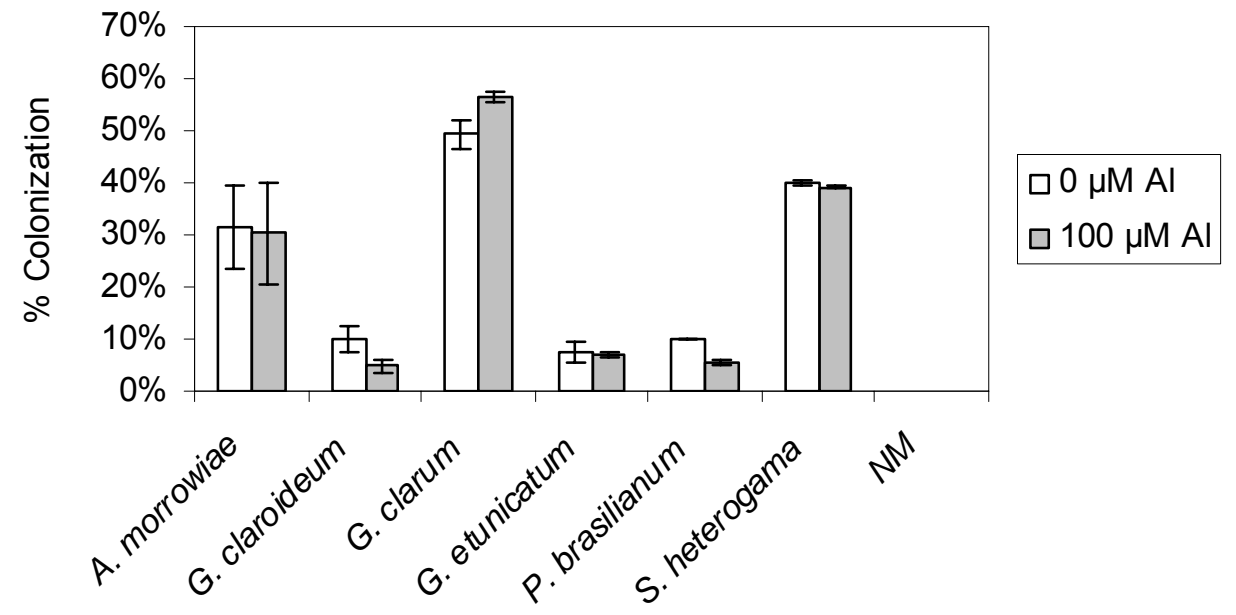

Figure 2. Colonization of A. virginicus plants inoculated with isolates collected from acidic soils and exposed to 0 and $100 \mu \mathrm{M} \mathrm{Al}$. 

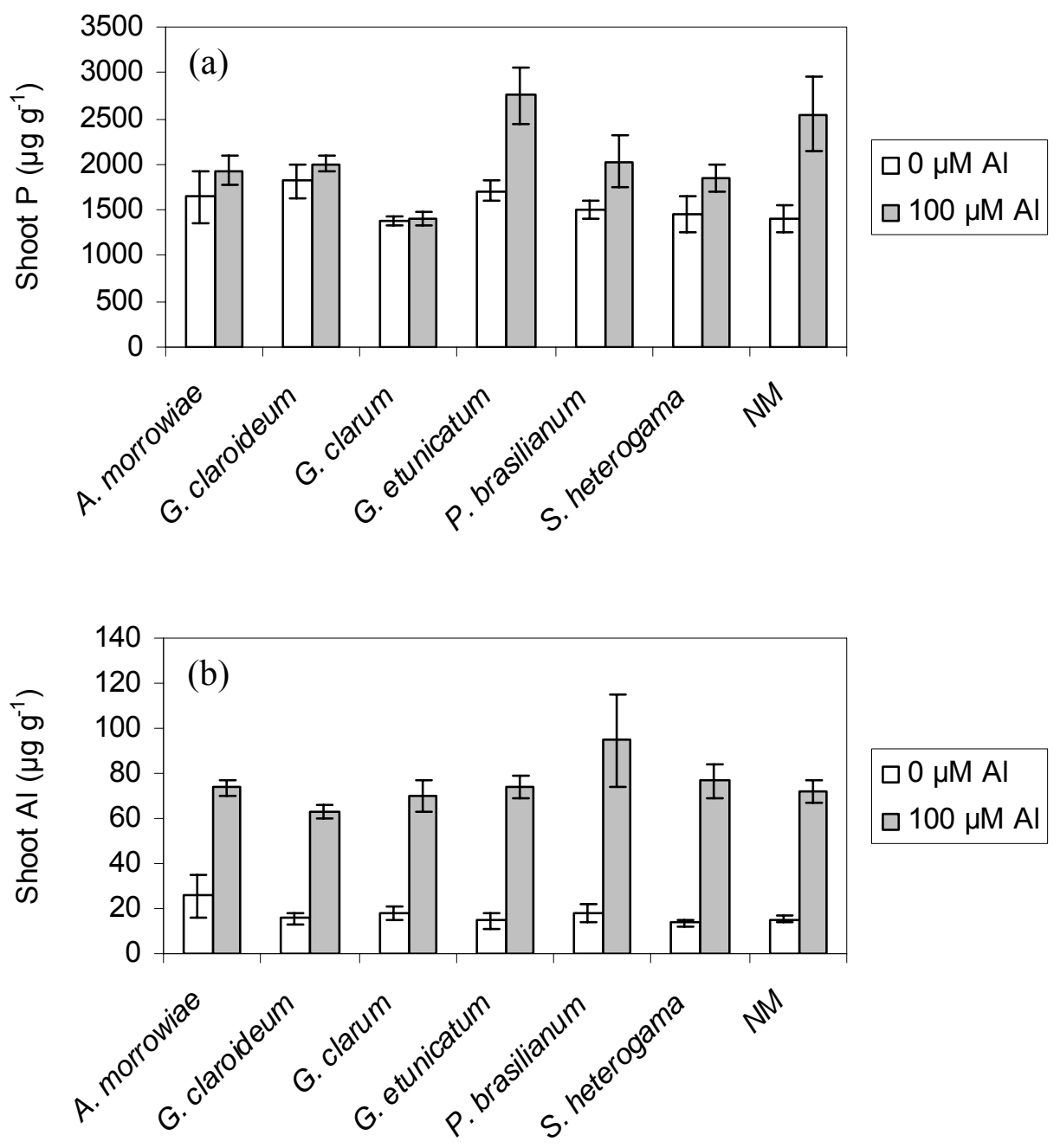

Figure 3. (a) Shoot phosphorous (P) concentrations and (b) shoot aluminum (Al) concentrations of mycorrhizal plants inoculated with isolates collected from acidic soils and non-mycorrhizal (NM) exposed to 0 and $100 \mu \mathrm{M} \mathrm{Al}$. 

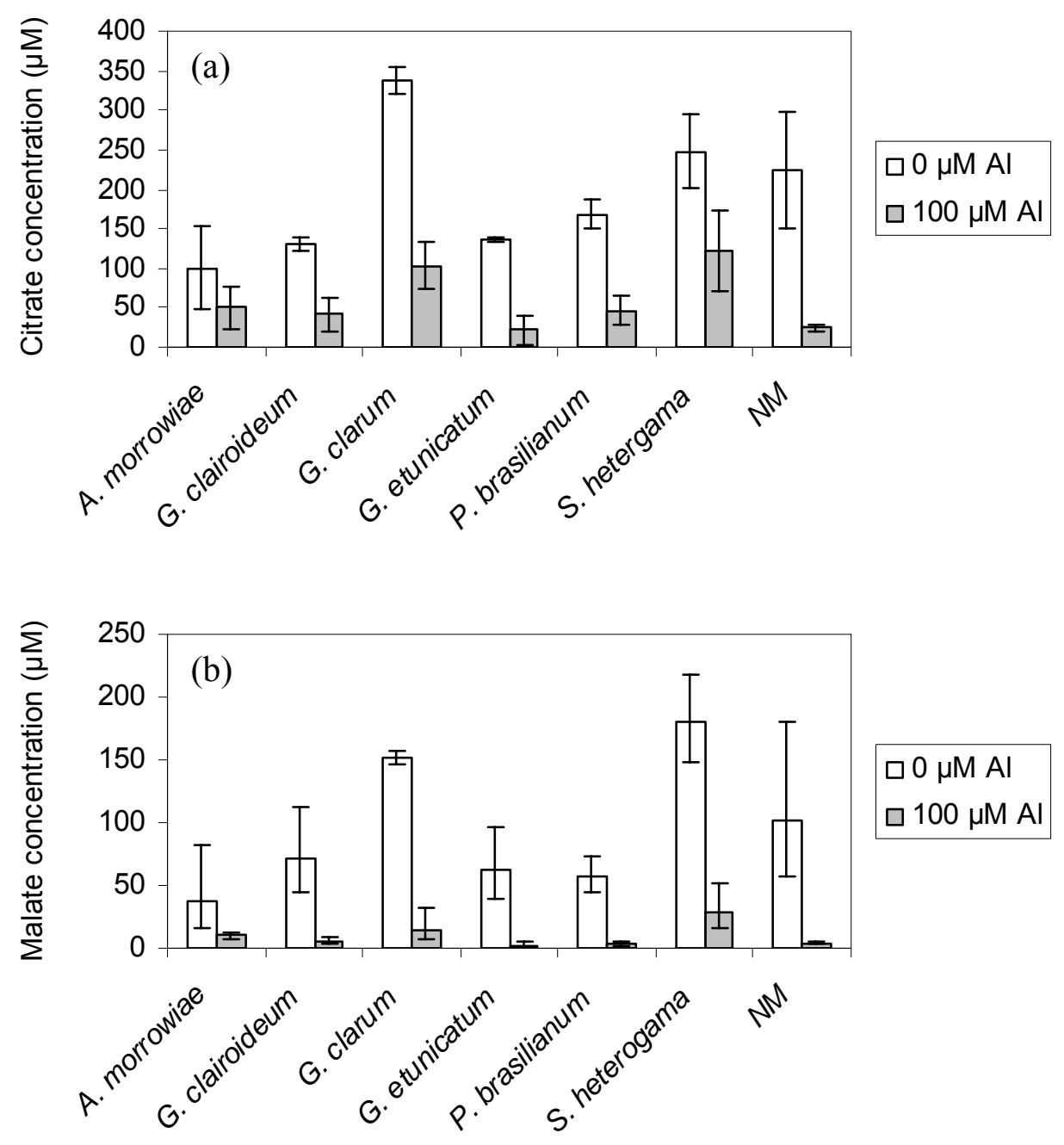

Figure 4. (a) Citrate and (b) malate concentrations in root zones of mycorrhizal plants inoculated with isolates collected from acidic soils and non-mycorrhizal (NM) exposed to 0 and $100 \mu \mathrm{M} \mathrm{Al}$. 

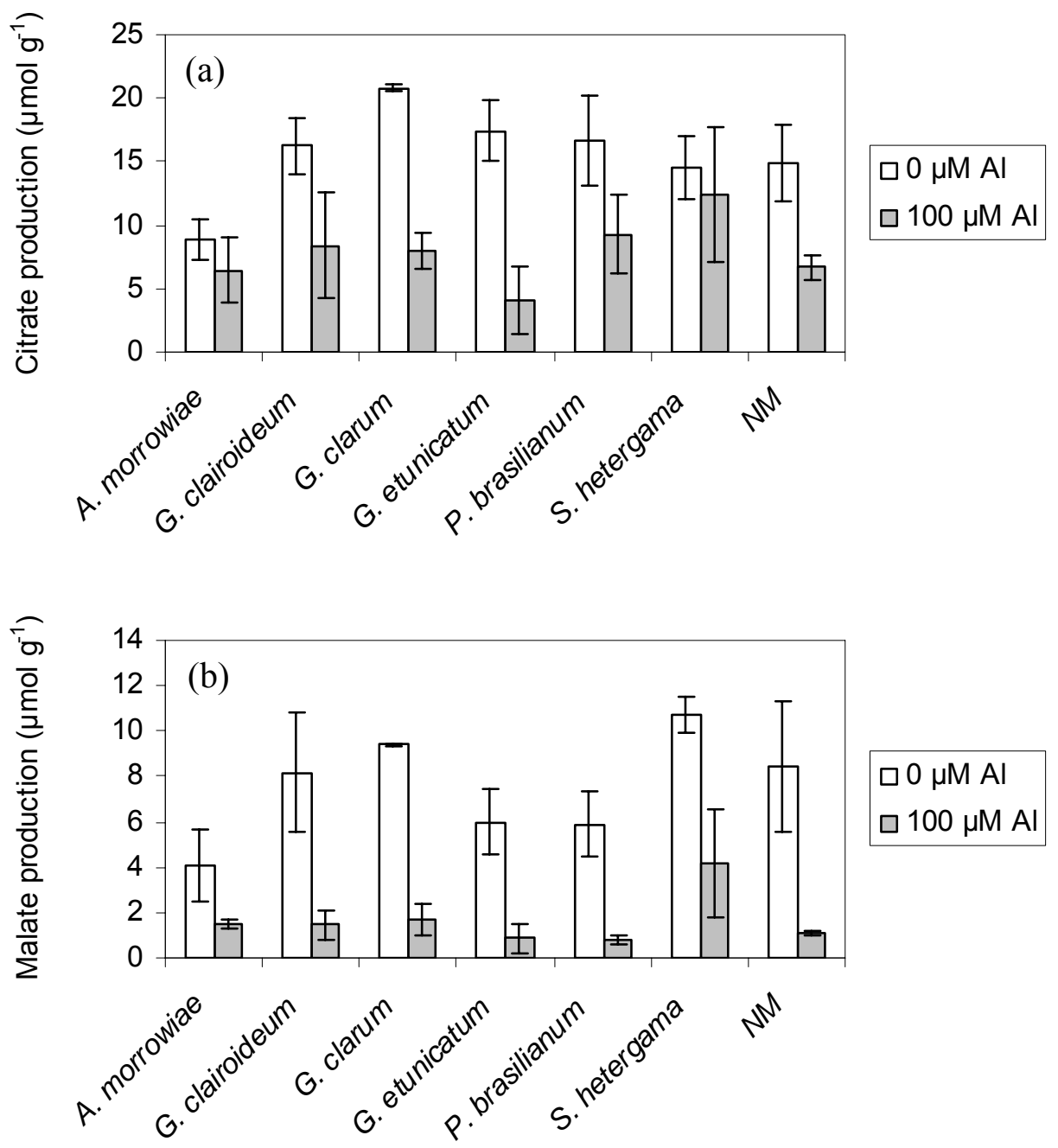

Figure 5. (a) Citrate and (b) malate production from root of mycorrhizal plants inoculated with isolates collected from acidic soils and non-mycorrhizal (NM) exposed to 0 and $100 \mu \mathrm{M} \mathrm{Al}$. 


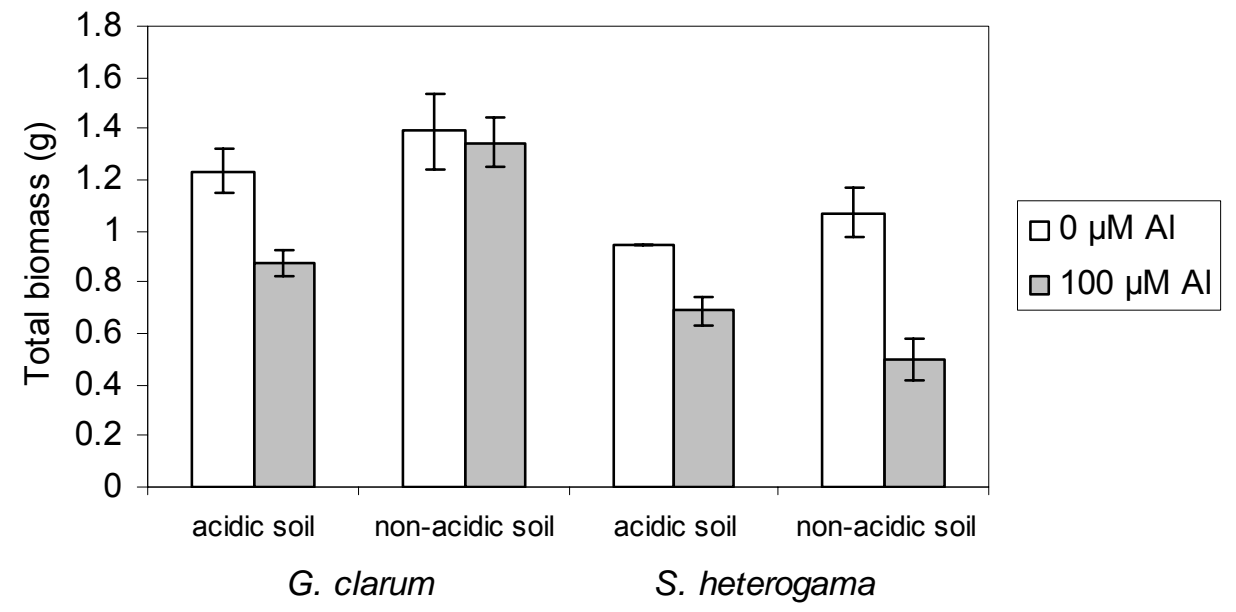

Figure 6. Biomass of plants inoculated with acidic and non-acidic isolates of G. clarum and S. heterogama and exposed to 0 and $100 \mu \mathrm{M} \mathrm{Al}$.

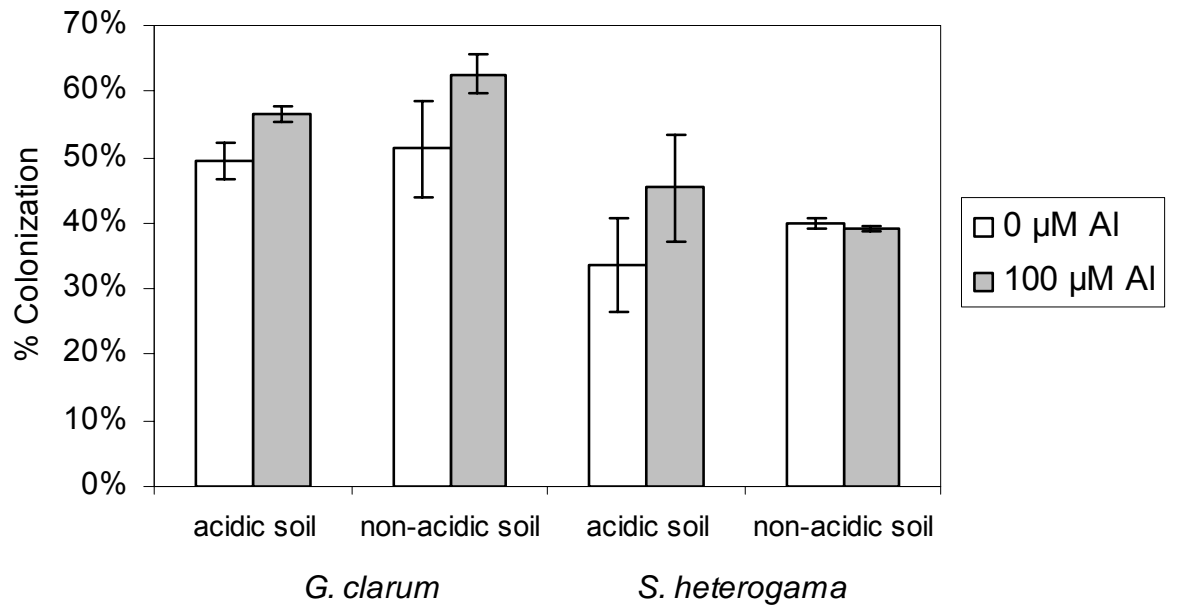

Figure 7. Colonization of A. virginicus plants inoculated with acidic and non-acidic isolates of $G$. clarum and S. heterogama and exposed to 0 and $100 \mu \mathrm{M} \mathrm{Al}$. 

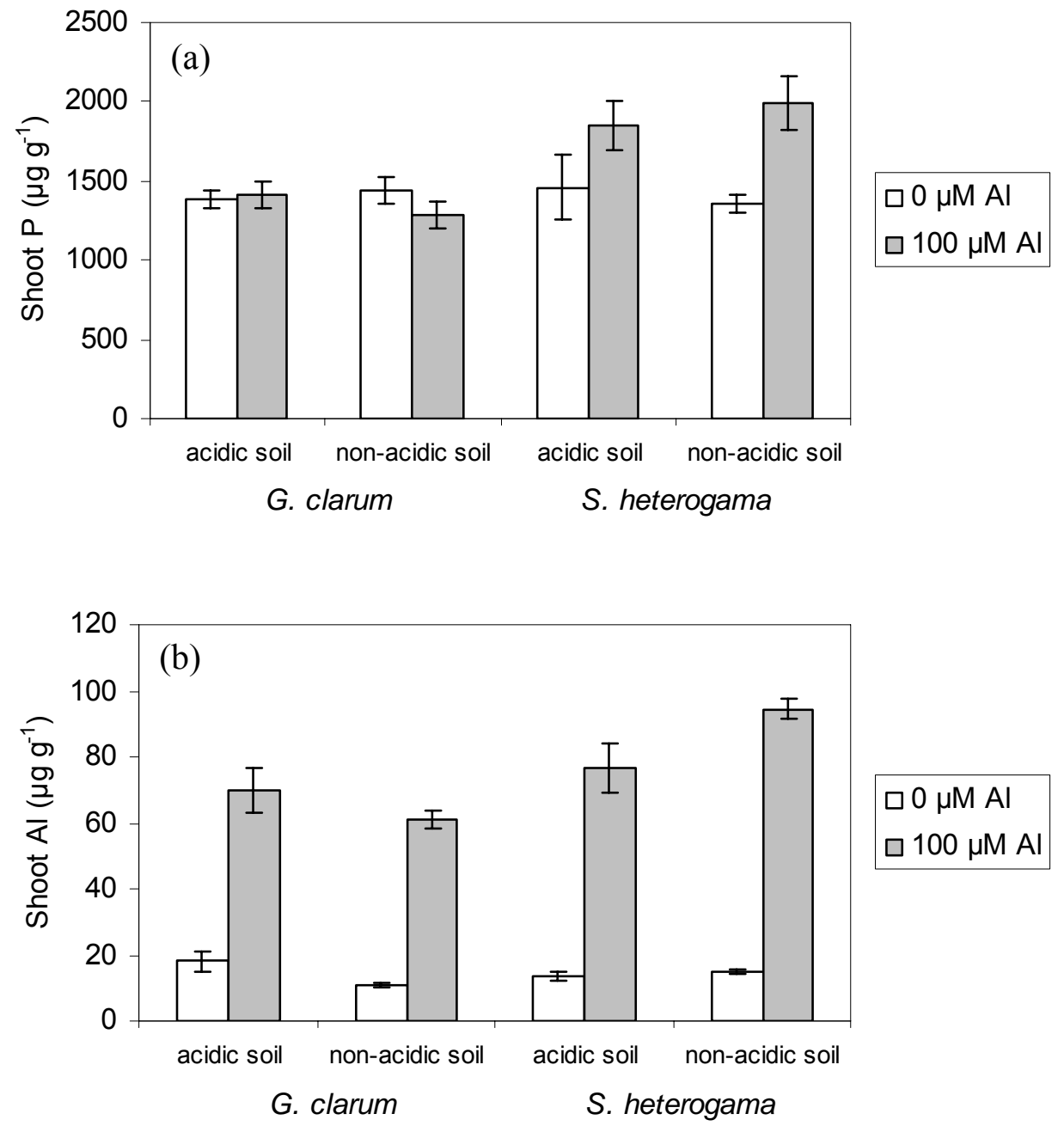

Figure 8. (a) Shoot phosphorous (P) concentrations and (b) shoot aluminum (Al) concentrations of plants inoculated with acidic and non-acidic isolates of G. clarum and S. heterogama and exposed to 0 and $100 \mu \mathrm{M} \mathrm{Al}$. 

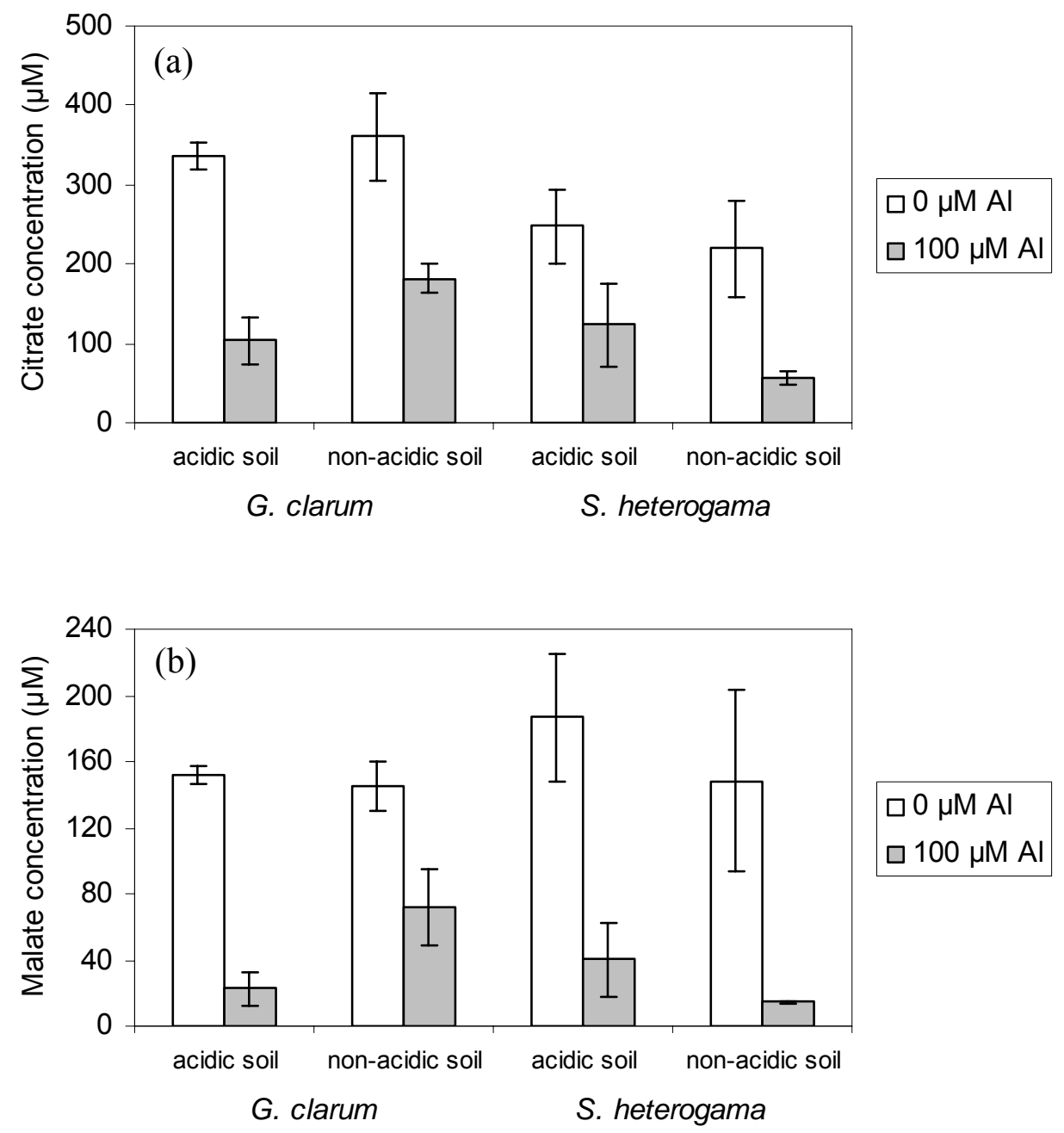

Figure 9. (a) Citrate and (b) malate concentrations in root zones of plants inoculated with acidic and non-acidic isolates of G. clarum and S. heterogama and exposed to 0 and $100 \mu \mathrm{M} \mathrm{Al}$. 


\section{Discussion}

Soil acidity and Al toxicity can be impediments to plant productivity on local and global scales (Driscoll et al., 2001). Plant resistance to Al has been studied extensively is often correlated with reduced accumulation of Al in root tips (Delhaize et al., 1993a). Organic acid exudation is an Al exclusion mechanism that is frequently cited as being responsible for the low Al concentrations found in roots of Al-resistant plants (Samuels et al., 1997; Matsumoto, 2000; Sylva et al. 2001) and may function in mycorrhizal as well as non-mycorrhizal plants. Since AM fungi alter the response of plants to acidic soils (Koslowsky \& Boerner, 1989; Clark, 1997; Rufyikiri et al., 2000), changes in Al speciation in root zones mediated by AM fungi may be responsible for observed benefits and may be related to the influence of AM fungi on organic acid exudation (Lux \& Cumming, 2001).

Variation among AM species in Al resistance was noted by Kelly et al. (2005), Vosatka et al. (1999), Bartolome-Esteban \& Schenck (1994), and Siqueira et al (1984), which may reflect differences in the exudation of Al-binding compounds. In the present study, citrate and malate concentrations, measured in the root zones of $A$. virginicus colonized by AM fungal species collected from acidic soils (experiment 1), varied with AM fungi. However, plants in all AM treatments had lower concentrations of citrate and malate upon exposure to $100 \mu \mathrm{M} \mathrm{Al}$. Interestingly, Glomus clarum and S. heterogama had much smaller reductions in biomass when grown for eight weeks under $100 \mu \mathrm{M}$ Al exposure than the other four AM species or the nonmycorrhizal plants, even though plants in these AM treatments did not have sustained production of organic acids or consistent concentrations of organic acids in the root zone across $\mathrm{Al}$ treatments. Under Al exposure, the significantly higher biomass of plants colonized by $G$. clarum and S. heterogama, compared to non-mycorrhizal plants, indicates that there is some conferred $\mathrm{Al}$ resistance to A. virginicus by these AM species, but, in this case, it does not appear to be associated with organic acid production. One caveat to this conclusion is that, in the present study, organic acid production was assessed on a root zone scale, which may be insufficient to identify exudation by and protection of the Al sensitive root tips frequently reported in crop species (Kochian et al., 2004).

The differences in P concentrations in shoot tissues of plants exposed to 0 and $100 \mu \mathrm{M} \mathrm{Al}$ were dependent upon AM fungal treatments. Phosphorous concentrations of plants colonized by most AM species studied and the non-mycorrhizal controls did not significantly differ with Al, 
but plants colonized by G. claroideum and non-mycorrhizal plants had increases in shoot P concentrations with the addition of $100 \mu \mathrm{M}$ Al. Since plants in these AM treatments were very small when exposed to $\mathrm{Al}$, the increase in shoot $\mathrm{P}$ likely represents a concentration of phosphorous in their tissues (reverse of a growth dilution effect). Similar results have been reported for this species (Cumming \& Ning 2003), where small A. virginicus plants had high shoot $\mathrm{P}$ relative to large plants. High biomass to $\mathrm{P}$ ratio may suggest that plants colonized by $G$. clarum and S. heterogama had higher P use efficiency given their smaller reductions in shoot biomass than other AM treatments upon exposure to Al. Ning \& Cumming (2001) also noted higher $\mathrm{P}$ use efficiency in A. virginicus plants colonized by AM fungi.

Glomus clarum and S. heterogama were among the AM species with the highest colonization percentages at 53\% and 39\%, respectively. Acaulospora morrowiae had similar colonization to $S$. heterogama at approximately $31 \%$, whereas other AM species had colonization percentages from $7.1 \%$ to $7.8 \%$. Such variation in colonization is common in experiments using multiple species of AM fungi. For example, Clark et al. (1999) observed colonization percentages ranging from 10 to 50\% among eight AM isolates grown in acidic soils. Similarly, Klironomos (2000) studied ten AM species and found that colonization in roots ranged from 20 to $80 \%$. These findings illustrate that AM species are not uniform in their colonization of different plant species, but these colonization differences are often not correlated with growth. For example, Klironomos (2000) found no correlation between percentage root colonization and growth for 30 plant-AM fungal species combinations. In the current study, A. virginicus plants across Al treatments had shoot biomass measurements that were independent of the degree of colonization ( $\mathrm{r}=0.2147, P=0.230$ ) (data not presented). This suggests that Al resistance may be a functional trait that varies among AM fungi and that colonization is not by itself responsible for Al resistance. Mechanisms related to exudation, nutrient uptake, or nutrient use efficiency may play roles in $\mathrm{Al}$ resistance in mycorrhizal plants.

I hypothesized that there would be differences among AM species in conferred Al resistance to plant hosts and that there would be differences among isolates collected from acidic and non-acidic soils as well. Andropogon virginicus plants colonized by isolates collected from acidic soils were expected to be more resistant to Al than those collected from non-acidic soils, and this resistance would be reflected in growth and nutrient relations. The differences in biomass of $A$. virginicus plants exposed to Al treatments were somewhat related to the $\mathrm{pH}$ of soil 
at the isolate collection site. However, the patterns were not as expected, and upon exposure to $100 \mu \mathrm{M}$ Al for eight weeks, plants colonized by all isolates exhibited a decrease in biomass, except for plants colonized by the isolate of G. clarum collected from the non-acidic soil. There was no consistent pattern of shoot $\mathrm{Al}$ or $\mathrm{P}$ concentration to suggest any isolate performed differently under exposure to Al. In addition, there were no corresponding differences in the concentrations of organic acids found in the root zones of plants colonized by isolates of $G$. clarum and S. heterogama. While both citrate and malate concentrations decreased with the addition of Al, no other factors influenced these organic acid concentrations. Furthermore, the production of organic acids ( $\mu \mathrm{mol} \mathrm{g}^{-1}$ root) did not change with Al additions, or AM species or isolate, suggesting that mycorrhizal plants in all treatments were producing similar amounts of citrate and malate. The conferred Al resistance of the non-acid isolate of G. clarum does not appear to be associated with organic acid production or concentrations in the root zone.

Colonization does not appear to be a factor, since colonization was higher in G. clarum isolates than S. heterogama isolates, and colonization did not depend on $\mathrm{Al}$ treatment or soil $\mathrm{pH}$ at the isolate collection site.

The data presented here provide evidence that there is functional variation among AM fungi and that the level of Al resistance conferred to host plants may vary among AM species. However, among acid isolates, only two species of AM fungi conferred Al resistance as measured by growth under Al exposure and this was not associated with organic acid production or concentrations of organic acids in the root zones of these plants. Additionally, isolates collected from acidic soils did not appear to confer greater Al resistance to host plants than isolates collected from non-acidic soils. One isolate collected from non-acidic soils did exhibit high biomass under $\mathrm{Al}$ exposure, but, as in the comparison of AM species collected from acidic soils, this did not appear associated with organic acid concentrations in the root zone. While this study provides supporting evidence of functional variation in conferred $\mathrm{Al}$ resistance to $A$. virginicus among AM fungi, the data collected do not suggest that organic acid exudation had a significant role. Nevertheless, diversity of AM species in ecosystems is likely important in promoting resistances to stresses, and, as suggested in this study, this includes stresses associated with acidic soils. 


\section{References}

Adams JF, Wood CW, Mitchell RI. 1999. Loblolly pine plant community structure and soil solution aluminum, organic acids, calcium, magnesium, and $\mathrm{pH}$. Communications in Soil Science and Plant Analysis 30: 1939-1950.

Antunes AMG, Nunes MA. 1997. Effects of aluminum on nutrient solution $\mathrm{pH}$ and nitrate/ammonium uptake by triticale. Journal of Plant Nutrition 20: 1391-1401.

Barinaga M. 1997. Making plants Al tolerant. Science 276: 1497.

Bartolome-Esteban H, Schenck NC. 1994. Spore germination and hyphal growth of arbuscular mycorrhizal fungi in relation to soil aluminum saturation. Mycologia 86: 217-226.

Bever JD, Schultz PA, Pringle A, Morton JB. 2001. Arbuscular mycorrhizal fungi: more diverse than meets the eye, and the ecological tale of why. Bioscience 51: 923-931.

Bolan NS. 1991. A critical review on the role of mycorrhizal fungi in the uptake of phosphorous by plants. Plant and Soil 134: 189-207.

Clark RB. 1997. Arbuscular mycorrhizal adaptation, spore germination, root colonization, and host plant growth and mineral acquisition at low pH. Plant and Soil 192: 15-22.

Clark RB, Zobel RW, Zeto SK. 1999. Arbuscular mycorrhizal fungal isolate effectiveness on growth and root colonization of Panicum virgatum in acidic soil. Soil Biology and Biochemistry 31: 1757-173.

Clarkson DT. 1985. Factors affecting mineral nutrient acquisition by plants. Annual Review of Plant Physiology 36: 11-115.

Cumming JR, Ning J. 2003. Arbuscular mycorrhizal fungi enhance aluminum resistance of broomsedge (Andropogon virginicus L.). Journal of Experimental Botany 54: 1447-1459.

Cumming JR, Swiger TD, Kurnik BS, Panaccione DG. 2001. Organic acid exudation by Laccaria bicolor and Pisolithus tinctorius exposed to aluminum in vitro. Canadian Journal of Forest Research 31: 703-710.

Delhaize E, Craig S, Beaton CD, Bennet RJ, Jagadish VC, Randall PJ. 1993a. Aluminum tolerance in wheat (Triticum aestivum L.) I. Uptake and distribution of aluminum in root apices. Plant Physiology 103: 685-693.

Delhaize E, Ryan PR. 1995. Aluminum toxicity and tolerance in plants. Plant Physiology 107: 315-321.

Delhaize E, Ryan PR, Randall PJ. 1993b. Aluminum tolerance in wheat (Triticum aestivum L.) II. Aluminum-stimulated excretion of malic acid from root apices. Plant Physiology 103: 695702. 
Driscoll CT, Lawrence GB, Bulger AJ, Butler TJ, Cronan CS, Eager C, Lambert KF, Likens GE, Stoddard JL, Weathers KC. 2001. Acidic deposition in the Northeastern United States: sources and inputs, ecosystem effects, and management strategies. BioScience 51: 180198.

Giovannetti M, Mosse B. 1980. An evaluation of techniques for measuring vesicular arbuscular mycorrhizal infection in roots. New Phytologist 84: 489-500.

Havlin JL, Beaton JD, Tisdale SL, Nelson WL. 1999. Soil fertility and fertilizers: An introduction to nutrient management, $6^{\text {th }}$ edn. Upper Saddle River, USA: Prentice Hall.

Helgason T, Merryweather JW, Denison J, Wilson P, Young JPW, Fitter AH. 2002. Selectivity and functional diversity in arbuscular mycorrhizas of co-occurring fungi and plants from a temperate deciduous woodland. Journal of Ecology 90: 371-384.

Huang JW, Shaff JE, Grunes DL, Kochian LV. 1992. Aluminum effects on calcium fluxes at the root apex of aluminum-tolerant and aluminum-sensitive wheat cultivars. Plant Physiology 98: $230-237$.

Hue NV, Craddock, GR, Adams F. 1986. Effect of organic acids on aluminum toxicity in subsoils. Soil Science Society of America Journal 50: 28-34.

Jones Jr. JB, Case VW. 1990. Sampling, handling, and analyzing plant tissue samples. In: Westerman RL, ed. Soil testing and plant analysis, $3^{\text {rd }}$ edn. Madison, USA: Soil Science Society of America, 389-427.

Kelly CN, Morton JB, Cumming JR. 2005. Variation in aluminum resistance among arbuscular mycorrhizal fungi. Mycorrhiza 15: 193-201.

Klironomos JN. 2000. Host-specificity and functional diversity among arbuscular mycorrhizal fungi. In: Bell CR, Brylinsky M, Johnson-Green P, eds. Microbial biosystems: new frontiers. Proceedings of the Eighth Annual International Symposium on Microbial Ecology. Halifax, CA: Atlantic Canada Society for Microbial Ecology, 845-851.

Kochian LV. 1995. Cellular mechanisms of aluminum toxicity and resistance in plants. Annual Review of Plant Physiology and Plant Molecular Biology 46: 237-260.

Kochian LV, Hoekenga OA, Piñeros MA. 2004. How do crop plants tolerate acid soils? Mechanisms of aluminum tolerance and phosphorous efficiency. Annual Review of Plant Biology 55: 459-493.

Kochian LV, Pence NS, Lethan DLD, Piñeros MA, Magalhaes JV, Hoekenga OA, Garvin DF. 2002. Mechanisms of metal resistance in plants: aluminum and heavy metals. Plant and Soil 247: 109-119.

Koslowsky SD, Boerner RE. 1989. Interactive effects of aluminum, phosphorous and mycorrhizae on growth and nutrient uptake of Panicum virgatum L. (Poaceae). Environmental Pollution 61: 107-125. 
Lux HB, Cumming JR. 2001. Mycorrhizae confer aluminum resistance to tulip-poplar seedlings. Canadian Journal of Forest Research 31: 694-702.

Lux HB, Cumming JR. 1999. Effect of aluminum on the growth and nutrition of tulip-poplar seedlings. Canadian Journal of Forest Research 29: 2003-2007.

Ma JF. 2000. Role of organic acids in detoxification of aluminum in higher plants. Plant and Cell Physiology 41: 383-390.

Ma JF, Hiradate S, Matsumoto H. 1998. High aluminum resistance in Buckwheat. Plant Physiology 117: 753-759.

Marschner H. 1991. Mechanisms of adaptation of plants to acid soils. In: Wright RJ, Baligar VC, Murrman RP, eds. Plant-soil interactions at low $\mathrm{pH}$. Dordrecht, Netherlands: Kluwer Academic Publishers, 683-702.

Marschner H. 1995. Mineral nutrition of higher plants. San Diego, USA: Academic Press, Inc.

Matsumoto H. 2000. Cell biology of aluminum toxicity and tolerance in higher plants. International Review of Cytology 200: 1-46.

Miranda LN DE, Rowell DL. 1989. Aluminum-phosphate interactions in wheat. New Phytologist 113: 7-12.

Miyasaka SC, Buta GJ, Howell RK, Foy CD. 1991. Mechanism of aluminum tolerance in snapbeans. Plant Physiology 96: 737-743.

Pellet DM, Papernik LA, Kochian LV. 1996. Multiple aluminum-resistance mechanisms in wheat: Roles of root apical phosphate and malate exudation. Plant Physiology 112: 591-597.

Rengel Z, Elliott DC. 1992. Mechanism of aluminum inhibition of net ${ }^{45} \mathrm{Ca}^{2+}$ uptake by Amaranthus protoplasts. Plant Physiology 98: 632-638.

Rufyikiri G, Declerck S, Dufey JE, Delvaux B. 2000. Arbuscular mycorrhizal fungi might alleviate aluminum toxicity in banana plants. New Phytologist 148: 343-352.

Samuels TD, Rincon-Zachary M, Kucukakyuz K. 1997. Al partitioning patterns and root growth as related to Al sensitivity and Al tolerance in wheat. Plant Physiology 113: 527-534.

Siqueira JO, Hubbell DH, Mahmud AW. 1984. Effect of liming on spore germination, germ tube growth and root colonization by vesicular-arbuscular mycorrhizal fungi. Plant and Soil 76: 115-124.

Silva IR, Smyth TJ, Raper CD, Carter TE, Rufty TW. 2001. Differential aluminum tolerance in soybean: An evaluation of the role of organic acids. Physiologia Plantarum 112: 200-210.

Taussky HH, Shorr E. 1953. A microcolorimetric method for the determination of inorganic phosphorus. Journal of Biological Chemistry 202: 675-685. 
von Uexküll HR, Mutert E. 1995. Global extent, development and economic impact of acid soils. Plant and Soil 171: 1-15.

Vosatka M, Batkhuugyin E, Albrechtova J. 1999. Response of three arbuscular mycorrhizal fungi to simulated acid rain and aluminum stress. Biologia Plantarum 42: 289-296. 


\section{Chapter 4: Spatial vegetation patterns and soil solution aluminum of an abandoned coal mine}

\section{Introduction}

Coal mining has been an important industry in West Virginia since the early to mid1900s and remains a crucial part of the economy today (Stewart \& Skousen, 2003). West Virginia currently ranks second among states in coal production (WV Coal Association, 2004), which accounts for approximately 14\% of the nation's total (OSM, 2003). Regulations of the Surface Mining Control and Reclamation Act (SMRCA) of 1977 ensure that today's mining corporations create plans to minimize environmental impacts of surface mining that disturb hundreds of thousands of acres each year in West Virginia (185,255 acres in 2004) (OSM, 2004). However, mining companies operating prior to 1977 were not required to adhere to reclamation standards and often simply abandoned mining sites when it was not longer cost effective to extract coal, leaving long lasting effects on the landscape. The Office of Surface Mining (OSM) in the Department of the Interior currently lists 3,876 sites in West Virginia in the Abandoned Mine Lands Inventory as un-reclaimed (OSM, 2003).

The Stewartstown Mine in Morgantown, WV was abandoned in the 1960s and exhibits the extreme edaphic conditions typical of abandoned surface mines in the region. Surface mining techniques remove topsoil and overburden to reach the coal seam. In regions where parent materials containing pyrite are exposed to oxygen and water, a series of chemical reactions occurs, resulting in the release of iron, sulfate, and proton acidity (Geidel \& Caruccio, 2000). The consequences of this rapid weathering and local soil acidification include increased concentrations of toxic aluminum (Al) and manganese $(\mathrm{Mn})$ in soil solutions and leaching of basic nutrient cations, such as magnesium $\left(\mathrm{Mg}^{2+}\right)$, calcium $\left(\mathrm{Ca}^{2+}\right)$, and potassium $\left(\mathrm{K}^{+}\right)$. This intensive chemical weathering creates an edaphic environment inhibitory to plant growth, where availability of nutrients is limited and $\mathrm{Al}$ and $\mathrm{Mn}$ are toxic to plant growth (Marschner 1991).

Some plant species have adapted to disturbed sites, including highly acidic soils. One of these is Andropogon virginicus L. (broomsedge), a primary successional species native to the eastern United States (USDA, 2004). This species commonly colonizes disturbed habitats, including construction sites, road cuts, and coal mine spoils (Nellessen \& Ungar, 1993). Andropogon virginicus is aggressively colonized by arbuscular mycorrhizal (AM) fungi, which 
may be important in enabling its success on acidified and nutrient depleted soils (Clarkson, 1985; Ning \& Cumming, 2001).

Spatial vegetation patterns suggest that successional processes are occurring at the Stewartstown Mine site. Plant species such as Solidago spp. (goldenrods), Acer rubrum (red maple), Eupatorium sp., Oxydendrum arboreum (sourwood), and even Liriodendron tulipifera (yellow poplar) have become established in some areas that appear to have been previously colonized by A. virginicus. Swaths of A. virginicus separate barren soils from areas where these other species are competing with $A$. virginicus. Colonization of bare soils by $A$. virginicus may have an ameliorating effect on these sites, subsequently enabling other species to colonize these sites.

Plant roots exude many compounds, including organic acids, proteins, and sugars. Low molecular weight organic acids are released by plant roots in response to acid soils and $\mathrm{Al}$ exposure, and these bind Al creating non-pytotoxic complexes (Hue et al., 1986; Marschner, 1991; Kochian, 2004). Once soils are colonized by A. virginicus, the exudation of organic acids into the soils may lead to the formation of non-toxic zones where A. virginicus and other species become further established. Over time, plant tissues deposited through leaf and root turnover may also add to the amelioration effect, since humic and fulvic acids released from decomposing organic matter also bind and immobilize Al (Vance et al., 1996; van Hees et al., 2000).

While it may be difficult to resolve questions about the specific role of A. virginicus in successional processes, analyses of soil solutions collected at the Stewartstown Mine site were used to examine potential relationships between Al availability and vegetation patterns. First, the Al chemistry of soils with vegetation (primarily A. virginicus) was compared with soils without vegetation. Second, I measured organic acid concentrations in soil solutions to determine if patterns in Al chemistry were associated with the presence of organic acids and vegetation.

\section{Materials and Methods}

Soils from the Stewartstown Mine were sampled every month from July to October of 2003. This time period represents one growing season of $A$. virginicus, beginning before the active growing season and ending during senescence. Samples were analyzed for total Al, labile Al, $\mathrm{pH}$, and organic acids. Eighteen samples were taken at each sampling site, nine from areas with vegetation, and nine from nearby areas without vegetation. Care was taken to sample from 
vegetated soils dominated by $A$. virginicus, and non-vegetated soils approximately $1 \mathrm{~m}$ from vegetation. Soils were returned to the lab, placed in $5 \mathrm{~cm}$ diameter $\times 18 \mathrm{~cm}$ deep pots (D-16 Deepots $^{\mathrm{TM}}$, Corvalis, OR, USA), saturated with distilled water, and allowed to drain overnight at $4^{\circ} \mathrm{C}$ to obtain soils at field capacity. Soils were transferred to modified centrifuge bottles containing a perforated plate separating and upper compartment for soils and a lower compartment to capture solutions modeled after published descriptions of similar apparatus (Adams et al., 1980; Elkhatib et al., 1987; Wolt, 1994). A $0.45 \mu \mathrm{m}$ pore size filter was placed on the perforated plate and soils were placed in the upper compartment. Modified bottles were centrifuged at $2,500 \mathrm{rpm}$ at $4^{\circ} \mathrm{C}$ for 60 minutes to extract soil solutions. Solutions were subsequently vacuum filtered through a $0.45 \mu \mathrm{m}$ pore size filter to remove any solids. The $\mathrm{pH}$ of the solutions were measured promptly when solutions reached room temperature. An aliquot of solution was acidified by adding nitric acid ( $2 \%$ by volume of sample) and analyzed for total $\mathrm{Al}$ concentrations using an inductively coupled plasma emission spectrophotometer (ICP). A second aliquot was used to quantify labile $\mathrm{Al}\left(\mathrm{Al}^{3+}, \mathrm{AlOH}^{2+}\right.$, and $\left.\mathrm{Al}(\mathrm{OH})_{2}^{+}\right)$using the 8hydroxyquinoline method (Bloom et al., 1978; James et al., 1983). The difference in total and labile Al was calculated and used to represent non-labile forms of Al (James et al., 1983). A final aliquot of solution was prepared for organic acid analysis by adding 1 drop $1 \mathrm{~N} \mathrm{NaOH}$ and $10 \%$ by volume $10 \mathrm{mM}$ EDTA to chelate $\mathrm{Al}$ and prevent suppression of organic acid detection (Cumming et al., 2001) prior to rotoevaporation. Residual salts were dissolved in deionized water, passed through a reverse phase column, and acetate, tartrate, citrate, malate, lactate, formate, glycolate, and succinate were quantified using ion chromatography with an ICE-AS6 column (Dionex Corp., Sunnydale, CA, USA) following the method of Cumming et al. (2001). Ion chromatography was used to quantify oxalate using an AS4A anion separation column, however no oxalate was detected.

The experiment was established as a two-way factorial design (4 collection times, 2 locations) with nine replicates $(n=9, N=72)$. Data were examined for normality using ShapiroWilk tests and transformations were undertaken where necessary to improve normality. Subsequently, data were analyzed using two-way ANOVAs followed by Tukey-Kramer's HSD to identify significant differences among treatment groups. Data were analyzed using JMP 5.0.1 (SAS Institute Inc., Cary, NC, USA). 


\section{Results}

The $\mathrm{pH}$ measured in soil solutions was higher in vegetated than non-vegetated soils (location effect $P<0.001$ ) and this difference became greater throughout the growing season (location $\times$ time $P<0.001$ ) (Figure 1). The $\mathrm{pH}$ of vegetated soil solutions was $1.7 \mathrm{pH}$ units higher than non-vegetated solutions in October, but was only between 0.6 and $0.7 \mathrm{pH}$ units higher in vegetated soil solutions during other months compared to non-vegetated soils solutions (Figure 1).

Total Al concentrations, measured by ICP, in soil solutions were higher in non-vegetated soil solutions $(848 \mu \mathrm{M} \mathrm{Al})$ than in vegetated samples $(14 \mu \mathrm{M} \mathrm{Al})$ (location effect $P<0.001)$ (Figure 2). The method using 8-hydroxyquinoline to extract Al from soil solutions was presumed to measure labile $\mathrm{Al}\left(\mathrm{Al}^{3+}, \mathrm{AlOH}^{2+}\right.$, and $\left.\mathrm{Al}(\mathrm{OH})_{2}^{+}\right)(\mathrm{Xia}$ et al., 2005; Luster et al., 1993 ) and is referred to as 8-hydroxyquinoline (8-HQ) extractable. The 8-HQ extractable Al was affected by location of soil collection and time of collection (location $\times$ time $P=0.036$ ) (Figure 3). 8-HQ extractable Al decreased in the solutions from non-vegetated soils over the course of the season from $677 \mu \mathrm{M}$ Al to $221 \mu \mathrm{M} \mathrm{Al}$, while it remained the same in solutions from non-vegetated soils (approximately $15 \mu \mathrm{M}$ Al). Differences in total and 8-HQ extractable Al would have represented non-labile Al. However, total Al concentrations measured in vegetated samples were not consistently higher that 8-HQ concentration and non-labile Al was not calculated.

The concentrations of some organic acids varied with location and time (Table 1). In October, higher concentrations in vegetated locations than non-vegetated locations were noted for citrate, malate, glycolate, formate, lactate, and succinate, but, during other months, these organic acids were similar in both locations. 
Table 1. Mean organic acid concentrations $(\mu \mathrm{M})$ in soil solutions of vegetated and nonvegetated soils collected from Stewartstown Mine in the months of July, August, September, and October. Within a row, letters with the same letter do not differ significantly.

\begin{tabular}{|c|c|c|c|c|c|c|c|c|c|}
\hline \multirow[b]{2}{*}{$\begin{array}{l}\text { Organic } \\
\text { acid }\end{array}$} & \multicolumn{2}{|c|}{ July } & \multicolumn{2}{|c|}{ August } & \multicolumn{2}{|c|}{ September } & \multicolumn{2}{|c|}{ October } & \multirow[b]{2}{*}{$\begin{array}{c}\text { Location } \\
\times \text { Time } \\
P\end{array}$} \\
\hline & $\begin{array}{c}\text { non- } \\
\text { vegetated }\end{array}$ & vegetated & $\begin{array}{c}\text { non- } \\
\text { vegetated }\end{array}$ & vegetated & $\begin{array}{c}\text { non- } \\
\text { vegetated }\end{array}$ & vegetated & $\begin{array}{c}\text { non- } \\
\text { vegetated }\end{array}$ & vegetated & \\
\hline Tartrate & $0.90^{\mathrm{a}}$ & $0.90^{\mathrm{a}}$ & $0.33^{\mathrm{a}}$ & $0.58^{\mathrm{a}}$ & $0.32^{\mathrm{a}}$ & $0.17^{\mathrm{a}}$ & $0.18^{\mathrm{a}}$ & $0.96^{\mathrm{a}}$ & 0.120 \\
\hline Citrate & $0.24^{\mathrm{b}}$ & $1.01^{\mathrm{b}}$ & $0.09^{\mathrm{b}}$ & $0.75^{\mathrm{b}}$ & $0.46^{\mathrm{b}}$ & $1.22^{\mathrm{b}}$ & $0.92^{\mathrm{b}}$ & $3.71^{\mathrm{a}}$ & 0.019 \\
\hline Malate & $0.06^{\mathrm{b}}$ & $0.74^{\mathrm{b}}$ & $0.08^{\mathrm{b}}$ & $0.37^{\mathrm{b}}$ & $0.33^{\mathrm{b}}$ & $0.31^{\mathrm{b}}$ & $0.50^{\mathrm{b}}$ & $2.12^{\mathrm{a}}$ & 0.005 \\
\hline Glycolate & $0.66^{\mathrm{b}}$ & $3.95^{\mathrm{b}}$ & $0.52^{\mathrm{b}}$ & $4.42^{\mathrm{b}}$ & $0.13^{\mathrm{b}}$ & $0.96^{\mathrm{b}}$ & $0.78^{\mathrm{b}}$ & $12.22^{\mathrm{a}}$ & $<0.001$ \\
\hline Formate & $25.85^{\mathrm{b}}$ & $35.74^{\mathrm{bc}}$ & $17.22^{\mathrm{bc}}$ & $22.17^{\mathrm{bc}}$ & $8.71^{\mathrm{c}}$ & $10.53^{\mathrm{c}}$ & $25.28^{\mathrm{bc}}$ & $77.05^{\mathrm{a}}$ & $<0.001$ \\
\hline Lactate & $1.15^{\mathrm{c}}$ & $7.92^{\mathrm{bc}}$ & $2.19^{\mathrm{c}}$ & $2.67^{\mathrm{c}}$ & $17.46^{\mathrm{a}}$ & $11.97^{\mathrm{ab}}$ & $2.29^{c}$ & $14.81^{\mathrm{ab}}$ & $<0.001$ \\
\hline Acetate & $28.89^{\mathrm{a}}$ & $70.27^{\mathrm{a}}$ & $29.05^{\mathrm{a}}$ & $65.14^{\mathrm{a}}$ & $35.98^{\mathrm{a}}$ & $56.18^{\mathrm{a}}$ & $41.55^{\mathrm{a}}$ & $43.98^{\mathrm{a}}$ & 0.070 \\
\hline Succinate & $0.00^{\mathrm{b}}$ & $0.35^{\mathrm{b}}$ & $0.03^{\mathrm{b}}$ & $0.06^{\mathrm{b}}$ & $0.09^{\mathrm{b}}$ & $0.02^{\mathrm{b}}$ & $0.04^{\mathrm{b}}$ & $1.93^{\mathrm{a}}$ & 0.025 \\
\hline
\end{tabular}




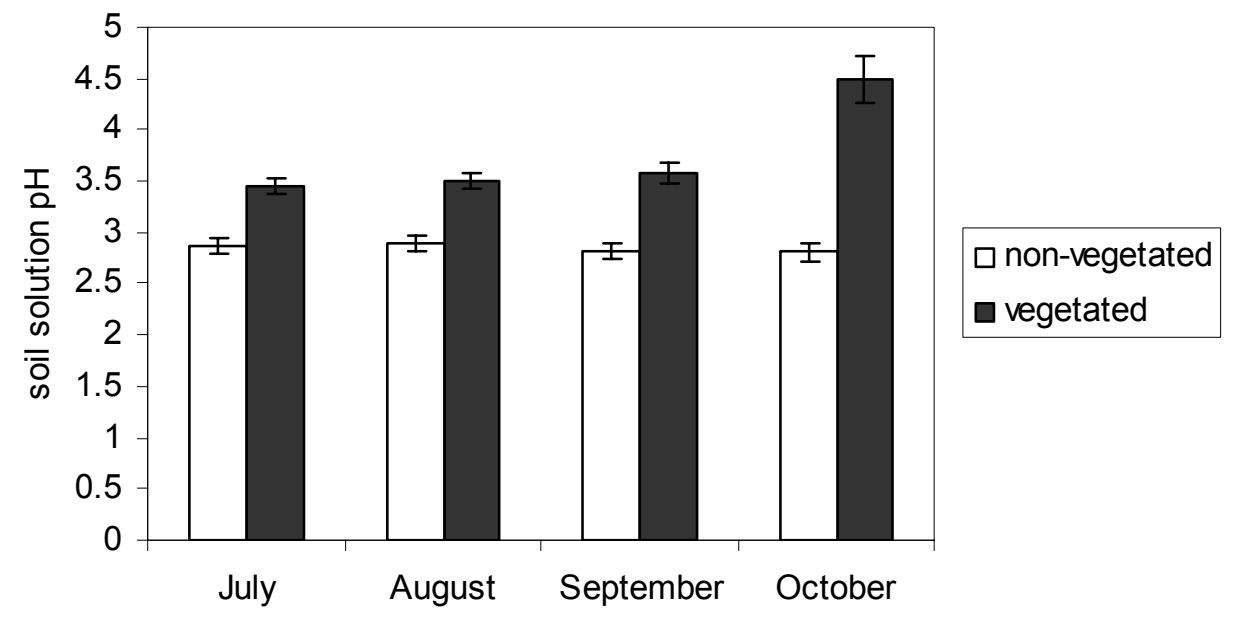

Figure 1. Soil solution $\mathrm{pH}$ collected from non-vegetated and vegetated soils in July, August, September, and October.

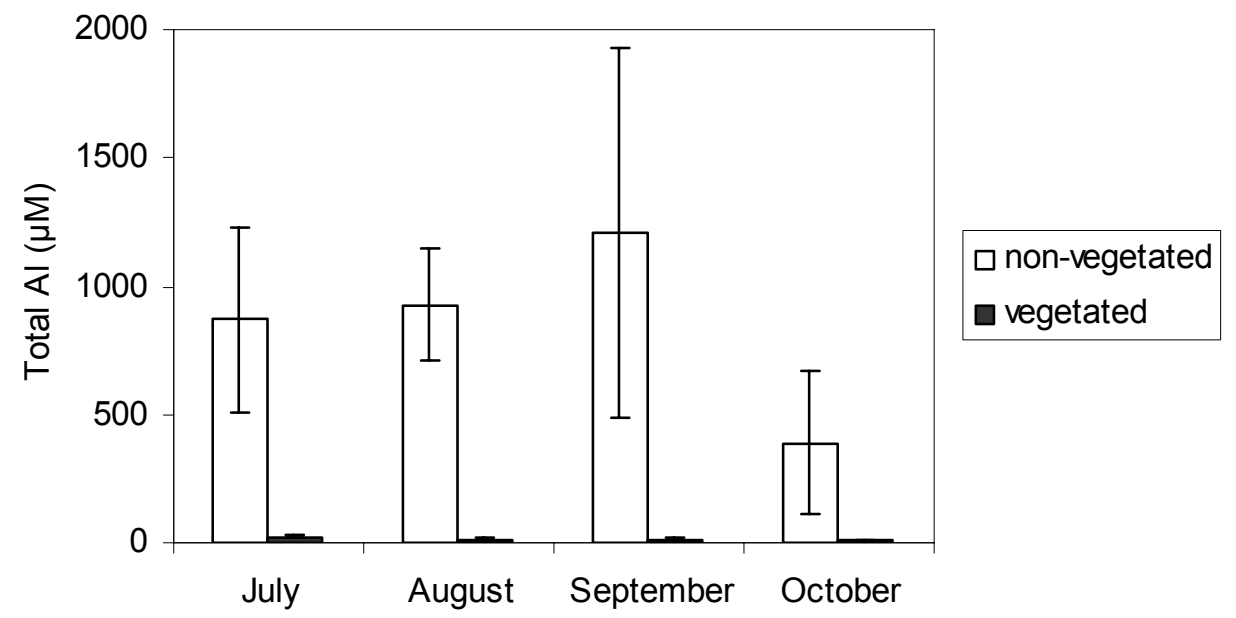

Figure 2. Total Al in soil solutions collected from non-vegetated and vegetated soils in July, August, September, and October. 


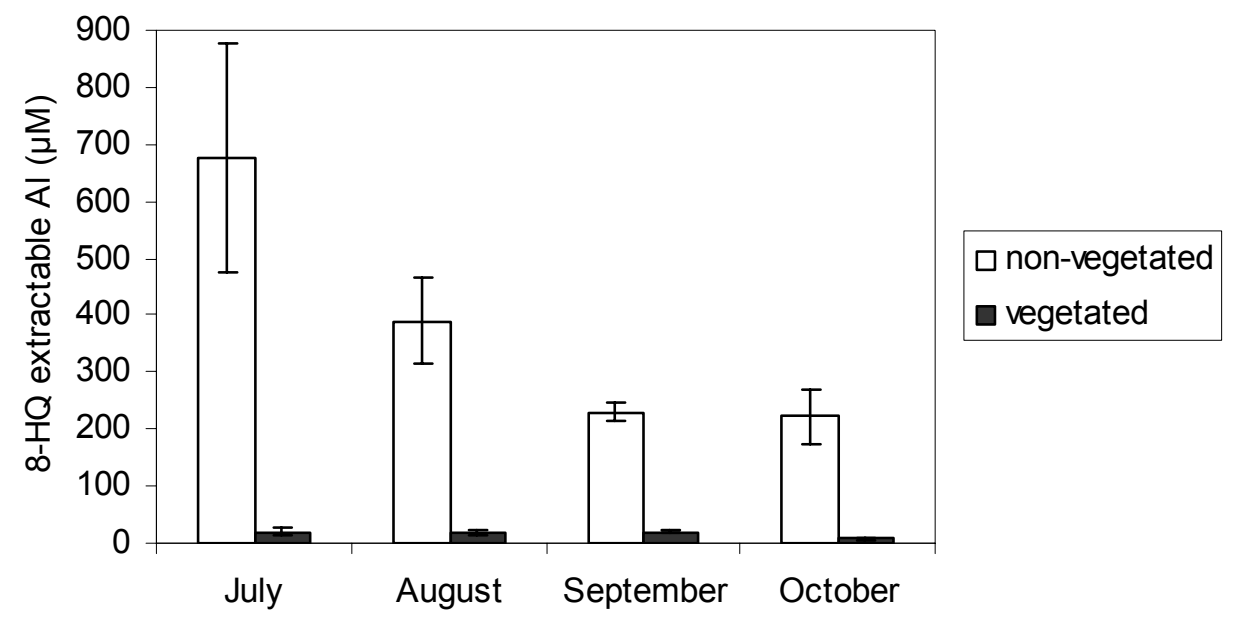

Figure 3. 8-hydroxyquinoline extractable $\mathrm{Al}$ in soil solutions collected from non-vegetated and vegetated soils in July, August, September, and October. 


\section{Discussion}

The amount of time required for a disturbed site to return to its original state depends on the intensity of disturbance. Primary succession can take thousands of years due to the severe disturbance of sites where bedrock is exposed and no soil strata or seed supply present (Schrock \& Munsee, 1987; Ricklefs \& Miller, 1999). In less disturbed locations, where the soils layers remain intact and a seed supply is available, secondary succession takes place and is much more rapid than primary succession (Schrock \& Munsee, 1987; Ricklefs \& Miller, 1999). The process that occurs after surface mining is an intermediate type of succession (Schrock \& Munsee, 1987). Topsoil is removed during surface mining and, before SMCRA required post mining reclamation activities that included the replacement of topsoil, mined lands were left with sterile sub-soils at the surface (Geidel \& Caruccio, 2000). While it is unlikely that sites such as these abandoned mine lands will take the thousands of years needed for primary succession, the process will be much slower than many secondary successional processes (Schrock \& Munsee, 1987).

The plant species that initially colonize disturbed sites play important roles in ecological succession. These species alter the environment by enriching the soils with organic matter and altering the nutrient levels available to successive plants (Bell \& Ungar, 1981). In many parts of Appalachia, sites that have been surface mined are characterized by extreme acidity and the first plants to colonize the site must be acid tolerant in order to survive and subsequently facilitate the later stages of succession. Andropogon virginicus is an early species that colonizes extreme sites, including soils of Appalachian surface mines (Bell \& Ungar, 1981; Nellessen \& Ungar, 1993). Indeed, this species is established at the Stewartstown Mine site, an abandoned mine site with soils characterized by high $\mathrm{Al}$ and low $\mathrm{pH}$ conditions (Figures 1 and 2). Andropogon virginicus is not uniquely adapted to extremely acidic soils, but is highly dependent on AM fungi for enhancing $\mathrm{Al}$ resistance (Cumming \& Ning, 2003) and for increasing phosphorous use efficiency (Ning \& Cumming, 2001). Abuscular mycorrhizal fungi are often credited with enhancing nutrient acquisition of plant hosts, and this may be particularly important in acid soils where nutrient levels are typically low (Smith \& Read, 1997; Clark \& Zeto, 1996; Kochian et al., 2004). Additionally, AM fungi confer resistance to Al (Marschner, 1995) and Mn (Malcová et al., 2003) in a variety of plant species. Thus, a healthy mycorrhizal community is critical to colonization and success on stressful soils. In addition to enhancing stress resistance and maintaining nutrient status of plant hosts, AM fungi can alter soil structures through the 
exudation of a variety of compounds that will alter soil chemistry and enhance plant growth. Organic acids are known Al chelators and organic acid production from mycorrhizal roots is maintained by AM fungi under Al stress (Chapter 2 of this dissertation). Glomalin is a glycoprotein released by AM fungi that is important in forming soil aggregates and improving soil structure (Wright \& Upadhyaya, 1999; Rillig et al., 2002; Jeffries et al., 2003). Thus, the presence of AM fungi may facilitate plant community development on disturbed sites by conferring stress resistance to plants during revegetation (Jeffries et al., 2003; Pattinson et al., 2004).

The Stewartstown Mine site has large patches of vegetation that are dominated by $A$. virginicus while other areas remain devoid of plants. In the present study, the $\mathrm{pH}$ of soil solutions measured from vegetated and non-vegetated areas at this site varied with location of collection as well at time. The typical growing season for $A$. virginicus begins in mid-summer and ends with senescence in fall (Strausbaugh \& Core, 1978). Early in the A. virginicus growing season (July), the $\mathrm{pH}$ of the vegetated areas of the study site was slightly higher than the $\mathrm{pH}$ of the non-vegetated areas. This $\mathrm{pH}$ difference became greater as the growing season progressed and by October, when the plants were fully grown and in stages of senescence, the $\mathrm{pH}$ of the vegetated areas was $1.7 \mathrm{pH}$ units higher than non-vegetated soils (Figure 1). Many models of ecological succession suggest that early species facilitate the colonization of later species by changing the microenvironment of the site (Ricklefs \& Miller, 1999) and changes in pH may be one example of changes to the environment that facilitates succession that is related to the growth of $A$. virginicus and the organic compounds that are added to the soil from root exudates and litter.

Low molecular weight organic acids are produced during decomposition of organic matter and are also released from actively growing plant roots (van Hees et al., 2000). Most organic acids measured in soil solutions (citrate, malate, glycolate, formate, lactate, and succinate) differed with location and time of collection and were higher in vegetated than nonvegetated location in October. This may represent an increase in organic acid release from roots as plants reach maturity or may also result from additions of decomposing litter to the soil as the plants senesce. As organic acid anions from either source decompose, decarboxylation reactions result in the consumption of protons and release of $\mathrm{CO}_{2}$ which can increase the $\mathrm{pH}$ of soils (Haynes \& Mokolobate, 2001). 
The observed increases in $\mathrm{pH}$ late in the A. virginicus growing season and the increase in organic acid concentrations of vegetated locations were congruent with lower concentrations of 8-HQ extractable Al. The addition of organic residues to acid soils can reduce Al toxicity due to the formation of non-phytotoxic Al-organic complexes (Haynes \& Mokolobate, 2001). Similarly, natural additions of organics to the soils from A. virginicus roots and leaf litter at the Stewartstown mine site could account for temporal increases in measured organic acids and reductions in 8-HQ extractable Al. In addition, humic substances also complex $\mathrm{Al}$ and comprise a large portion of organic matter in soils (Haynes \& Mokolobate, 2001; Vance et al., 1996). This, too, may be related to reductions in 8-HQ extractable Al later in the A. virginicus growing season when additions of organic matter would be expected to be high. Organic acids and decomposing organic matter products, such as humic and fulvic acids, will have additional benefits to plant colonization of acidic mine soils.

While 8-HQ extractable Al, used to represent labile or non-complexed Al, varied with time as well as location, total $\mathrm{Al}$ concentrations remained constant throughout the growing season. This finding reflects those of a previous study in which concentrations of soluble $\mathrm{Al}$ in surface waters of an acid mine watershed were high on sites 20 years after mining (Karathanasis et al., 1988), suggesting that weathering of Al-containing materials can be a significant source of $\mathrm{Al}$ even after plants have colonized a site for a substantial amount of time. Sources of Al are continuously weathered and the supply of Al from substrates likely remains constant.

The highly disturbed soils of abandoned Appalachian surface mines, such as the Stewartstown Mine site, provide severe limitations to successional processes. In the current study, late season organic acid concentrations found in the locations vegetated with A. virginicus compared to non-vegetated soils may be related to elevated $\mathrm{pH}$. In addition, concentrations of 8$\mathrm{HQ}$ extractable $\mathrm{Al}$ were lower as the growing season progressed. Root exudation and the decomposition of litter may influence the $\mathrm{pH}$ of soils and potentially limit the $\mathrm{Al}$ available for plants. Initial plant species colonizing these sites, such as A. virginicus, may ameliorate the extreme edaphic conditions, thereby helping to facilitate growth of other plants species, promoting revegetation and ecological succession of these sites. 


\section{References}

Adams F, Burmester C, Hue NV, Long FL. 1980. A comparison of column-displacement and centrifuge methods for obtaining soil solutions. Soil Science Society of America Journal 44: 733735.

Bell TJ, Ungar IA. 1981. Factors affecting the establishment of natural vegetation on a coal strip mine spoil bank in southeastern Ohio. The American Midland Naturalist 105: 19-31.

Bloom PR, Weaver RM, McBride MB. 1978. The spectrophotometric and fluorometric determination of aluminum with 8-hydroxyquinoline and butyl acetate extraction. Soil Science Society of America Journal 42: 713-716.

Clark RB, Zeto SK. 1996. Mineral Acquisition by mycorrhizal maize grown on acid and alkaline soil. Soil Biology and Biochemistry 28: 1495-1503.

Clarkson DT. 1985. Factors affecting mineral nutrient acquisition by plants. Annual Review of Plant Physiology 36: 11-115.

Cumming JR, Ning J. 2003. Arbuscular mycorrhizal fungi enhance aluminum resistance of broomsedge (Andropogon virginicus L.). Journal of Experimental Botany 54: 1447-1459.

Cumming JR, Swiger TD, Kurnik BS, Panaccione DG. 2001. Organic acid exudation by Laccaria bicolor and Pisolithus tinctorius exposed to aluminum in vitro. Canadian Journal of Forest Research 31: 703-710.

Elkhatib EA, Hern JL, Staley TE. 1987. A rapid centrifugation method for obtaining soil solution. Soil Science Society of America Journal 51:578-583.

Geidel G, Caruccio F. 2000. Geochemical factors affecting coal mine drainage quality. In: Barnhisel R, Darmody R, Daniels L eds. Reclamation of Drastically Disturbed Lands, $2^{\text {nd }}$ edn. Agronomy Monographs 41. Madision, USA: American Society of Agronomy.

Haynes RJ, Mokolobate MS. 2001. Amelioration of Al toxicity and P deficiency in acid soils by additions of organic residues: a critical review of the phenomenon and the mechanisms involved. Nutrient Cycling in Agroecosystems 59: 47-63.

Hue NV, Craddock, GR, Adams F. 1986. Effect of organic acids on aluminum toxicity in subsoils. Soil Science Society of America Journal 50: 28-34.

James BR, Clark CJ, Riha SJ. 1983. An 8-hydroxyquinoline method for labile and total aluminum in soil extracts. Soil Science Society of America Journal 47: 893-897.

Jeffries P, Gianinazzi S, Perotto S, Turnau K, Barea JM. 2003. The contribution of arbuscular mycorrhizal fungi in sustainable maintenance of plant health and soil fertility. Biology and Fertility of Soils 37: 1-16. 
Karathanasis AD, Evangelou VP, and Thompson YL. 1988. Aluminum and iron equilibria in soil solutions and surface waters of acid mine watersheds. Journal of Environmental Quality 17: 534-543.

Kochian LV, Hoekenga OA, Piñeros MA. 2004. How do crop plants tolerate acid soils? Mechanisms of aluminum tolerance and phosphorous efficiency. Annual Review of Plant Biology 55: 459-493.

Luster J, Yang A, Sposito G. 1993. On the interpretation of labile aluminum as determined by reaction with 8-hydroxyquinoline. Soil Science Society of America Journal 57: 976-980.

Malcová R, Rydlova J, Vosatka M. 2003. Metal-free cultivation of Glomus sp. BEG 140 isolated from Mn-contaminated soil reduces tolerance to Mn. Mycorrhiza 13: 151-157.

Marschner H. 1991. Mechanisms of adaptation of plants to acid soils. In: Wright RJ, et al. eds. Plant-soil interactions at low pH. Netherlands: Kluwer Academic Publishers, 683-702.

Marschner H. 1995. Mineral nutrition of higher plants. San Diego, USA: Academic Press, Inc.

Nellessen JE, Ungar IA. 1993. Physiological comparisons of old-field and coal-mine-spoil populations of Andropogon virginicus L. (broomsedge). American Midland Naturalist 130: 90105.

Ning J, Cumming JC. 2001. Arbuscular mycorrhizal fungi alter phosphorous relations of broomsedge (Andropogon virginicus L.) plants. Journal of Experimental Botany 52: 1883-1891.

Office of Surface Mining. 2003. Annual Evaluation Summary Report for the Regulatory and Abandoned Mine Land Reclamation Programs Administered by the State of WEST VIRGINIA. Office of Surface Mining, Department of the Interior, Washington, DC, USA.

Office of Surface Mining. 2004. State and Indian Regulatory Program Permitting 2004. Office of Surface Mining, Department of the Interior, Washington, DC, USA.

Pattinson GS, Hammill KA, Sutton BG, McGee PA. 2004. Growth and survival af seedling of native plants in an impoverished and highly disturbed soil following inoculation with arbuscular mycorrhizal fungi. Mycorrhiza 14: 339-346.

Ricklefs RE, Miller GL. 1999. Ecology. New York, USA: WH Freeman and Company.

Rillig MC, Wright SF, Eviner VT. 2002. The role of arbuscular mycorrhizal fungi and glomalin in soil aggregation: comparing effects of five plants species. Microbial Ecology 238: 325-333.

Schrock JR, Munsee JR. 1987. A comparison of surface vegetation on unreclaimed 1949 Indiana coal spoilbanks in 1964 and 1981. Ecology 96: 257-271.

Smith SE, Read DJ. 1997. Mycorrhizal Symbiosis: $2^{\text {nd }}$ Edn. San Diego, USA: Academic Press. 
Stewart J, Skousen J. 2003. Water quality changes in a polluted stream over a twenty-five-year period. Journal of Environmental Quality 32: 654-661.

Strausbaugh PD, Core EL. 1978. Flora of West Virginia. Morgantown, USA: Seneca Books, Inc.

USDA, NRCS. 2004. The PLANTS Database, Version 3.5 (http://plants.usda.gov). Baton Rouge, USA: National Plant Data Center

Vance GF, Stevenson F J, Sikora FJ. 1996. Environmental chemistry of aluminum-organic complexes. In: Sposito G, ed. The environmental chemistry of aluminum $2^{\text {nd }}$ edition. New York, USA: CRC Press, Inc., 169-220.

van Hees PAW, Lundström US, Giesler R. 2000. Low molecular weight organic acids and their Al-complexes in soil solution-composition, distribution and seasonal variation in three podzolized soils. Geoderma 94: 173-200.

West Virginia Coal Association. 2004. Coal Facts 2004. WV Coal Association, Charleston, WV, USA.

Wolt J. 1994. Soil solution chemistry: Applications to environmental science and agriculture. John Wiley and Sons, Inc., New York, NY.

Wright SF, Upadhyaya A. 1999. Quantification of arbuscular mycorrhizal fungi activity by the glomalin concentration on hyphal traps. Mycorrhiza 8: 283-285.

Xia L, Hu BH, Jiang Z, Wu Y, Chen LL, Chen R. 2005. 8-Hydroxyquinoline-chloroform single drop microextraction and electrothermal vaporization ICP-MS for the fractionation of aluminum in natural waters and drinks. Journal of Analytical Atomic Spectrometry 20: 441-446. 


\section{Chapter 5: Stability of aluminum stress resistance in arbuscular mycorrhizal fungi}

\section{Introduction}

Arbuscular mycorrhizal (AM) fungi form extremely important ecological associations with the roots of $80 \%$ of terrestrial plant species (Smith \& Read 1997). The plant-AM fungal association evolved 400 million years ago and was instrumental to colonization of land by plants (Malloch et al., 1980; Brundrett, 2002). This association mediates plant-soil interactions, such as nutrient uptake and resistance to soil stresses, and is thus critical to plant productivity worldwide (Marschner, 1991; Clark, 1997).

One factor limiting plant growth worldwide is soil acidity (von Uexküll \& Mutert, 1995). Aluminum ( $\mathrm{Al}$ ) in acid soils is toxic to plants, altering numerous physiological processes and growth (Kochian, 1995). However, the AM association alters the Al resistance of plants, suggesting some AM-induced change in the ability of mycorrhizal plants to withstand the stresses associated with Al exposure (Lux \& Cumming, 2001; Cumming \& Ning, 2003). Although the mechanisms of Al resistance are not known, organic exudates produced by AM fungi and plant roots that bind and detoxify $\mathrm{Al}$ in the root zone are proposed mechanisms for which evidence is mounting (Delhaize \& Ryan, 1995; Hue et al., 1996; Ma et al., 1998; Sylva et al., 2001; Kochian et al., 2004).

Arbuscular mycorrhizal species differ in their ability to promote plant growth depending on environmental conditions and plant host species (Bever et al., 2001). Not all AM species exhibit similar levels of resistance to Al and soil acidity (Siqueira et al., 1984; BartolomeEsteban \& Schenck, 1994; Klugh \& Cumming, 2003; Kelly et al., 2005). These recent research findings highlight that AM species are not functionally redundant, and that extensive variation exists among and within AM fungal species. This is not surprising, given the wide range of soil conditions in the environment. Ecotypic variation exhibited among geographically isolated fungal populations suggests that AM fungi have the ability to adapt to local environmental conditions (Bartolome-Esteban \& Schenck, 1994; Clark, 1997) and such adaptation may be instrumental in plant productivity on stressful soils.

Heritable phenotypic variation has been observed in AM fungi, despite their lack of sexual reproduction (Bentivenga et al., 1997; Bever \& Morton, 1999). AM fungi are multinucleate and reproductive spores can contain thousands of genetically distinct nuclei 
(Cooke et al., 1987; Sanders et al., 1995; Bever \& Morton, 1999; Kuhn et al., 2001). If selection pressures are present, nuclei containing genetic material coding for phenotypes compatible for a specific environment could be selected for and enriched during spore production. Malcová et al. (2003) cultivated Glomus sp., originating in a manganese (Mn) contaminated soil, in both the original Mn contaminated soil and a metal-free soil. When subsequently experimentally exposed to $\mathrm{Mn}$, the metal-free cultivated Glomus sp. was less Mn-tolerant than the Glomus sp. cultivated in the original substrate (Malcová et al., 2003). This result could potentially be due to the selection of nuclei conferring metal-stress resistant traits in subsequent generations, leading to the evolution of metal-adapted populations, and the dilution of such traits in non-selected populations (Meharg \& Cairney, 2000; Malcová et al., 2003). Similar processes could operate in acidic soils with the development Al-resistant AM fungi.

This study addressed questions pertaining to acid soil stress resistance, the heritability of stress resistant phenotypes of AM fungi, and potential shifts in AM fungal Al resistance under stress. Variation in conferred Al resistance between AM fungal isolates collected from acidic and non-acidic soils cultivated under Al exposure and Al-free conditions was evaluated. Spores from AM fungi cultivated under Al exposure and Al-free conditions were used as inoculum for a second set of plants to determine if AM fungi collected from Al rich environments retain resistance to stress after maintenance in stress-free conditions, or, conversely, if AM fungi collected from Al-free environments can develop stress resistance after cultivation under Al exposure.

\section{Materials and Methods}

Several groups of plants were grown for the experiment as described below and in Appendix 1. Seeds of Andropogon virginicus (broomsedge) were stratified in moist perlite at $4^{\circ}$ $\mathrm{C}$ for 90 days before planted in $4 \mathrm{~cm}$ diameter $\times 21 \mathrm{~cm}$ deep pots (Cone-tainers ${ }^{\mathrm{TM}}$, Stuewe and Sons, Corvalis, OR, USA) containing acid washed sand and fungal inoculum from the International Culture Collection of Vesicular Arbuscular Mycorrhizae (INVAM, West Virginia University, Morgantown, WV, USA). Two isolates each (one collected from a non-acidic site and one collected from an acidic site) of three AM species were used in the experiment: Acaulospora morrowiae (INVAM AZ225B, non-acidic and INVAM WV952, acidic), Glomus clarum (INVAM BR152, non-acidic and INVAM WV234, acidic), and Scutellospora heterogama (INVAM NY320, non-acidic and INVAM WV108, acidic). A control inoculum 
containing roots of non-mycorrhizal sudangrass was also used. Inoculum was wet sieved (500 $\mu \mathrm{m}$ and $38 \mu \mathrm{m}$ pore size sieves) before mixing with sand and added to pots. Seeds were allowed to germinate in the laboratory for one week and extra plants were removed to leave one plant per pot. After germination, plants were maintained in a growth chamber receiving $400 \mu \mathrm{mol} \mathrm{m}^{-2} \mathrm{~s}^{-1}$ for 14 hours each day, day/night temperatures of $28 / 20^{\circ} \mathrm{C}$, and $60 \%$ relative humidity. Plants received nutrient solutions three times daily containing $1.0 \mathrm{mM} \mathrm{NO}_{3}, 0.4 \mathrm{mM} \mathrm{NH}_{4}, 0.5 \mathrm{mM} \mathrm{K}$, $0.2 \mathrm{mM} \mathrm{Ca}, 0.05 \mathrm{mM} \mathrm{H}_{2} \mathrm{PO}_{4}, 0.1 \mathrm{mM} \mathrm{Mg}$ and $\mathrm{SO}_{4}, 50.5 \mu \mathrm{M} \mathrm{Cl}, 20 \mu \mathrm{M} \mathrm{Fe}, 25 \mu \mathrm{M} \mathrm{B}, 2 \mu \mathrm{M} \mathrm{Mn}$ and $\mathrm{Zn}$, and $0.5 \mu \mathrm{M} \mathrm{Cu}, \mathrm{Na}, \mathrm{Co}$, and Mo. Nutrient solutions were modified to deliver $\mathrm{Al}$ (as $\left.\mathrm{Al}_{2}\left(\mathrm{SO}_{4}\right)_{3}\right)$ concentrations of 0 and $200 \mu \mathrm{M}$ and were adjusted to $\mathrm{pH} 4.0$ with $\mathrm{HCl}$.

The first group of plants, G1 plants (for plants inoculated with AM fungal generation 1) was exposed to $\mathrm{Al}$ for eight weeks. At harvest, stems were clipped at the sand surface and shoots were washed in $0.1 \%$ Tween- 80 solution to remove debris, rinsed, dried at $60{ }^{\circ} \mathrm{C}$, and weighed. A root sample from each plant was used to determine AM colonization by boiling in $10 \% \mathrm{KOH}$ for five minutes, rinsed in water, acidifying with $2 \% \mathrm{HCl}$ for five minutes, staining with boiling $0.05 \%$ trypan blue in glycerol for five minutes, and quantifying colonization using the gridline intersect method (Giovannetti \& Mosse, 1980). Prior to staining, fresh roots samples were weighed. Remaining roots were rinsed free of sand, weighed fresh, dried at $60{ }^{\circ} \mathrm{C}$ and reweighed. Fresh weight/dry weight ratios were used to calculate total root biomass.

Dried shoots and roots were ground to pass through a 20 mesh screen and then digested in nitric acid and peroxide following procedures of Jones \& Case (1990). Tissue digests were analyzed for $\mathrm{Al}$ concentrations using a graphite furnace atomic absorption spectrophotometer (Varian, Inc., Mulgrave, Victoria, Australia) and inorganic phosphorous was quantified with the colorimetric method of Taussky \& Shorr (1953).

A second group of plants were similarly grown to produce inoculum under Al exposure for use later in a second exposure cycle. The set-up, growth conditions, and solution delivery are the same as those above, except multiple plants were grown in $5 \mathrm{~cm}$ diameter $\times 18 \mathrm{~cm}$ deep pots (D-16 Deepots ${ }^{\mathrm{TM}}$, Stuewe and Sons, Corvallis, OR, USA). Plants were harvested after 4 months when mature spores were present.

Subsequently, a third group of plants was used to assess variation in Al resistance among $\mathrm{AM}$ isolates using inoculum generated with and without $\mathrm{Al}$ exposure, above, again exposing plants to 0 and $200 \mu \mathrm{M} \mathrm{Al}$ treatments. For this group of plants, G2 plants (for plants inoculated 
with AM fungal generation 2), 120 pots each with one plant were used (6 isolates $\times 2 \mathrm{Al}$ level during inoculum cultivation $\times 2$ Al levels of current exposure $\times 6$ replicates for plants inoculated with G. clarum, S. heterogama, and non-mycorrhizal plants and 3 replicates for plants inoculated with A. morrowiae). Plants were maintained in a growth chamber under the same conditions as the plants in G1. Similarly, plant shoot and root biomass, mycorrhizal colonization, and tissue $\mathrm{Al}$ and $\mathrm{P}$ concentrations were measured in the same manner as outlined for G1, above.

Concentrations of organic acids were measured in root zones of G2 plants. Delivery of solutions was suspended eight hours prior to harvest to prevent organic acids produced from being leached from cones. At harvest, the contents of each cone (plant roots and sand) were placed in a beaker and $50 \mathrm{ml}$ of water was added and allowed to stand for five minutes. This root zone (rhizosphere, rhizoplane, and bulk sand) extract was filtered through a $0.45 \mu \mathrm{m}$ pore size filter and used for organic acid analysis. To $5 \mathrm{ml}$ of root zone extract, 1 drop of $1 \mathrm{~N} \mathrm{NaOH}$ and $0.5 \mathrm{~mL}$ of $\mathrm{Na}_{2}$-EDTA were added to chelate $\mathrm{Al}$ and ensure that organic acid analysis was not inhibited (Cumming et al., 2001). Samples were rotoevaporated and frozen for storage. Onehalf $\mathrm{mL}$ of water was used to dissolve residual salts and concentrated solutions were passed through a reverse phase column, and assessed for acetate, citrate, formate, glycolate, lactate, malate, tartrate, and succinate. The organic acids were separated and quantified using ion chromatography with an ICE-AS6 column (Dionex Corp., Sunnydale, CA, USA). Ion chromatography was also used to quantify oxalate using an AS4 anion separation column; however, no oxalate was detected in root zone samples.

Data from each group of plants was analyzed separately using two- or three-way nested ANOVAs according to the models below. Statistical significance was judged at $P \leq 0.10$ in light of limited degrees of freedom in the nested designs of the ANOVAs. 


\section{G1 Expected Means Squares:}

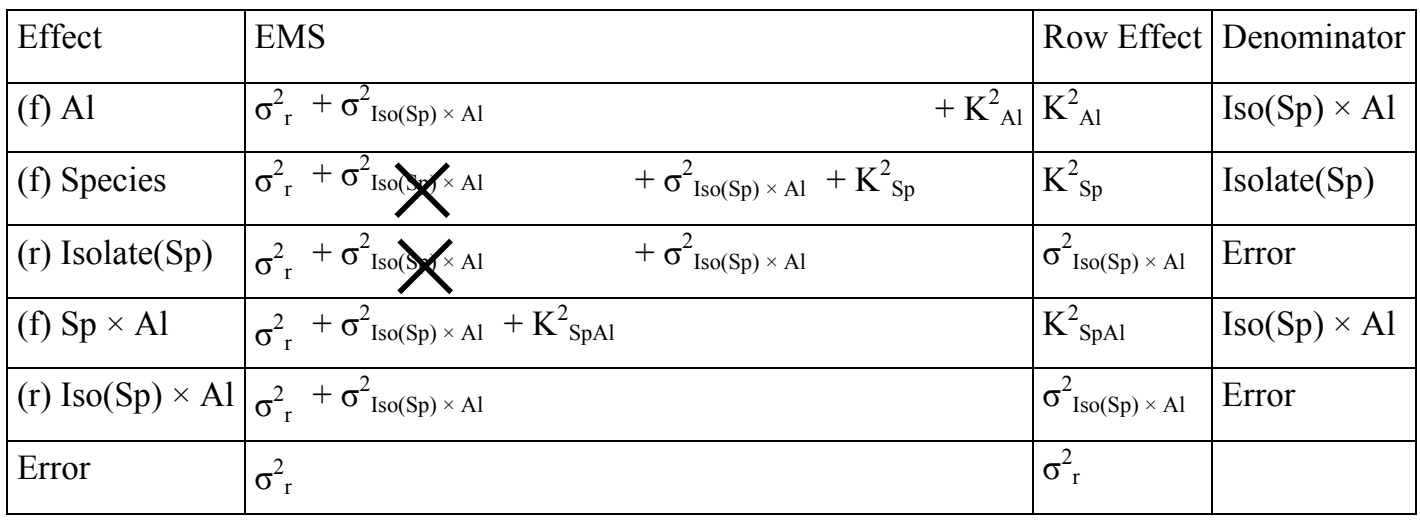


G2 Expected Means Squares:

\begin{tabular}{|c|c|c|c|c|c|c|}
\hline Effect & EMS & & & & Row Effect & Denominator \\
\hline (f) $\mathrm{pAl}$ & $\sigma_{\mathrm{r}}^{2}+\sigma_{\mathrm{Iso}}^{2} /{ }_{/ X \mathrm{PAl} \times \mathrm{Al}}$ & & $+\sigma_{\mathrm{Iso}(\mathrm{Sp}) \times \mathrm{pAl}}^{2}$ & $+\mathrm{K}_{\mathrm{pAl}}^{2}$ & $\mathrm{~K}_{\mathrm{pAl}}^{2}$ & Iso(Sp) $\times \mathrm{pAl}$ \\
\hline (f) $\mathrm{Al}$ & $\sigma_{\mathrm{r}}^{2}+\sigma_{\mathrm{Iso}}^{2} \propto\langle\mathrm{pAl} \times \mathrm{Al}$ & $+\sigma_{\mathrm{Iso}(\mathrm{Sp}) \times \mathrm{Al}}^{2}$ & & $+\mathrm{K}_{\mathrm{Al}}^{2}$ & $\mathrm{~K}_{\mathrm{Al}}^{2}$ & $\mathrm{Iso}(\mathrm{Sp}) \times \mathrm{Al}$ \\
\hline (f) $\mathrm{Sp}$ & $\sigma_{\mathrm{r}}^{2}+\sigma_{\mathrm{Iso}}^{2} \searrow_{\langle\mathrm{pAl} \times \mathrm{Al}}$ & $+\sigma_{\text {Iso }}^{2} \not X_{\mathrm{X}} \times \mathrm{Al}$ & $+\sigma_{\text {Isoo }}^{2} \not \mathbf{X} \times \mathrm{pAl}$ & $+\mathrm{K}_{\mathrm{Sp}}^{2}$ & $\mathrm{~K}_{\mathrm{Sp}}^{2}$ & Iso(Sp) \\
\hline (r) Iso(Sp) & $\sigma_{\mathrm{r}}^{2}+\sigma_{\text {Isoo }}^{2} \times \mathrm{pAl} \times \mathrm{Al}$ & $+\sigma_{\text {Iso) }}^{2}(x) \times \mathrm{Al}$ & $+\sigma_{\text {Isoo }}^{2} \ \times$ PAl & & $\sigma_{\mathrm{Iso}(\mathrm{Sp})}^{2}$ & Error \\
\hline (f) $\mathrm{pAl} \times \mathrm{Al}$ & $\sigma_{\mathrm{r}}^{2}+\sigma_{\mathrm{Iso}(\mathrm{Sp}) \mathrm{pAl} \times \mathrm{Al}}^{2}$ & & $+\mathrm{K}_{\mathrm{pAl} \times \mathrm{Al}}^{2}$ & & $\mathrm{~K}_{\mathrm{pAl} \times \mathrm{Al}}^{2}$ & $\mathrm{Iso}(\mathrm{Sp}) \times \mathrm{pAl} \times \mathrm{Al}$ \\
\hline (f) $\mathrm{Sp} \times \mathrm{pAl}$ & $\sigma_{\mathrm{r}}^{2}+\sigma_{\text {Isoo }}^{2} \times \mathrm{pAl} \times \mathrm{Al}$ & & $+\sigma_{\mathrm{Iso}(\mathrm{Sp}) \times \mathrm{pAl}}^{2}$ & & $\mathrm{~K}_{\mathrm{Sp} \times \mathrm{pAl}}^{2}$ & $\mathrm{Iso}(\mathrm{Sp}) \times \mathrm{pAl}$ \\
\hline (f) $\mathrm{Sp} \times \mathrm{Al}$ & $\sigma_{\mathrm{r}}^{2}+\sigma_{\text {Isoo }}^{2} /\langle\mathrm{pAl} \times \mathrm{Al}$ & $+\sigma_{\mathrm{Iso}(\mathrm{Sp}) \times \mathrm{Al}}^{2}$ & $+\mathrm{K}_{\mathrm{Sp} \times \mathrm{Al}}^{2}$ & & $\mathrm{~K}_{\mathrm{Sp} \times \mathrm{Al}}^{2}$ & $\mathrm{Iso}(\mathrm{Sp}) \times \mathrm{Al}$ \\
\hline (r) $\mathrm{Iso}(\mathrm{Sp}) \times \mathrm{pAl}$ & $\sigma_{\mathrm{r}}^{2}+\sigma_{\text {Isoo }}^{2} /\langle\mathrm{pAl} \times \mathrm{Al}$ & & $+\sigma_{\mathrm{Iso}(\mathrm{Sp}) \times \mathrm{pAl}}^{2}$ & & $\sigma_{\text {Iso(Sp) }) \times \mathrm{pAl}}^{2}$ & Error \\
\hline (r) $\mathrm{Iso}(\mathrm{Sp}) \times \mathrm{Al}$ & $\sigma_{\mathrm{r}}^{2}+\sigma_{\mathrm{Iso}}^{2} \backslash \mathrm{pAl} \times \mathrm{Al}$ & $+\sigma_{\mathrm{Iso}(\mathrm{Sp}) \times \mathrm{Al}}^{2}$ & & & $\sigma_{\mathrm{Iso}(\mathrm{Sp}) \times \mathrm{Al}}^{2}$ & Error \\
\hline (f) $\mathrm{Sp} \times \mathrm{pAl} \times \mathrm{Al}$ & $\sigma_{\mathrm{r}}^{2} \quad+\sigma_{\mathrm{Iso}(\mathrm{Sp}) \mathrm{pAl} \times \mathrm{Al}}^{2}$ & $+\mathrm{K}_{\mathrm{Sp} \times \mathrm{pAl} \times \mathrm{Al}}^{2}$ & & & $\mathrm{~K}_{\mathrm{Sp} \times \mathrm{pAl} \times \mathrm{Al}}^{2}$ & $\mathrm{Iso}(\mathrm{Sp}) \times \mathrm{pAl} \times \mathrm{Al}$ \\
\hline (r) $\mathrm{Iso}(\mathrm{Sp}) \times \mathrm{pAl} \times \mathrm{Al}$ & $\sigma_{\mathrm{r}}^{2}+\sigma_{\mathrm{Iso}(\mathrm{Sp}) \mathrm{pAl} \times \mathrm{Al}}^{2}$ & & & & $\sigma_{\mathrm{Iso}(\mathrm{Sp}) \mathrm{pAl} \times \mathrm{Al}}^{2}$ & Error \\
\hline Error & $\sigma_{\mathrm{r}}^{2}$ & & & & $\sigma_{\mathrm{r}}^{2}$ & \\
\hline
\end{tabular}

$\mathrm{pAl}=$ previous $\mathrm{Al}$ exposure of inoculum during cultivation

$\mathrm{Al}=\mathrm{Al}$ treatments for the current experiment

$\mathrm{Sp}=$ species

Iso $=$ isolates within species 


\section{Results}

The effect of $\mathrm{Al}$ on AM colonization was dependent upon isolate in the first generation exposure $(\mathrm{G} 1)($ Isolate $($ Species $) \times \mathrm{A} 1$ interaction $P<0.001)$ (Figure 1). Acaulospora morrowiae AZ 225 and WV 952, Glomus clarum WV234, and S. heterogama WV108, maintained levels of colonization under $\mathrm{Al}$ exposure that were similar to those at $0 \mu \mathrm{M}$ Al. Both G. clarum BR152 and S. heterogama NY320 had significantly higher levels of colonization when exposed to 200 $\mu \mathrm{M} \mathrm{Al}$, increasing from $11.8 \%$ to $73.7 \%$ and $23.0 \%$ to $58.2 \%$, respectively.

The effect of $\mathrm{Al}$ on plant biomass differed among $\mathrm{AM}$ species $(\mathrm{AM} \times \mathrm{Al}$ interaction $P=$ 0.073). Plants colonized by A. morrowiae and non-mycorrhizal plants had large decreases in biomass when exposed to $200 \mu \mathrm{M} \mathrm{Al}$, with $81.4 \%$ and $71.7 \%$ reductions in biomass, respectively, compared to plants exposed to $0 \mu \mathrm{M}$ Al. Plants colonized by $G$. clarum and $S$. heterogama exhibited decreases upon $\mathrm{Al}$ exposure that were less dramatic and were $27.5 \%$ and $34.9 \%$ smaller, respectively, than plants exposed to $0 \mu \mathrm{M}$ Al. Across Al treatments, plants inoculated with $G$. clarum and S. heterogama had greater biomass than plants inoculated with $A$. morrowiae or non-mycorrhizal plants (AM effect $P=0.006)$ (Figure 2). Plants had lower biomass when exposed to $200 \mu \mathrm{M}$ Al compared to those not exposed to Al (Al effect $P=0.008$ ). Isolates within species had similar biomass.

When not exposed to $\mathrm{Al}, A$. virginicus plants had total biomass measurements that were independent of the degree of colonization $(\mathrm{r}=0.051, P=0.825)$ (Figure 3). Biomass of plants inoculated with G. clarum BR152 and S. heterogama NY320 was high when not exposed to Al and colonization was low. Conversely, under Al exposure, colonization by AM fungi was highly correlated with biomass $(r=0.824, P<0.001)$ (Figure 3).

The concentration of $\mathrm{P}$ in plant shoots differed among fungal species, with $A$. morrowiae and non-mycorrhizal plants having the highest concentrations (AM effect $P=0.013$ ) (Table 1). Neither Al nor isolate had an effect on shoot $\mathrm{P}$ concentrations. The concentration of Al in shoot tissues was dependent on $\mathrm{AM}$ fungal treatment and solution $\mathrm{Al}(\mathrm{AM} \times \mathrm{Al}$ interaction $P=0.046)$ (Table 1). When exposed to $200 \mu \mathrm{M} \mathrm{Al}$, non-mycorrhizal plants accumulated up to $140 \mu \mathrm{g} \mathrm{Al} \mathrm{g}^{-}$ ${ }^{1}$ of shoot tissue, significantly more Al than plants in the mycorrhizal treatments, which accumulated between 52.2 and $72.3 \mu \mathrm{g} \mathrm{Al} \mathrm{g}^{-1}$.

G2 plants were exposed to 0 or $200 \mu \mathrm{M} \mathrm{Al}$ and inoculated with AM species and isolates cultivated with or without prior Al exposure. Root colonization with the AM isolates depended 
on $\mathrm{Al}$ treatments and whether the inoculum was previously exposed to $\mathrm{Al}$ during cultivation (Isolate(Species) $\times \mathrm{Al} \times$ previous $\mathrm{Al}$ interaction $P<0.001$ ) (Figure 4). In plants colonized by $A$. morrowiae isolates, there were significant decreases in colonization under $\mathrm{Al}$ exposure, regardless of whether or not the inoculum had been previously exposed to Al. Scutellospora heterogama colonization was similar under all $\mathrm{Al}$ treatments and was not related to previous inoculum exposure to $\mathrm{Al}$ (Figure 4). However, colonization by G. clarum BR152 increased when inoculum was previously cultivated with $\mathrm{Al}$ and plants were treated with $200 \mu \mathrm{M} \mathrm{Al}$, whereas colonization by G. clarum WV234 not previously exposed to Al was consistently high regardless of current $\mathrm{Al}$ exposure (Figure 4).

Across all AM fungal treatments, the biomass of G2 plants was lower in the $200 \mu \mathrm{M} \mathrm{Al}$ treatment than in the $0 \mu \mathrm{M} \mathrm{Al}$ treatment (Al effect $P=0.046$ ) (Figure 5). Plants inoculated with AM isolates cultivated under $200 \mu \mathrm{M} \mathrm{Al}$ tended to have higher biomass than plants inoculated with $\mathrm{AM}$ isolates cultivated without $\mathrm{Al}$ (previous $\mathrm{Al}$ effect $P=0.097$ ). This was particularly evident in A. morrowiae WV952 and G. clarum BR152.

Phosphorous concentrations in shoots did not exhibit consistent patterns among treatment groups and ranged from 1130 to $1716 \mu \mathrm{g}$ per gram of shoot tissue (Table 2). The concentration of $\mathrm{Al}$ in shoots was only affected by $\mathrm{Al}$, with higher concentrations of $\mathrm{Al}$ in shoots of plants treated with $200 \mu \mathrm{M} \mathrm{Al}$ ( $\mathrm{Al}$ effect $P=0.001$ ). Shoot $\mathrm{Al}$ concentrations and did not vary among species, isolates, or previous $\mathrm{Al}$ exposure of inoculum (Table 2).

In the absence of $\mathrm{Al}$, biomass of $A$. virginicus plants had a weak negative correlation with the degree of colonization $(r=-0.243, P=0.092)$ (Figure 6). However, when under Al exposure, increases in biomass were strongly related to increases in colonization $(\mathrm{r}=0.440, P=0.001)$ (Figure 6).

The concentrations of organic acids were measured in root zones of G2 plants at harvest. Citrate concentrations were not affected by Al treatments, but citrate concentrations among species varied depending on whether inoculum was cultivated in the presence of $\mathrm{Al}$ (species $\times$ previous Al interaction $P=0.031$ ) (Figure 7a). Plants colonized by A. morrowiae and G. clarum had concentrations that increased with Al-cultivated inoculum compared to unexposed inoculum, whereas no such difference was evident in S. heterogama. Malate concentrations were significantly affected by $\mathrm{Al}$, with lower concentrations evident in plants treated with $\mathrm{Al}$ ( $\mathrm{Al}$ effect $P=0.041$ ) (Figure 7b). Previous exposure of inoculum appeared to have an effect on root 
zone malate concentrations, with plants colonized by inoculum with previous $\mathrm{Al}$ exposure having moderately elevated concentrations (previous Al effect $P=0.078$ ) (Figure $7 b$ ). To further investigate patterns of exudation by mycorrhizal plants, production of organic acids ( $\mu$ mol g ${ }^{-1}$ root mass) was calculated. The production of citrate and malate was lower in plants receiving $200 \mu \mathrm{M} \mathrm{Al}$ treatments than those treated with $0 \mu \mathrm{M} \mathrm{Al}$ (Al effect $P=0.095$ and $P=$ 0.004, respectively) (Figure 8). Previous Al exposure of inoculum did not affect citrate production, but appeared to have an effect on malate production (previous Al effect $P=0.099$ ) (Figure 8). 
Table 1. Concentrations of Al and P in shoot tissues of non-mycorrhizal (NM) and mycorrhizal A. virginicus plants exposed to 0 and $200 \mu \mathrm{M}$ Al.

\begin{tabular}{|c|c|c|c|c|}
\hline AM Species & Isolate & Al treatment & $\mathrm{P}\left(\mathrm{mg} \mathrm{g}^{-1}\right)$ & $\mathrm{Al}\left(\mu \mathrm{g} \mathrm{g}^{-1}\right)$ \\
\hline \multirow{4}{*}{ A. morrowiae } & \multirow{2}{*}{ AZ225 } & 0 & 1.21 & 44.8 \\
\hline & & 200 & 1.49 & 66.1 \\
\hline & \multirow{2}{*}{ WV952 } & 0 & 1.67 & 25.8 \\
\hline & & 200 & 1.30 & 71.2 \\
\hline \multirow{4}{*}{ G. clarum } & \multirow{2}{*}{ BR152 } & 0 & 1.06 & 25.1 \\
\hline & & 200 & 0.78 & 52.2 \\
\hline & \multirow{2}{*}{ WV234 } & 0 & 0.96 & 26.9 \\
\hline & & 200 & 0.81 & 67.3 \\
\hline \multirow{4}{*}{ S. heterogama } & \multirow{2}{*}{ NY320 } & 0 & 1.07 & 23.9 \\
\hline & & 200 & 1.28 & 72.3 \\
\hline & \multirow{2}{*}{ WV108 } & 0 & 1.11 & 41.7 \\
\hline & & 200 & 1.11 & 71.1 \\
\hline \multirow{2}{*}{ NM } & & 0 & 1.21 & 26.3 \\
\hline & & 200 & 1.35 & 140.9 \\
\hline
\end{tabular}

Table 2. Concentration of $\mathrm{Al}$ and $\mathrm{P}$ in shoot tissues of mycorrhizal $A$. virginicus plants inoculated with AM isolates of A. morrowiae, G. clarum and S. heterogama cultivated in the presence of $200 \mu \mathrm{M} \mathrm{Al}(+)$ or $0 \mu \mathrm{M} \mathrm{Al} \mathrm{(-)} \mathrm{and} \mathrm{exposed} \mathrm{to} 0$ and $200 \mu \mathrm{M} \mathrm{Al}$.

\begin{tabular}{|c|c|c|c|c|c|}
\hline Species & Isolate & Previous Al & Al treatment & $\mathrm{P}\left(\mathrm{mg} \mathrm{g}^{-1}\right)$ & $\mathrm{Al}\left(\mu \mathrm{g} \mathrm{g}^{-1}\right)$ \\
\hline \multirow{8}{*}{ A. morrowiae } & \multirow{4}{*}{ AZ225 } & \multirow[t]{2}{*}{ 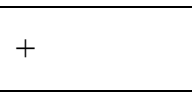 } & 0 & 1.21 & 21.7 \\
\hline & & & 200 & 0.88 & 89.9 \\
\hline & & \multirow{2}{*}{-} & 0 & 1.23 & 30.4 \\
\hline & & & 200 & 1.21 & 101.2 \\
\hline & \multirow{4}{*}{ WV952 } & \multirow{2}{*}{+} & 0 & 0.95 & 29.4 \\
\hline & & & 200 & 1.62 & 107.4 \\
\hline & & \multirow{2}{*}{-} & 0 & 2.15 & 30.5 \\
\hline & & & 200 & 1.43 & 182.5 \\
\hline \multirow{8}{*}{ G. clarum } & \multirow{4}{*}{ BR152 } & \multirow{2}{*}{+} & 0 & 1.15 & 70.7 \\
\hline & & & 200 & 1.03 & 107.2 \\
\hline & & \multirow{2}{*}{-} & 0 & 1.52 & 48.0 \\
\hline & & & 200 & 1.59 & 141.5 \\
\hline & \multirow{4}{*}{ WV234 } & \multirow{2}{*}{+} & 0 & 1.30 & 43.0 \\
\hline & & & 200 & 0.89 & 120.3 \\
\hline & & \multirow{2}{*}{-} & 0 & 1.07 & 32.5 \\
\hline & & & 200 & 1.49 & 120.6 \\
\hline \multirow{8}{*}{ S. heterogama } & \multirow{4}{*}{ NY320 } & \multirow{2}{*}{+} & 0 & 0.94 & 30.8 \\
\hline & & & 200 & 1.77 & 126.7 \\
\hline & & \multirow[b]{2}{*}{ - } & 0 & 1.23 & 32.8 \\
\hline & & & 200 & 1.62 & 98.5 \\
\hline & \multirow{4}{*}{ WV108 } & \multirow{2}{*}{+} & 0 & 2.15 & 29.1 \\
\hline & & & 200 & 1.62 & 168 \\
\hline & & \multirow[b]{2}{*}{-} & 0 & 1.38 & 30.4 \\
\hline & & & 200 & 1.72 & 120.0 \\
\hline
\end{tabular}




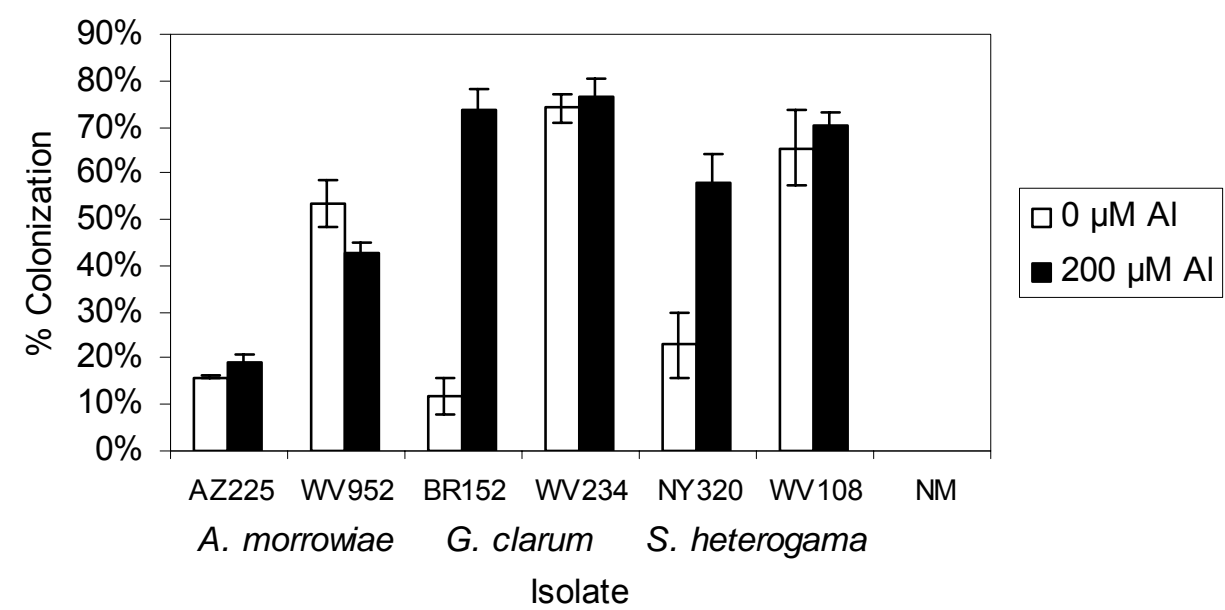

Figure 1. Colonization of mycorrhizal plants inoculated with isolates of A. morrowiae, G. clarum and S. heterogama exposed to 0 and $200 \mu \mathrm{M} \mathrm{Al}$.

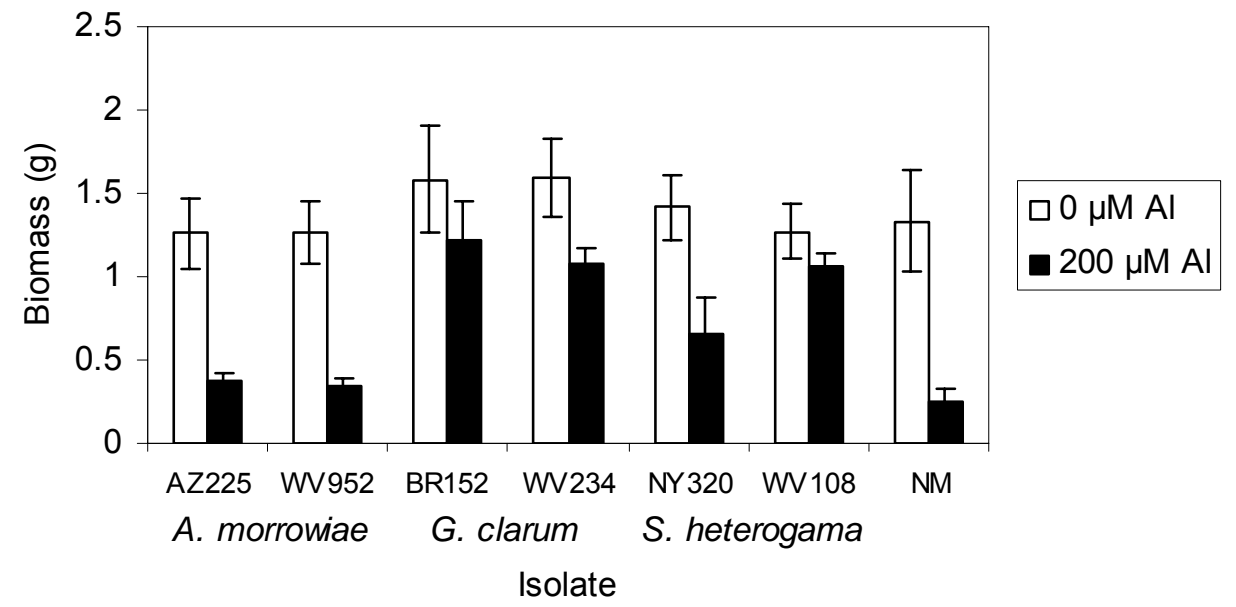

Figure 2. Biomass of non-mycorrhizal (NM) and mycorrhizal plants inoculated with isolates of A. morrowiae, G. clarum, and S. heterogama exposed to 0 and $200 \mu \mathrm{M} \mathrm{Al}$. 


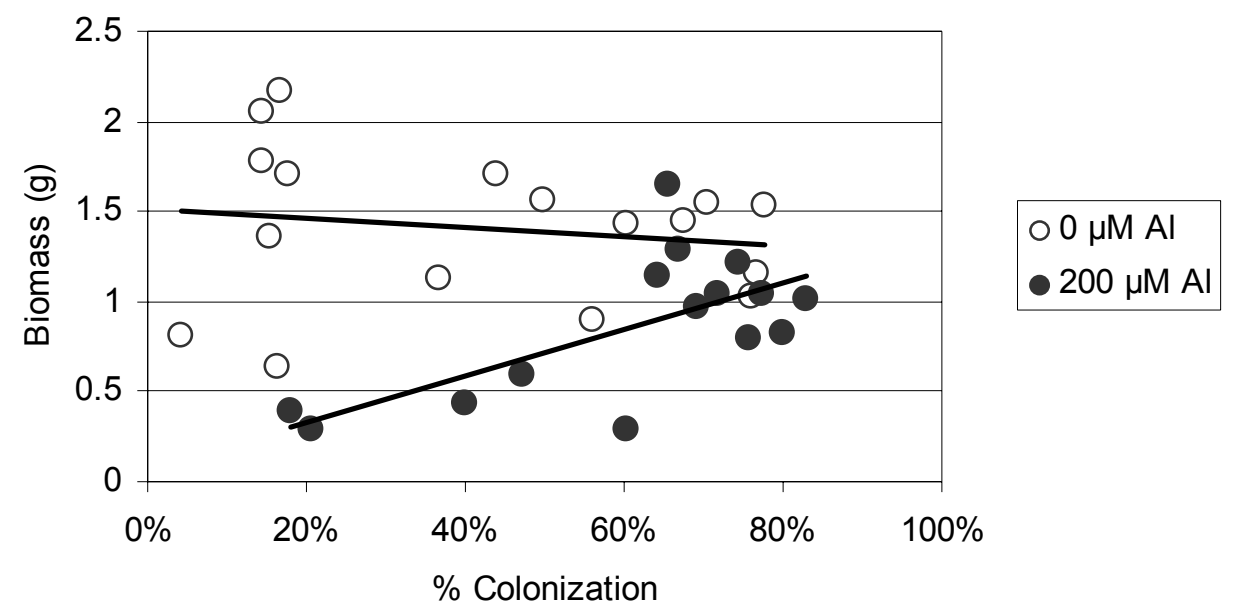

Figure 3. Relationship between \% colonization and total biomass of mycorrhizal plants inoculated with isolates of A. morrowiae, G. clarum and S. heterogama exposed to 0 and 200 $\mu \mathrm{M} \mathrm{Al}$.

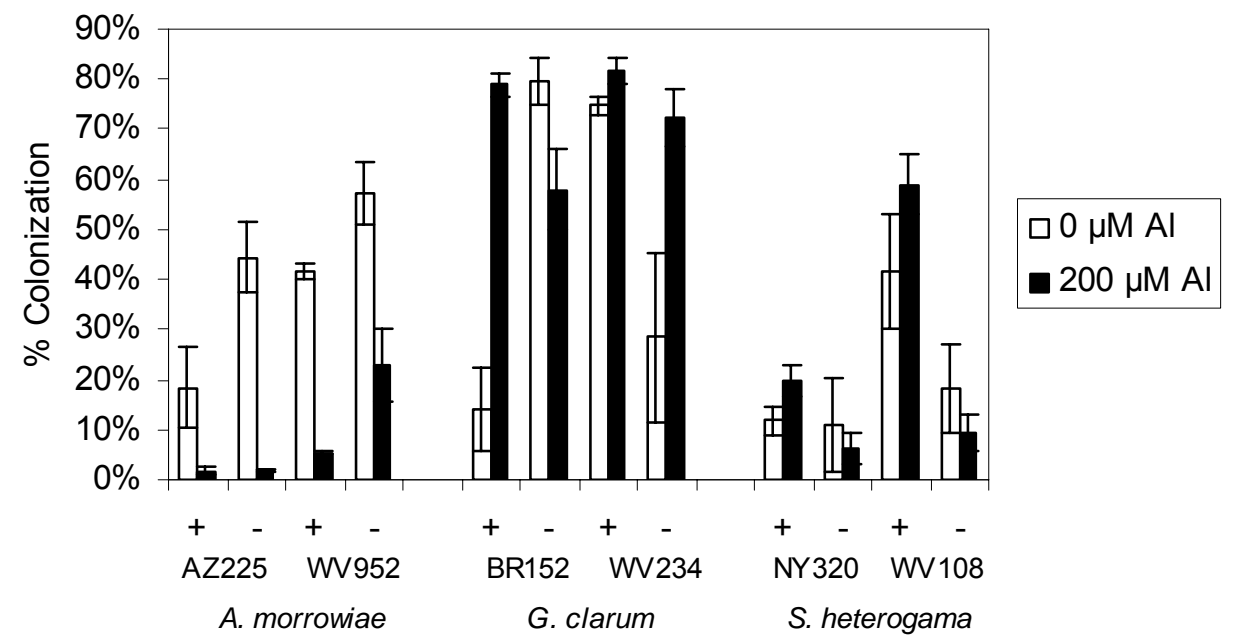

Figure 4. Colonization of mycorrhizal plants inoculated with isolates of A. morrowiae, G. clarum and S. heterogama cultivated in the presence of $200 \mu \mathrm{M} \mathrm{Al}(+)$ or $0 \mu \mathrm{M} \mathrm{Al}(-)$ and exposed to 0 () and $200 \mu \mathrm{M} \mathrm{Al}(\mathbf{\bullet})$. 


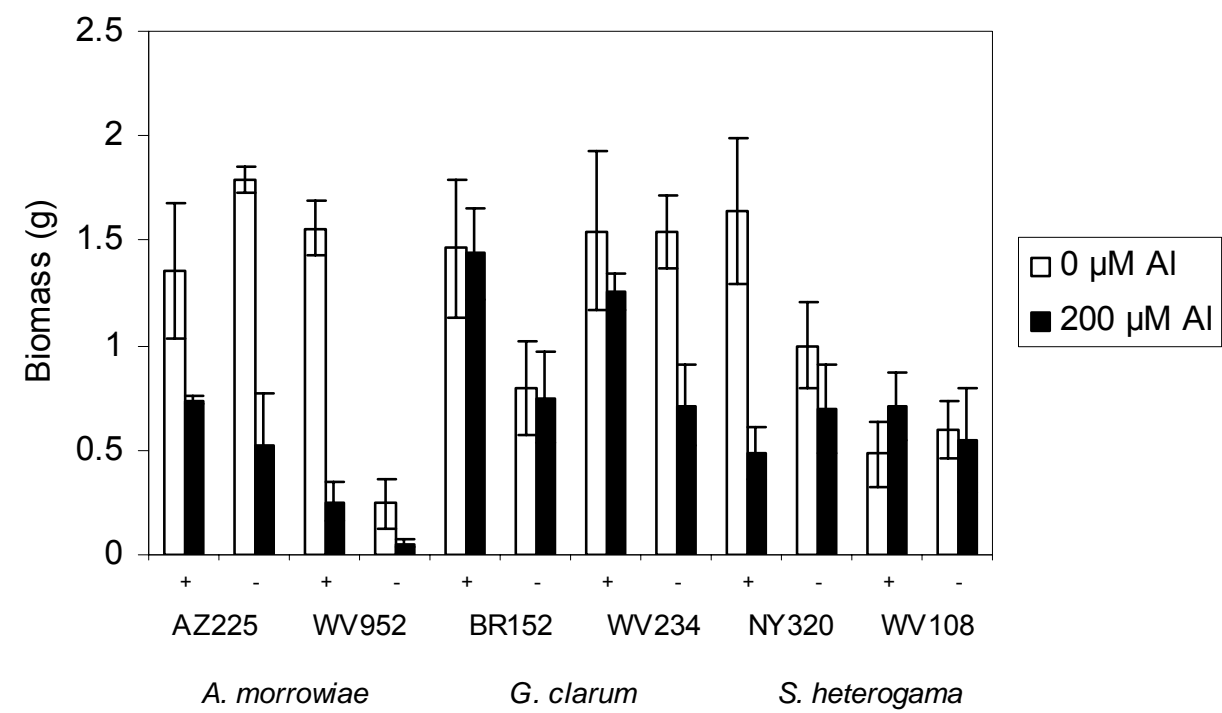

Figure 5. Biomass of non-mycorrhizal (NM) and mycorrhizal plants inoculated with isolates of A. morrowiae, G. clarum and S. heterogama cultivated in the presence of $200 \mu \mathrm{M} \mathrm{Al}(+)$ or 0 $\mu \mathrm{M} \mathrm{Al}(-)$ and exposed to 0 ( $\square)$ and $200 \mu \mathrm{M} \mathrm{Al}(\mathbf{\square})$.

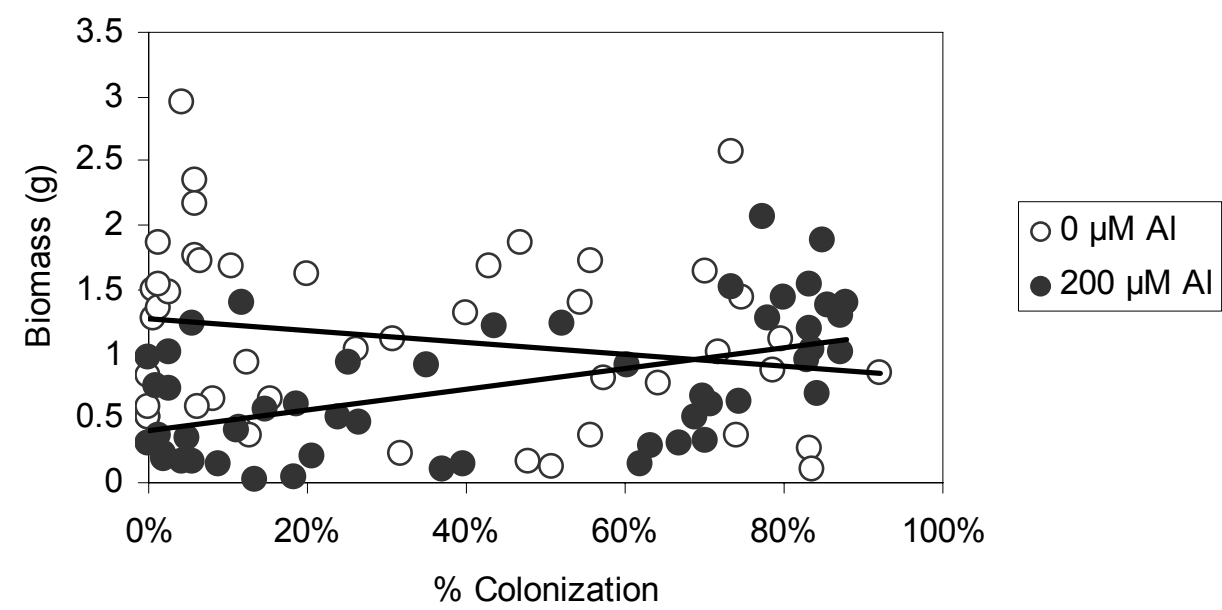

Figure 6. Relationship between \% colonization and total biomass of mycorrhizal plants inoculated with isolates of A. morrowiae, G. clarum and S. heterogama cultivated in the presence of $200 \mu \mathrm{M} \mathrm{Al}(+)$ or $0 \mu \mathrm{M} \mathrm{Al}(-)$ and exposed to 0 () and $200 \mu \mathrm{M} \mathrm{Al}(\mathbf{-})$. 

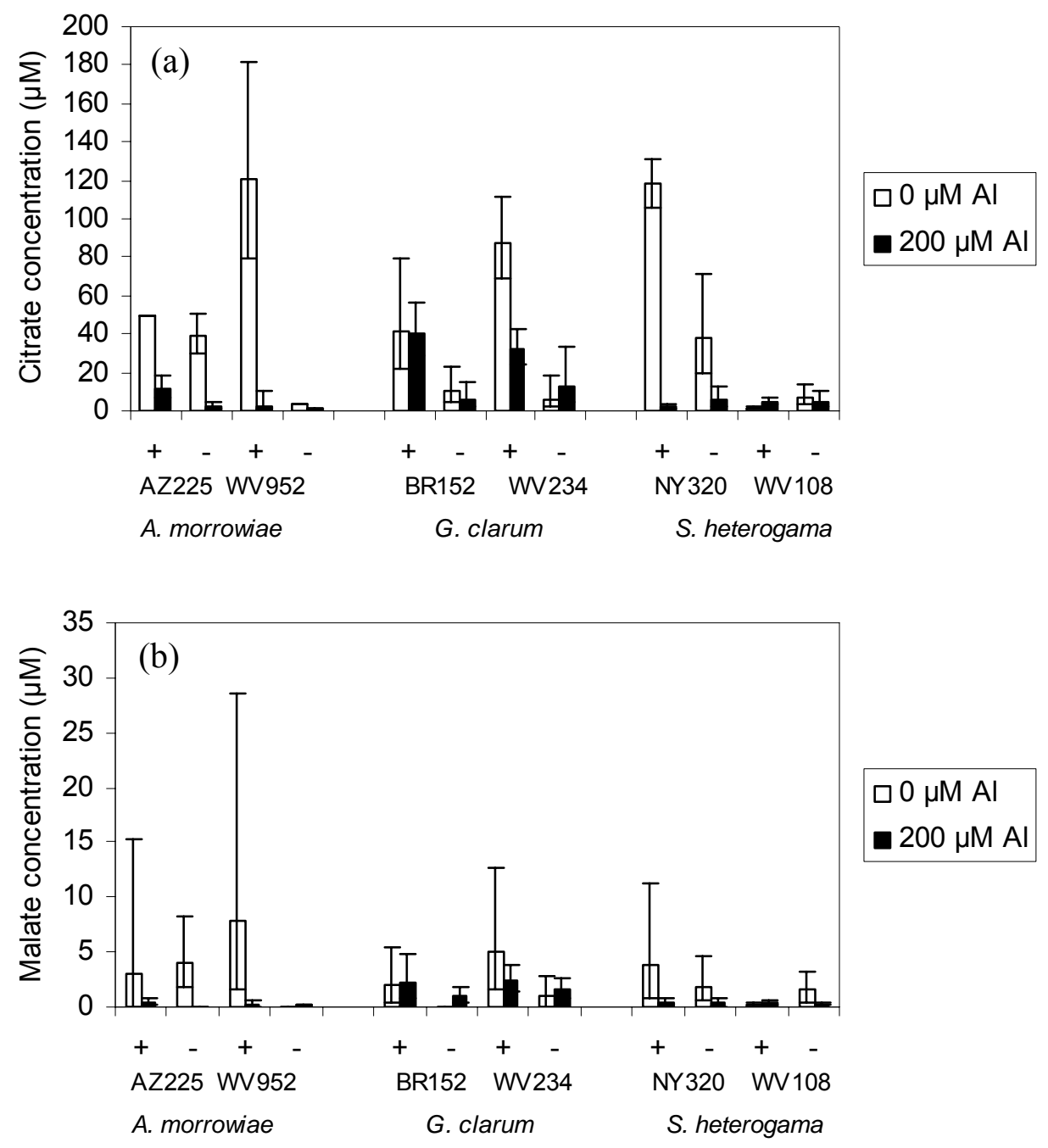

Figure 7. (a) Citrate and (b) malate concentrations $(\mu \mathrm{M})$ in root zones of non-mycorrhizal (NM) and mycorrhizal plants colonized by isolates cultivated in the presence of $200 \mu \mathrm{M} \mathrm{Al}(+)$ or 0 $\mu \mathrm{M} \mathrm{Al}(-)$ and exposed to 0 (ם) and $200 \mu \mathrm{M} \mathrm{Al}(\mathbf{\square})$. 

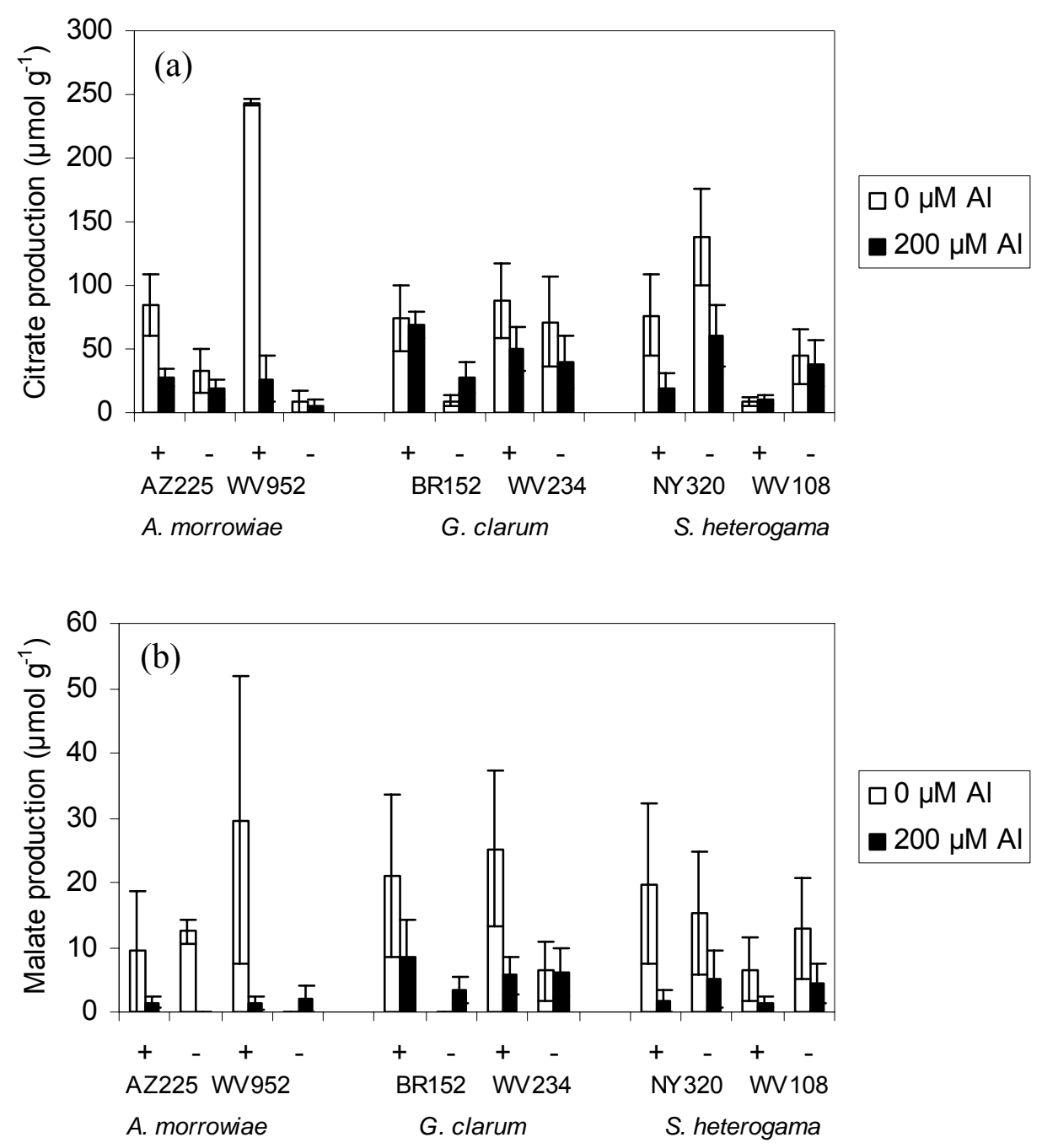

Figure 8. (a) Citrate and (b) malate production ( $\mu \mathrm{mol} \mathrm{g}^{-1}$ root mass) in root zones of nonmycorrhizal (NM) and mycorrhizal plants colonized by isolates cultivated in the presence of 200 $\mu \mathrm{M} \mathrm{Al}(+)$ or $0 \mu \mathrm{M} \mathrm{Al}(-)$ and exposed to 0 () and $200 \mu \mathrm{M} \mathrm{Al}(\mathbf{\bullet})$. 
Appendix 1. Schematic representation of the experimental design.

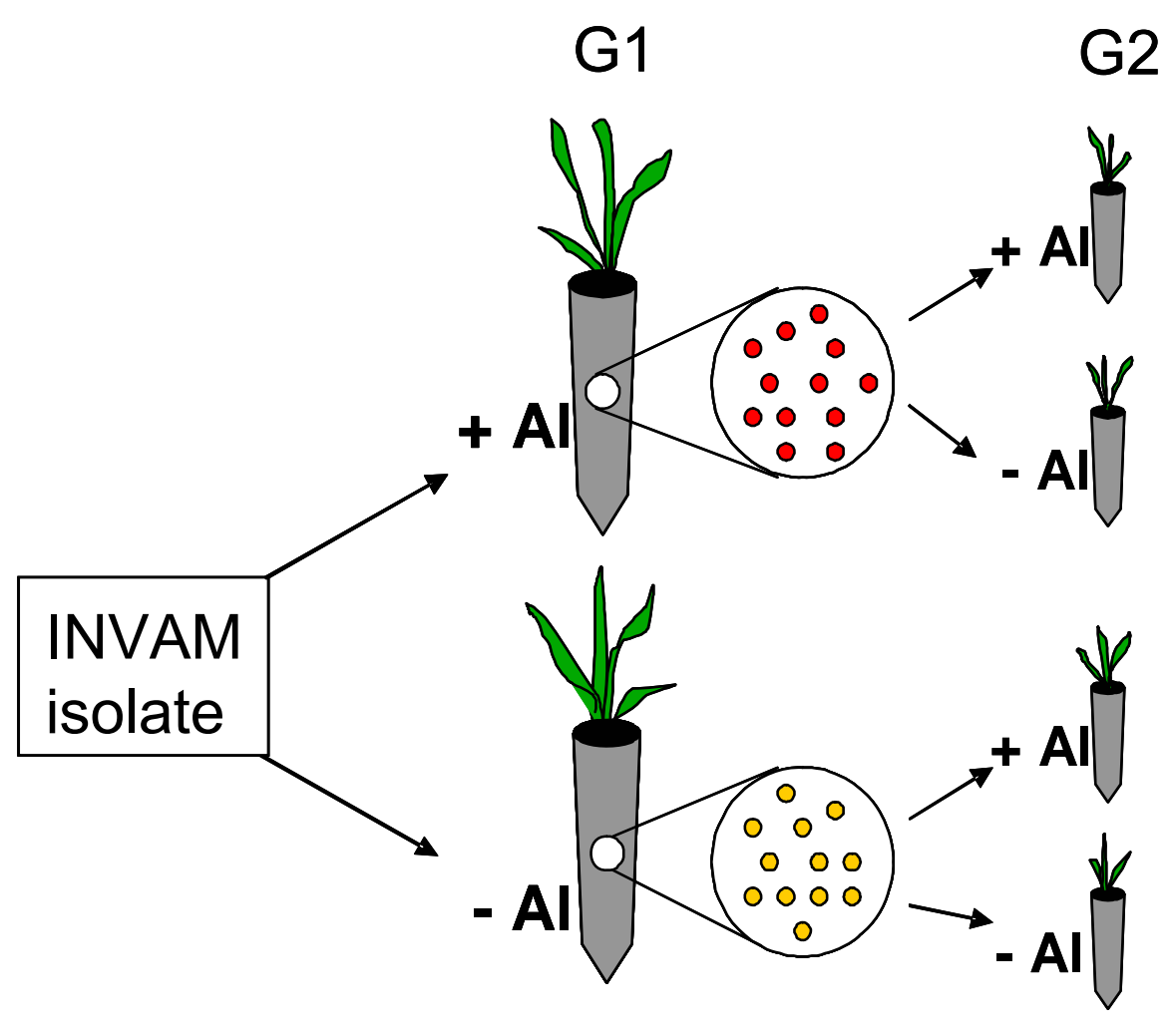




\section{Discussion}

The ubiquity of the AM association among higher plant species in various environments around the world illustrates the ecological importance of this association. Many soils exhibit nutrient limitation or chemical imbalances that restrict plant growth and the AM association enhances plant productivity under such conditions (Marschner, 1991). Acidic soils characteristically have low nutrient availability and high concentrations of phytotoxic Al. Arbuscular mycorrhizal associations have important roles in plant survival on acidic soils by enhancing nutrient uptake (Clark, 1997) and additionally, by conferring Al resistance to their plant hosts (Marschner, 1995). In studies of Panicum virgatum, Liriodendron tulipifera, and A. virginicus, non-mycorrhzal plants were more sensitive to Al than mycorrhizal plants (Koslowsky \& Boerner, 1989; Lux \& Cumming, 2001; Cumming \& Ning, 2003). Changes in Al speciation in root zones of mycorrhizal plants may be responsible for the observed mycorrhizal benefit and may be related to AM influence on organic acid exudation, extraradical binding of Al to fungal hyphae, or altered cation-anion balance, all of which would alter the bioavailability and uptake of $\mathrm{Al}$ in the rhizosphere.

Communities of AM fungi in ecosystems are diverse and AM species vary in their ability to promote plant growth depending on host species and environmental conditions (Clark et al., 1999; Bever et al., 2001; Helgason et al., 2002). Arbuscular mycorrhizal species also exhibit variable responses to acidic soils and $\mathrm{Al}$, as measured by differences is spore germination, colonization, and host plant growth (Siqueira et al., 1984; Bartolome-Esteban \& Schenck, 1994; Vosatka et al., 1999). Variation among isolates has also been observed, as noted by Munkvold et al. (2004), who reported intraspecific differences in plant growth promotion among 24 isolates of four different Glomus species. Additionally, variation among responses to soil type and moisture

was observed among G. mosseae isolates collected from dissimilar habitats (Stahl \& Christensen, 1991 ) and inter- and intraspecific variation in Al resistance was observed for G. clarum, A. morrowiae, and S. heterogama (Kelly et al., 2005).

In the present study, G1 plants exhibited variation in growth depending on the colonizing species of AM fungus and Al treatments, with plants colonized by G. clarum and S. heterogama appearing to have smaller decreases in biomass upon $\mathrm{Al}$ exposure than plants colonized by $A$. morrowiae or non-mycorrhizal plants. Across Al treatments plants colonized by G. clarum and S. heterogama had higher biomass than plants colonized by A. morrowiae or non-mycorrhizal 
plants. Colonization of G1 plants inoculated with different isolates of AM fungi varied with Al treatments. For most isolates, colonization remained similar between 0 and $200 \mu \mathrm{M} \mathrm{Al}$ treatments. However, G. clarum BR251 and S. heterogama NY320 both had greater percentages of colonization under $\mathrm{Al}$ exposure, suggesting that $\mathrm{Al}$ stress enhanced fungal infectivity or precluded the host plant to colonization. Indeed, colonization is often increased in plants exposed to stress, particularly low P (Smith \& Read, 1997), and this may be a factor influencing colonization in treatments with $200 \mu \mathrm{M}$ Al compared to $0 \mathrm{Al}$ treatments. The change in the relationships between $A$. virginicus biomass production and colonization depending on $\mathrm{Al}$ exposure (Figure 3) illustrates the high dependency of $A$. virginicus on the AM association under stress. In natural environments, the soil AM fungal community will consist of numerous species and the capacity of the aggregate community to colonize $A$. virginicus under stress may play a key role in the ability of this pioneer species to colonize stressful environments.

Concentrations of $\mathrm{P}$ in shoot tissues of G1 plants were highest in non-mycorrhizal plants and plants colonized by $A$. morrowiae. However, high $\mathrm{P}$ concentrations do not appear to be indicative of resistance to stress or overall plant health in A. virginicus given the small size of $\mathrm{NM}$ and A. virginicus plants. Rather, the high $\mathrm{P}$ concentrations may represent a concentration of $\mathrm{P}$ in shoot tissues of small plants under Al stress. Similar growth dilution effects have been previously reported for this species (Cumming \& Ning, 2003). Furthermore, plants colonized by G. clarum and S. heterogama were larger than non-mycorrhizal plants or plants colonized by $A$. morrowiae, and their low biomass to $\mathrm{P}$ ratio suggests a higher $\mathrm{P}$ use efficiency induced by these AM species (Ning \& Cumming, 2001).

Previous studies indicate that AM fungi exhibit interspecific variation to acidic soils and Al (Siqueira et al., 1984; Bartolome-Esteban \& Schenck, 1994; Vosatka et al., 1999; Kelly et al., 2005). Such variation should be related to changes in bioavailable Al in the rhizosphere (Marschner, 1991; Matsumoto, 2000), and this may be a result of variation in exudation of Albinding compounds from mycorrhizal root zones. This variation in environmental stress resistance among AM species and isolates may be a result of their origin and cultivation history (Malcová et al., 2003), which would select for traits conferring Al resistance. In G2 of the present study, organic acids were measured as a potential Al resistance mechanism in roots zones of plants colonized by isolates of three species cultivated under Al stress and non-Al conditions. In root zones of plants colonized by A. morrowiae and G. clarum, higher concentrations of 
citrate were found when inoculum was cultivated under Al exposure compared to unexposed inoculum. In addition, malate concentrations were also moderately higher in root zones of plants colonized by previously Al-exposed inoculum. These patterns are reflected in $\mathrm{G} 2$ biomass of plants colonized by A. morrowiae WV952 and G. clarum BR152, where, across Al treatments, plants with these isolates not cultivated under $\mathrm{Al}$ exposure were $83 \%$ and $46 \%$ smaller, respectively, than plants colonized with these same isolates cultivated under Al stress (Figure 5).

The effect of $\mathrm{Al}$ on colonization of isolates was dependent on whether or not the inoculum was cultivated under $\mathrm{Al}$ exposure. Colonization of plants inoculated with $A$. morrowiae isolates was consistently lower with the addition of $200 \mu \mathrm{M} \mathrm{Al}$ regardless of cultivation history, and S. heterogama isolates had similar colonization across $\mathrm{Al}$ treatments and previous $\mathrm{Al}$ exposures. However, plants with G. clarum isolates had variable responses to Al and these differed with previous exposure to Al. While colonization by some isolates may be affected by cultivation history, degree of colonization is not related to biomass in the absence of Al stress. Biomass of G2 plants was not strongly related to colonization in the absence of Al. However, the positive correlation of biomass and colonization under Al exposure highlights the importance of the association under stress. This pattern was also observed in G1 plants.

I hypothesized that there would be differences among AM species cultivated under Al and non-stress conditions in conferred $\mathrm{Al}$ resistance and that there would be differences among isolates collected from acidic and non-acidic soils as well. I expected that isolates exposed to acidic soils would be more likely than those collected from non-acidic soils to promote growth of A. virginicus when exposed to Al. No differences in growth among isolates from acidic and nonacidic soils were observed in G1 or G2 and, upon exposure to $200 \mu \mathrm{M}$ Al for eight weeks, all plants exhibited reduced biomass. In addition, in G2, shoot $\mathrm{P}$ concentrations were similar among all treatments, and shoot $\mathrm{Al}$ concentrations were higher in $\mathrm{Al}$ treatments, but were not affected by species, isolates, or previous exposure to Al. Furthermore, no differences in organic acid exudation were related to origin of AM isolate, suggesting that isolates collected from acidic and non-acidic soils do not exhibit any fundamental differences in capacity to detoxity $\mathrm{Al}$ in the rhizosphere. Large plastic responses have been observed within isolates exposed to soil stress (Stahl \& Christensen, 1991), and the apparent ability of AM isolates used in this study to acclimate (G1) and/or to adapt (G2) to Al stress may be responsible for the lack of variation observed in growth and nutritional status of A. virginicus among isolates collected from acidic 
and non-acidic soils. Conversely, these isolates have been maintained under uniform and nonstressful culture conditions in the INVAM collection for a variable number of generation and genes or traits conferring Al resistance my have been diluted (Kelly et al., 2005). More than one generation under Al stress may be required to foster separation of resistance to Al.

This study provides data to suggest that functional variation in conferred Al resistance exists among AM fungi as measured by difference in plant growth. Furthermore, trends in the data suggest that cultivation under stress may enhance stress resistance of AM fungi over time through the selection for Al-resistant genotypes. Under stressful conditions, plant growth may be enhanced when hosts are associated with stress-cultivated fungi. This may be related to organic acid exudation, as observed as trends of higher citrate and malate concentrations found in root zones of plants inoculated with AM fungi cultivated under Al exposure compared to plants with unexposed inoculum. While these trends in the data represent the potential for adaptive mechanisms, stronger evidence may be acquired with additional experimentation that would include cultivation of subsequent generations of AM fungi under Al stress. Repeated exposure to $\mathrm{Al}$ stress could enhance the development of $\mathrm{Al}$ stress resistant traits in $\mathrm{AM}$ fungi that could be conferred to plants hosts. Patterns of Al stress resistance were not observed among isolates collected from acidic and non-acidic soils. However, the small number of isolates used in this study are likely insufficient to draw conclusions and a larger sample of isolates from stress and non-stress conditions may be required. 


\section{References}

Bartolome-Esteban H, Schenck NC. 1994. Spore germination and hyphal growth of arbuscular mycorrhizal fungi in relation to soil aluminum saturation. Mycologia 86: 217-226.

Bentivenga, SP. Bever, JD, Morton, JB. 1997. Genetic variation of morphological characters within a single isolate of the endomycorrhizal fungus Glomus clarum (Glomaceae). America Journal of Botany 84: 1211-1216.

Bever JD, Morton J. 1999. Heritable variation of mechanisms of inheritance of spore shape within a population of Scutelopspora pellucida, and Arbuscular mycorrhizal fungus. American Journal of Botany 86: 1209-1216.

Bever JD, Schultz PA, Pringle A, Morton JB. 2001. Arbuscular mycorrhizal fungi: more diverse than meets the eye, and the ecological tale of why. Bioscience 51: 923-931.

Brundrett MC. 2002. Coevolution of roots and mycorrhizas of land plants. New Phytologist 154: $275-304$.

Clark RB. 1997. Arbuscular mycorrhizal adaptation, spore germination, root colonization, and host plant growth and mineral acquisition at low pH. Plant and Soil 192: 15-22.

Clark RB, Zobel RW, Zeto SK. 1999. Arbuscular mycorrhizal fungal isolate effectiveness on growth and root colonization of Panicum virgatum in acidic soil. Soil Biology and Biochemistry 31: $1757-173$.

Cooke JC, Gemma JN, Koske KE. 1987. Observations of nuclei in vesicular-arbuscular mycorrhizal fungi. Mycologia 79:331-333.

Cumming JR, Ning J. 2003. Arbuscular mycorrhizal fungi enhance aluminum resistance of broomsedge (Andropogon virginicus L.). Journal of Experimental Botany 54: 1447-1459.

Cumming JR, Swiger TD, Kurnik BS, Panaccione DG. 2001. Organic acid exudation by Laccaria bicolor and Pisolithus tinctorius exposed to aluminum in vitro. Canadian Journal of Forest Research 31: 703-710.

Delhaize E, Ryan PR. 1995. Aluminum toxicity and tolerance in plants. Plant Physiology 107: 315-321.

Giovannetti M, Mosse B. 1980. An evaluation of techniques for measuring vesicular arbuscular mycorrhizal infection in roots. New Phytologist 84: 489-500.

Helgason T, Merryweather JW, Denison J, Wilson P, Young JPW, Fitter AH. 2002. Selectivity and functional diversity in arbuscular mycorrhizas of co-occurring fungi and plants from a temperate deciduous woodland. Journal of Ecology 90: 371-384.

Hue NV, Craddock, GR, Adams F. 1986. Effect of organic acids on aluminum toxicity in subsoils. Soil Science Society of America Journal 50: 28-34. 
Jones Jr. JB, Case VW. 1990. Sampling, handling, and analyzing plant tissue samples. In: Westerman RL, ed. Soil Testing and Plant Analysis, $3^{\text {rd }}$ edn. Madison, USA: Soil Science Society of America, 389-427.

Kelly CN, Morton JB, Cumming JR. 2005. Variation in aluminum resistance among arbuscular mycorrhizal fungi. Mycorrhiza 15:193-201.

Klugh KR, Cumming JR. 2003. Variation in organic acid exudates among mycorrhizal species colonizing Liriodendron tulipifera L. (yellow-poplar) in the presence of aluminum. Poster Presentation at the $88^{\text {th }}$ Annual Meeting of the Ecological Society of America, Savannah, GA.

Kochian LV. 1995. Cellular mechanisms of aluminum toxicity and resistance in plants. Annual Review of Plant Physiology and Plant Molecular Biology 46: 237-260.

Kochian LV, Hoekenga OA, Piñeros MA. 2004. How do crop plants tolerate acid soils? Mechanisms of aluminum tolerance and phosphorous efficiency. Annual Review of Plant Biology 55: 459-493.

Koslowsky SD, Boerner RE. 1989. Interactive effects of aluminum, phosphorous and mycorrhizae on growth and nutrient uptake of Panicum virgatum L. (Poaceae). Environmental Pollution 61: 107-125.

Kuhn G, Hijri G, Sanders IR. 2001. Evidence for the evolution of multiple genomes in arbuscular mycorrhizal fungi. Nature 414: 745-748.

Lux HB, Cumming JR. 2001. Mycorrhizae confer aluminum resistance to tulip-poplar seedlings. Canadian Journal of Forest Research 31: 694-702.

Ma JF, Hiradate S, Matsumoto H. 1998. High aluminum resistance in Buckwheat. Plant Physiology 117: 753-759.

Malcová R, Rydlova J, Vosatka M. 2003. Metal-free cultivation of Glomus sp. BEG 140 isolated from Mn-contaminated soil reduces tolerance to Mn. Mycorrhiza 13: 151-157.

Malloch DW, Priozynski KA, Raven PH. 1980. Ecological and evolutionary significance of mycorrhizal symbioses in vascular plants (A Review). Proceedings of the National Academy of Science 77: 2113-2118.

Marschner H. 1991. Mechanisms of adaptation of plants to acid soils. In: Wright RJ, et al. eds. Plant-soil interactions at low pH. Netherlands: Kluwer Academic Publishers, 683-702.

Marschner H. 1995. Mineral nutrition of higher plants. San Diego, CA: Academic Press, Inc.

Matsumoto H. 2000. Cell biology of aluminum toxicity and tolerance in higher plants. International Review of Cytology 200: 1-46.

Meharg AA, Cairney JWG. 2000. Co-evolution of mycorrhizal symbionts and their hosts to metal-contaminated environments. Advances in Ecological Research 30: 69-112. 
Munkvold L, Kjøller R, Vesberg M, Rosendahl S, Jakobsen, I. 2004. High functional diversity within species of arbuscular mycorrhizal fungi. New Phytologist 164: 357-364.

Ning J, Cumming JC. 2001. Arbuscular mycorrhizal fungi alter phosphorous relations of broomsedge (Andropogon virginicus L.) plants. Journal of Experimental Botany 52: 1883-1891.

Sanders IR, Alt M, Groppe K, Boller T, Weimken A. 1995. Identification of ribosomal DNA polymorphisms among and within spores of the Glomales: application to studies on the genetic diversity of Arbuscular mycorrhizal fungal communities. New Phytologist 130: 419-427.

Silva IR, Smyth TJ, Raper CD, Carter TE, Rufty TW. 2001. Differential aluminum tolerance in soybean: An evaluation of the role of organic acids. Physiologia Plantarum 112: 200-210.

Siqueira JO, Hubbell DH, Mahmud AW. 1984. Effect of liming on spore germination, germ tube growth and root colonization by vesicular-arbuscular mycorrhizal fungi. Plant and Soil 76: 115-124.

Smith SE, Read DJ. 1997. Mycorrhizal Symbiosis: $2^{\text {nd }}$ Edn. San Diego, USA: Academic Press.

Stahl PD, Christensen M. 1991. Population variation in the mycorrhizal fungus Glomus mosseae: breadth of environmental tolerance. Mycological Research 3: 300-307.

Taussky HH, Shorr E. 1953. A microcolorimetric method for the determination of inorganic phosphorus. Journal of Biological Chemistry 202: 675-685.

von Uexküll HR, Mutert E. 1995. Global extent, development and economic impact of acid soils. Plant and Soil 171: 1-15.

Vosatka M, Batkhuugyin E, Albrechtova J. 1999. Response of three arbuscular mycorrhizal fungi to simulated acid rain and aluminum stress. Biologia Plantarum 42: 289-296. 


\section{Chapter 6: Summary}

High Al concentrations common in acidic soils have the potential to limit plant productivity. However, plants have $\mathrm{Al}$ resistance mechanisms that include the exudation of organic acids and the formation of AM symbioses. In this dissertation, I describe four studies that address questions regarding $\mathrm{Al}$ resistance of mycorrhizal plants.

In the first experiment, I inoculated Liriodendron tulipifera, a common tree species in northeastern US forests, with several species of AM fungi and exposed them to Al. The objectives were to determine if there was variation among the AM fungi in their ability to promote Al resistance to their host plants. Additionally, I measured organic acid production as a potential $\mathrm{Al}$ resistance mechanism that may vary among AM species. At the conclusion of the experiment, I found that there was, in fact, variation among AM species colonizing L. tulipifera, and the AM species Glomus clarum appeared to provide the most benefit to host plants. When exposed to high levels of $\mathrm{Al}(200 \mu \mathrm{M})$, plants colonized by this species were larger, accumulated low concentrations of $\mathrm{Al}$ in leaf tissues, and were able to acquire high amounts of $\mathrm{P}$ compared to plants colonized by other species and non-mycorrhizal plants. In addition, organic acid concentrations, specifically the strong Al-chelating citrate and malate, were found in highest concentration in root zones of plants colonized with G. clarum and these high organic acid concentrations may be responsible for the observed benefit in L. tulipifera colonized by this AM species. The variation among AM fungi observed in this study highlights the importance of diversity in ecosystem response to environmental stress.

In the second experiment, I measured growth of Andropogon virginicus inoculated with several species and isolates of AM fungi, exposed mycorrhizal plants to Al, and focused on organic acids as a potential $\mathrm{Al}$ resistance mechanism. Andropogon virginicus is an early successional herbaceous species that commonly colonized disturbed soils, including the extreme soils of abandoned surface coal mines, which can be extremely acidic and contain high concentrations of phytotoxic Al. Andropogon virginicus is highly mycotrophic and depends heavily on AM fungi for growth, particularly when exposed to Al. In the first part of the experiment, several species originally collected from acidic soils were compared and in the second part, isolates collected from acidic soils and from non-acidic soils were compared. I had hypothesized that plants colonized by AM fungal isolates originally collected from acidic soils would be more Al resistant than those colonized by isolates from non-acidic soils. As in the first 
experiment, variation among AM species was observed in their ability to promote plant growth under Al exposure (100 $\mu \mathrm{M} \mathrm{Al})$, with plants colonized by G. clarum and Scutellospora heterogama having small reductions in biomass compared to plants colonized by other AM species or non-mycorrhizal plants. Differences between AM isolates were also observed, but results were not as expected and the one isolate of G. clarum collected from a non-acidic soil appeared to promote growth under $\mathrm{Al}$ exposure more than any other isolate. In both parts of the experiment, organic acids (citrate and malate) did not show clear patterns that would correlate high exudation with increased growth. However, functional variation was observed among AM fungi and supports the notion that AM diversity in ecosystems is important, particularly if the environment provides stresses to plant growth.

The third project is a field study that explored the relationship between factors that limit plant growth on the extreme soils of an abandoned coal mine and the growth of the highly mycotrophic A. virginicus at this site. Soil solutions collected from vegetated and non-vegetated locations at the Stewartstown Mine were analyzed for $\mathrm{pH}$, total Al, labile Al, and organic acid concentrations each month throughout the growing season of $A$. virginicus. The solutions from vegetated locations had higher $\mathrm{pH}$, especially at the end of the growing season. In vegetated locations, total $\mathrm{Al}$ and labile $\mathrm{Al}$ were lower an did not change over the course of the growing season. Several organic acids were similar in vegetated and non-vegetated soils until October, when concentrations were higher in vegetated plots. These higher concentrations of organic acids may be related to increased exudation from roots as plants reached maturity or increases in decomposing organic matter from leaf litter deposited by senescing plants. The increase in $\mathrm{pH}$ in vegetated soils late in the season may be due to the decomposition of abundant organic residues during this time. Initial colonization of extreme sites by A. virginicus may ameliorate the edaphic conditions, facilitating the growth of other plant species and promote ecological succession.

Since A. virginicus is sensitive to Al when non-mycorrhizal, AM fungi likely play important roles in survival of this species at the abandoned mine site studied in the third project of this dissertation. Additionally, given the variation among AM fungi in their capacity to promote host plant growth demonstrated in the first two studies of this dissertation as well as elsewhere in the literature, it is likely that the AM fungi colonizing A. virginicus are adapted to the extremely high $\mathrm{Al}$ and low $\mathrm{pH}$ conditions. However, in experiments using $\mathrm{AM}$ fungi, species 
and isolates are often from collections where fungi have been maintained in culture conditions that may be very unlike those of their original collection sites and may no longer be exposed to stresses that existed in the field. Currently, there are questions regarding the ability of fungi that were originally stress resistant to maintain those traits when maintained without stress. In the final experiment of this dissertation, I inoculated A. virginicus with several AM species and isolates of each that were collected from acidic and non-acidic soils. After exposing them to Al, I used the AM spores that were produced as inoculum for a second set of plants and again exposed them to Al to determine if plants with inoculum that had been cultivated under exposure to $200 \mu \mathrm{M}$ Al would be more Al resistant than plants with inoculum cultivated under non-stress conditions. Also, I was interested to learn if isolates that would likely have been exposed to Al in their original environments, as would the isolates collected from acidic soils, would confer more Al resistance to their hosts than isolates collected from non-acidic soils. Trends in the data showed that when plants were inoculated with AM fungi cultivated under Al stress, they were larger and more Al resistant than plants inoculated with AM fungi cultivated in a non-stress environment and, in some cases, had higher concentrations of citrate and malate in root zones that may be related to Al resistance. No differences among plants colonized with AM fungi originally collected from acidic and non-acidic soils. These results suggest that cultivation under stressful conditions could enhance the stress resistance of AM fungi over time through the selection for stress resistance genotypes. While the trends in the data represent the potential for adaptive mechanisms, stronger evidence may be acquired with additional experimentation that would include the cultivation of subsequent generations of AM fungi under stress.

When examining the results of these studies together, it is evident that there are differences in responses of L. tulipifera and A. virginicus when inoculating the host plants with several similar AM species and exposing them to Al stress. In the first experiment, using $L$. tulipifera as a plant host, there were congruent patterns between organic acid exudation and Al stress resistance and these patterns were corroborated with nutritional data, where these largest plants also excluded Al from tissues and maintained P uptake, even at high levels of Al. However, in experiments using A. virginicus as a host, neither nutritional data nor organic acid exudation patterns matched those observed in the L. tulipifera experiment. Aluminum concentrations in shoot tissues of $A$. virginicus in the chapter 3 and chapter 5 did not have patterns that varied with factors other than the concentration of supplied Al. Furthermore, plants 
in different AM treatments did not have differences in $\mathrm{P}$ concentrations in tissues that matched differences in biomass. Often with A. virginicus in high $\mathrm{Al}$ treatments, the smallest plants in the experiments had the highest concentrations of $\mathrm{P}$ in tissues and may be explained as a reverse growth dilution effect. Similar results have been reported for this species, where small A. virginicus plants had high $P$ in shoots relative to large plants (Cumming \& Ning 2003). In chapter 3 and G1 of chapter 5, under Al exposure, plants colonized by G. clarum and S. heterogama had higher biomass and lower $\mathrm{P}$ than other AM treatments, suggesting a higher $\mathrm{P}$ use efficiency. Ning \& Cumming (2001) also noted a higher P use efficiency in A. virginicus plants colonized by AM fungi.

In addition to measurements of $\mathrm{Al}$ and $\mathrm{P}$ in shoot tissues, L. tulipifera differed from $\mathrm{A}$. virginicus in the concentrations and profiles of organic acids measured in root zones. Citrate, malate, and oxalate are all cited as important $\mathrm{Al}$ chelators exuded from plant roots. Liriodendron tulipifera root zones had high concentrations of citrate (up to $368 \mu \mathrm{M}$ ) and malate (up to 1136 $\mu \mathrm{M}$ ), and also had oxalate present (up to $34 \mu \mathrm{M}$ ). Andropogon virginicus root zones contained similar concentrations of citrate, significantly less malate, and did not contain any measurable oxalate compared to L. tulipifera.

Experiments in this dissertation included objectives to determine if organic acid exudation from roots functioned as a mechanism responsible for $\mathrm{Al}$ resistance in mycorrhizal plants. In chapter 2, L. tulipifera plants had high concentrations organic acids in roots zones and, additionally, the production ( $\mu \mathrm{mol} \mathrm{g}^{-1}$ root) of citrate and malate were high in plants colonized by Al-resistant G. clarum. Under Al exposure, plants colonized by this AM species were able to maintain $\mathrm{C}$ flux to the root zone that enabled to exudation of Al-chelating organic acids. Chemical speciation analyses from GEOCHEM indicated that these plants also had low concentrations of phytotoxic Al compared to plants colonized by other AM species. Interactions of $\mathrm{Al}$ and $\mathrm{P}$ may be responsible for toxicity symptoms in L. tulipifera and, with reduced availability of phytotoxic $\mathrm{Al}$, availability of $\mathrm{P}$ for plants is enhanced and $\mathrm{Al}$ uptake is reduced, both of which may alleviate $\mathrm{Al}$ toxicity symptoms in this plant species. Organic acid exudation was consistent with Al-resistance in mycorrhizal L. tulipifera. However, similar patterns in A. virginicus were not evident. While organic acids still may potentially have a role, in these experiments, other mechanisms may also be operative. According to Jianchang Ning (dissertation, 2000), improvements in micronutrient nutrition in mycorrhizal vs. non-mycorrhizal 
A. virginicus may have had a role increased plant growth. Specifically, Cu concentrations were higher in tissues of mycorrhizal plants and may have led to more effective carbohydrate transformations. This may also be a factor in experiments in this dissertation. However, micronutrients were not quantified in tissues. Other mechanisms of Al resistance may also have roles in Al resistance of mycorrhizal plants, including Al binding by fungal hyphae and/or glomalin. Glomalin is a glycoprotein produced by Glomalean fungi that influences soil structure and the formation of aggregates. In the presence of Al, it could also have important roles in chelating phytotoxic $\mathrm{Al}$ and ultimately alleviating $\mathrm{Al}$ toxicity symptoms.

In chapters 2, 3, and 5 of this dissertation, variation among AM fungi in their ability to confer Al stress resistance to their host plants was observed. In all of these chapters, G. clarum appeared to be more beneficial to plants than other AM species studied. Other research conducted in the Cumming lab has also suggested that this species of AM fungus is Al resistant. Heidi Lux (thesis, 1999) studied Al resistance of mycorrhizal L. tulipifera, and when inoculated with G. clarum and G. diaphanum and exposed to $200 \mu \mathrm{M} \mathrm{Al}$, plants maintained biomass similar to those not exposed to Al. Similarly, Ning (dissertation, 2000), who experimented with G. clarum colonizing $A$. virginicus, found that plants exposed to Al were only slightly smaller than plants receiving no Al. Charlene Kelly (thesis, 2004) also studied Al resistance in A. virginicus, but used several G. clarum isolates in her experiments. While isolates of other AM species varied in their conferred Al resistance to hosts, G. clarum isolates were uniformly beneficial to plant growth under $\mathrm{Al}$ exposure to levels of $400 \mu \mathrm{M}$ Al, although to a lesser degree then in Ning's experiments. It is interesting to note that all of these experiments, including ones in this dissertation, use the same isolate of G. clarum originally collected from the Stewartstown Mine described in chapter 4 of this dissertation. This species (and this isolate in particular) appears to be beneficial in conferred Al resistance across plant host species and is more effective than other AM species. However, the ability of this fungus to promote plant growth under Al exposure seems to be declining. While the work of Lux and Ning in 1999 and 2000 present data that suggest that $G$. clarum has the capacity to confer near complete resistance to Al, Kelly's work in 2004 and data from this dissertation show that plants colonized by G. clarum and exposed to Al are $\sim 50 \%$ as large as those not exposed to $\mathrm{Al}$. These trends may suggest that this fungus did not maintain its Al-resistant traits when maintained over several generational cycles in culture without the presence of Al stress. In chapter 5 of this dissertation, I studied the development of 
stress resistance in AM fungi and I found that there is the potential for AM fungi to confer a higher degree of $\mathrm{Al}$ stress resistance to hosts when $\mathrm{AM}$ inoculum is cultured in the presence of Al stress. With the numerous studies comparing functional variation among AM fungi being conducted, it may be important to consider treatment of inocula prior to experimentation. It may be useful to maintain inoculum under conditions similar to those at the original site of collection in order to maintain functional characteristics of AM fungi, especially stress resistant traits.

The potential for organic acid exudation by mycorrhizal roots as an $\mathrm{Al}$ resistance mechanism was a focus in the experiments in this dissertation. However, I was also interested how the organic acid measurements of root zones of mycorrhizal plants in experimental settings related to those in the field. Profiles of organic acids measured from the soil solutions collected from the Stewartstown Mine, described in chapter 4, differed from those of the experiments described in chapters 2,3, and 5. The concentrations in the soil solutions were one, and sometimes two, orders of magnitude lower than those found in root zones of experimental plants, with the exception of formate, which was similar among experiments and field collected soil solutions. In addition, in the soil solutions, the organic acids found in highest concentrations were formate and acetate, whereas citrate and malate were among the organic acids found in greatest amounts in the experiments. Interestingly, the organic acids that are most commonly found cited as being responsible for the detoxification of $\mathrm{Al}$ in root zones are citrate, malate, and oxalate. None of these were found in very high concentrations in soil solutions of the Stewartstown Mine, but concentrations of phytotoxic $\mathrm{Al}$ in vegetated locations were very low. Therefore, while exudation of these low molecular weight organic acids by plant roots may have roles in detoxification of $\mathrm{Al}$, there are likely other mechanisms responsible for maintaining low phytotoxic $\mathrm{Al}$ concentrations in these vegetated locations. Humic substances from decomposing plant litter, while not measured in this study, have the capacity to complex free $\mathrm{Al}$ and may be important for alleviating $\mathrm{Al}$ toxicities. Regardless of mechanism, the detoxification of $\mathrm{Al}$ is important for the ecological succession of sites such as the Stewartstown Mine. Colonization by A. virginicus appears to have an ameliorating effect on the soils, and these areas are subsequently colonized by other plant species, such as Acer rubrum, Aster spp., Lespedeza sp., Lycopodium spp., Oxydendron arboreum, Quercus sp., Rubus sp., and Solidago spp.

In experiments conducted in the Cumming lab, the isolate of G. clarum, collected from the extreme soils of the Stewartstown Mine in association with A. virginicus, was found to confer 
more $\mathrm{Al}$ resistance to plant hosts than other AM species. There are other AM species commonly associated with vegetation of this site, and one found in abundance is Acaulospora morrowiae (Joe Morton, WVU, INVAM curator, personal communication). In Kelly’s work and in experiments in this dissertation, A. morrowiae was consistently weak compared to other AM species and conferred little to no resistance to plant hosts under Al exposure. Given its presence at the Stewartstown Mine, it may be possible that A. virginicus associated with G. clarum ameliorates to edaphic conditions such that the soils are habitable for not only new plant species, but successive AM species as well. As Al is detoxified in the soil through the potential mechanisms outlined, other Al sensitive species are able to survive at this site with formerly formidable soil conditions.

The research presented in this dissertation provides insight into the roles of AM fungi in conferring Al resistance to plant hosts growing in acid soils. Variation was observed in conferred Al resistance among AM fungi and, in the case of L. tulipifera, was related to organic acid exudation, supporting current theories of Al-resistance in non-mycorrhizal plants. Other Alresistance mechanisms may also have important roles, particularly in A. virginicus, where organic acids exudation was not clearly correspondent to Al-resistance, and field measurements showed detoxification of $\mathrm{Al}$ in soils colonized by $A$. virginicus even without high concentration of Al-chelating organic acids present. Plants growing in stressful conditions may benefit from AM association and the functional variation observed in these studies illustrates the importance of AM diversity in ecosystems. 